\title{
Characterisation of a dual-colour retinoic acid reporter system for analysing cells and embryos
}

\section{Bianca Black}

A thesis submitted to Victoria University of Wellington in fulfilment of the requirements for the degree of Master of Biomedical Science

2018

Supervisor: Dr Peter Pfeffer 





\section{$\underline{\text { Abstract }}$}

Vitamin $\mathrm{A}$ is an important component in the diet as its metabolites, the retinoids, play key roles in a vast range of cellular functions, from production of germ cells, to embryonic development and right through until adulthood. The function of retinoids, in particular retinoic acid (RA), is especially important during early embryonic development, where it is responsible for many different key developmental events. Some of the processes controlled by RA include brain region patterning, Hox gene expression, axis establishment and somite formation. Here, we aimed to characterise the expression pattern of retinoic acid in the early murine embryo and isolate cell populations from a range of RA concentrations to analyse the mRNA expression.

To do this, we used a transgenic mouse line which expressed a reporter plasmid that was able to show, through the expression of two fluorescent proteins, areas of high RA concentration and area of low RA concentration. We tested the function of this reporter system in vitro, using cell lines which were transfected with the plasmid and exposed to RA in their growth media. This worked showed a somewhat does-dependent response from the reporter system expressing the fluorescent proteins. We then imaged transgenic embryos at various stages of early development, to ascertain the areas of RA expression and repression. Here, we saw fluorescent protein expression patterns that indicated both high and low concetrations of RA. Using this information, we dissociated transgenic E8.5 embryos and sorted the cells based on their levels of expression of the two fluorescent proteins, as well as by tissue type, which had been marked with antibodies. mRNA was extracted from these populations and PCR was performed to identify the presence of Hox genes and to see any difference in expression patterns across the various cell populations. 


\section{Acknowledgements}

Thank you to my supervisor, Peter, for taking me on and giving me such an interesting and enjoyable project (even if there were moments of frustration along the way). I thoroughly enjoyed being part of the PP lab group and will always be grateful for your guidance and wisdom.

Thank you also to the members of the Pfeffer lab group 2016-2018. You all helped me at some point along the way, whether it was teaching me a new technique, giving me a hand with something that was particularly tricky, or listening to my talk at lab meetings and discussing my results with me - I appreciate you all.

Thanks to my friends who took me out for coffee, went for walks with me on the weekend or listened to me rant in moments of frustration. Thank you for being supportive and helping me take my mind off science when I needed it.

To my family, both here and on the other side of the world, you were always interested and wanted to know what I was doing, even if you had no idea what I was talking about when I tried to explain it. There's no way I could have managed this without all of you and your messages, video calls and care packages, so thank you/danke.

And finally, thank you, Kasper. Thank you for always being there when I needed someone to listen to me, whether it was because I was excited about something working or, more often, crying because an experiment hadn't worked for the $6^{\text {th }}$ time in a row. Thank you for picking me up when I had to stay late, making sure that I had food and just generally taking care of me. Never in a million years could I have done this without your support. I love you. 


\section{Contents}

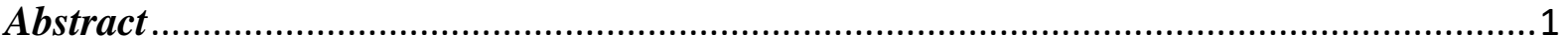

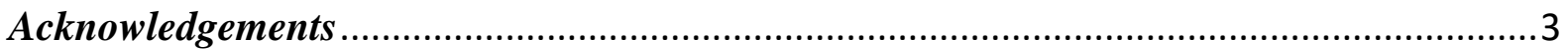

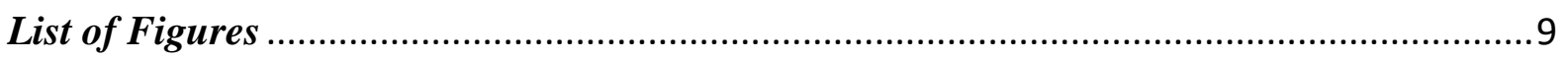

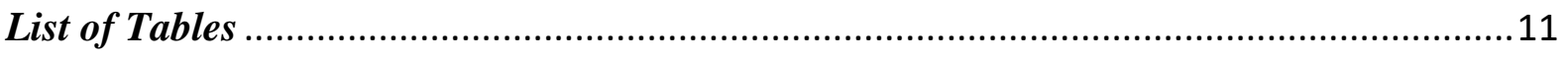

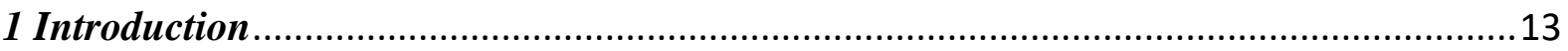

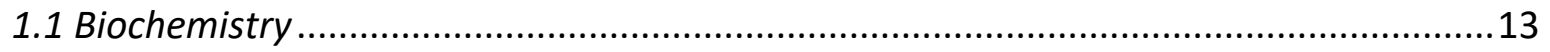

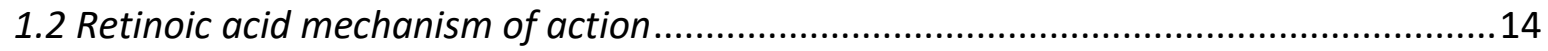

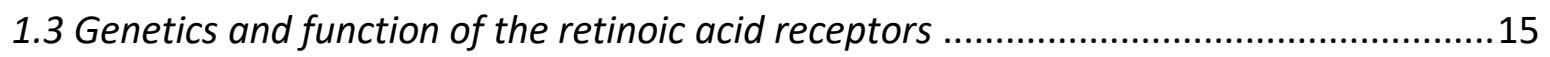

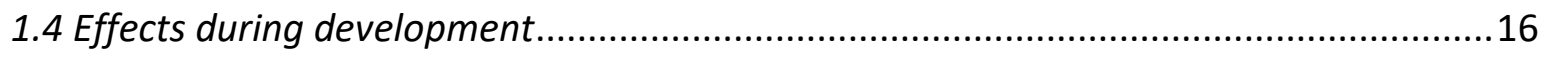

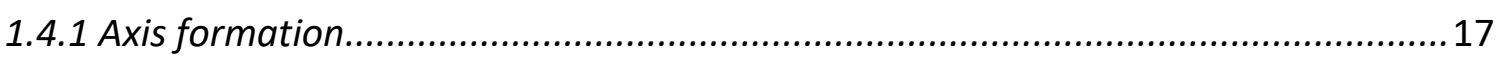

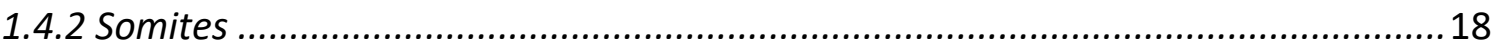

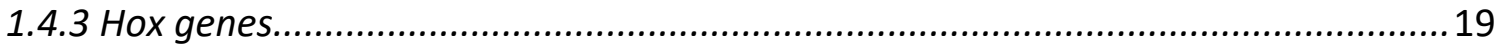

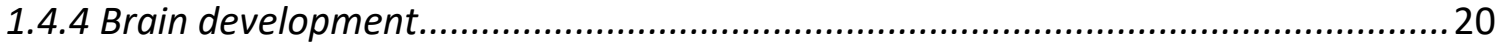

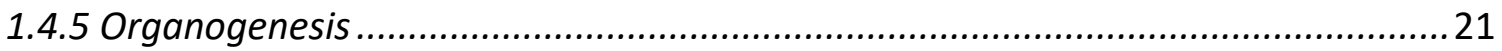

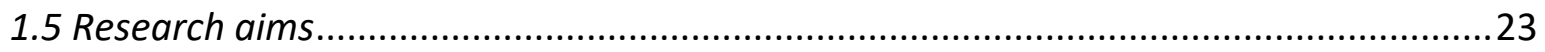

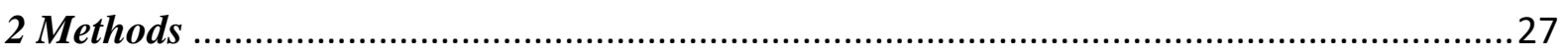

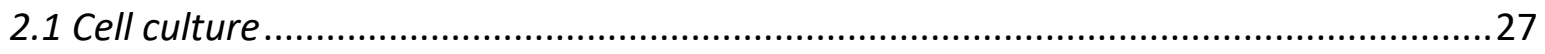

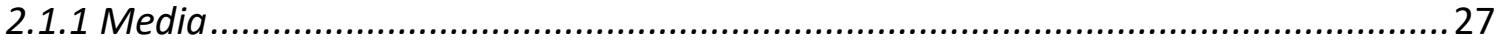

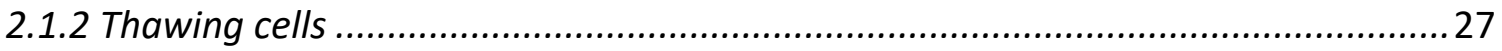

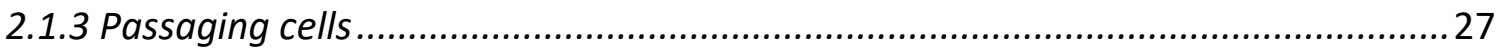

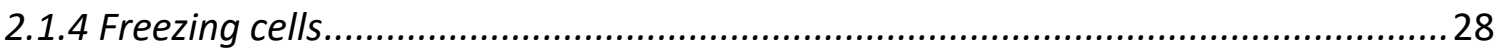

2.2 Creating a TOMATO-protein-expressing expressing plasmid .......................................28

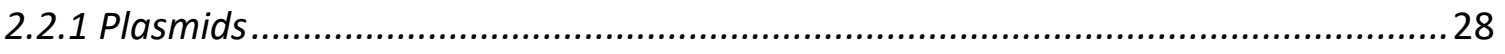

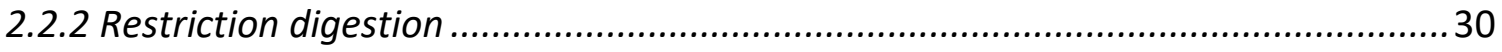

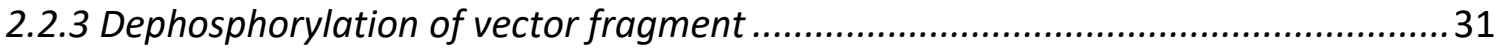

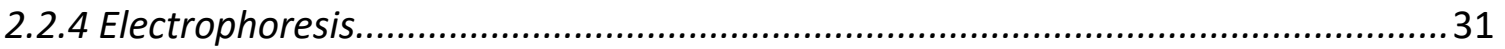

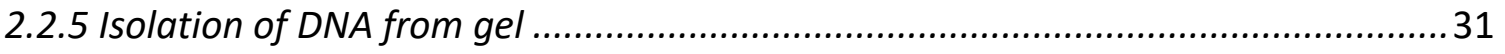

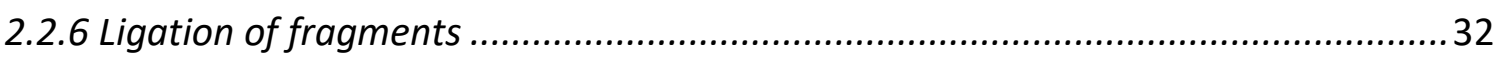

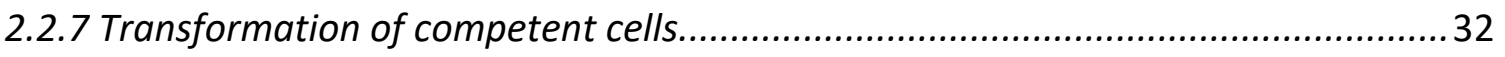

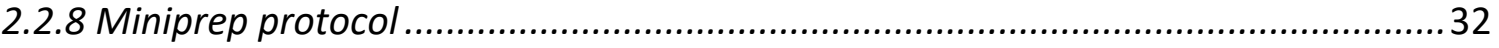

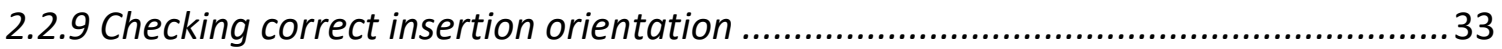




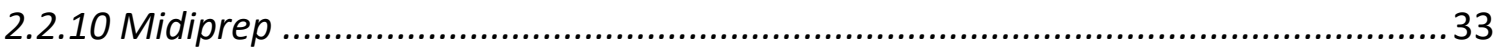

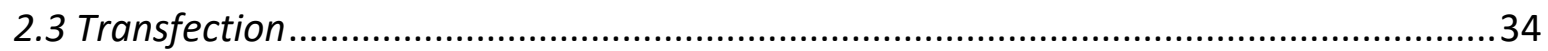

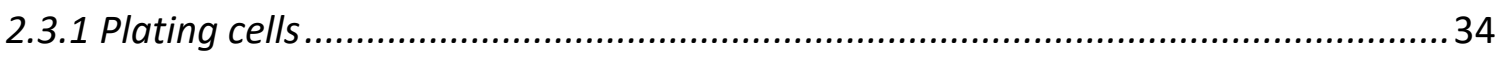

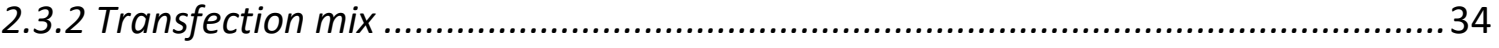

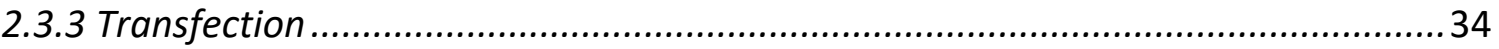

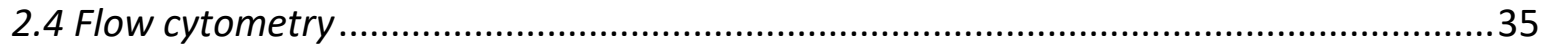

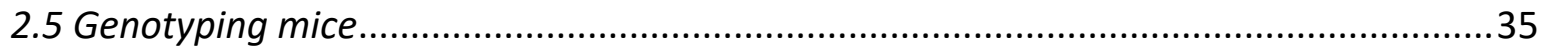

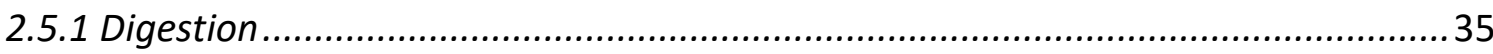

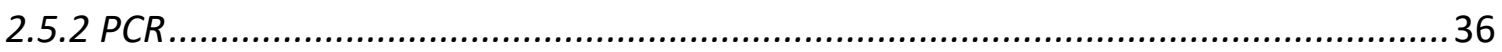

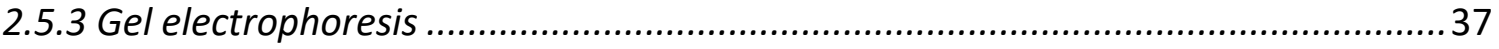

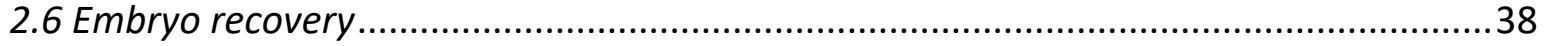

2.7 Preparation of primary mouse embryonic fibroblasts ..............................................39

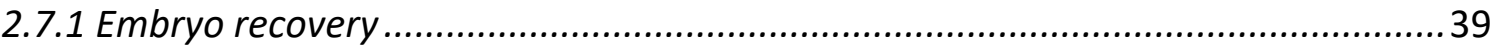

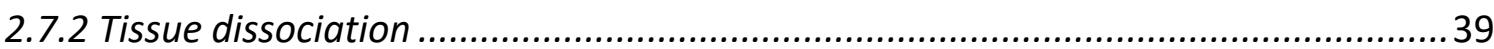

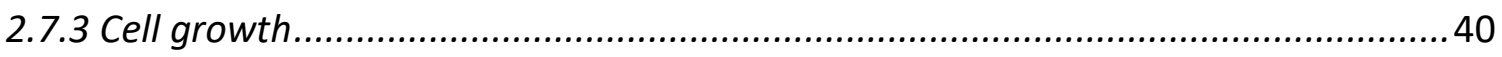

2.8 Flow sorting:

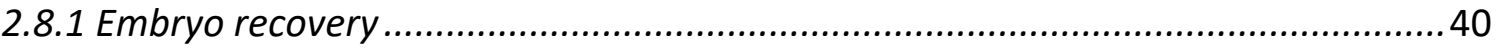

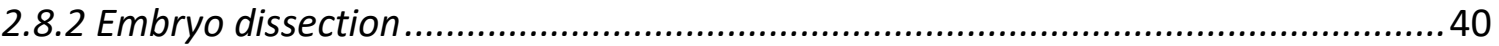

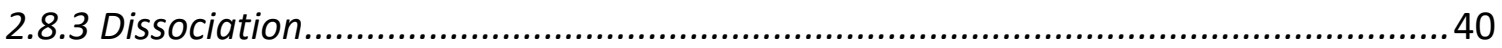

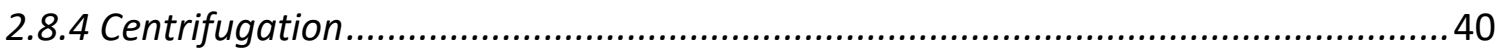

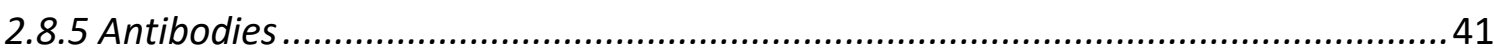

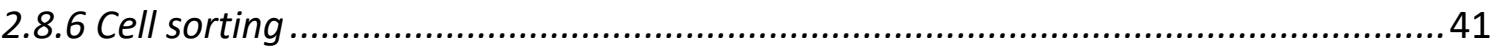

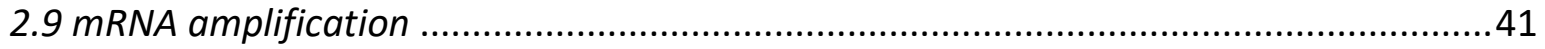

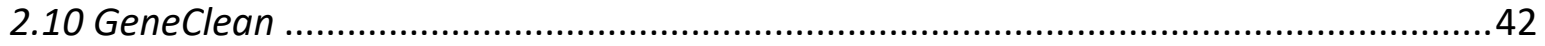

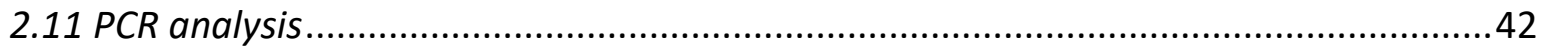

3 Results I: Creation of dTOMATO expressing plasmid ....................................................43

4 Results II: Testing functionality of the dual retinoic acid reporter

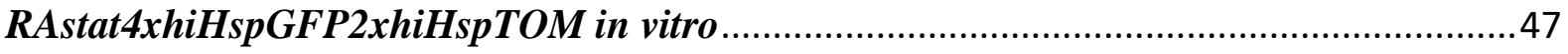

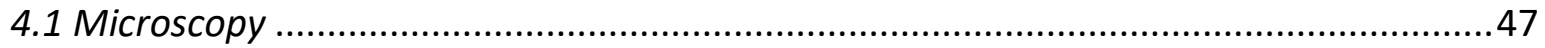

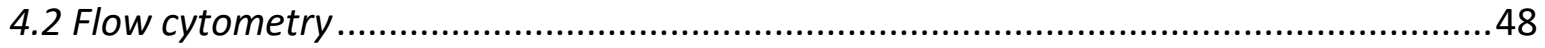

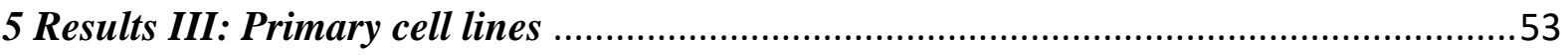

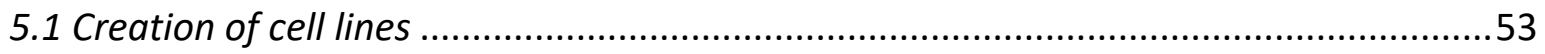

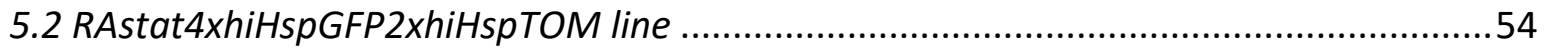

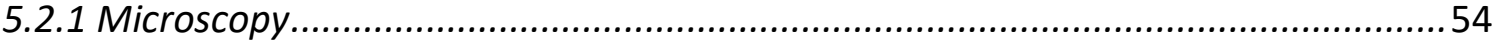




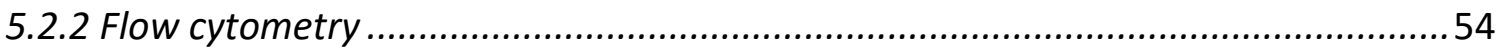

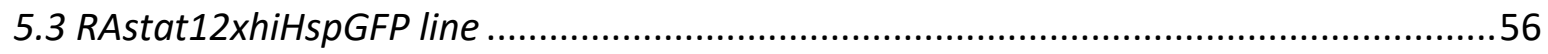

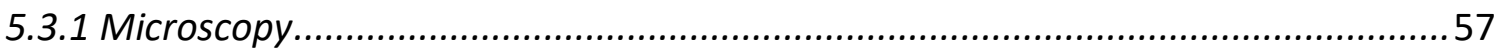

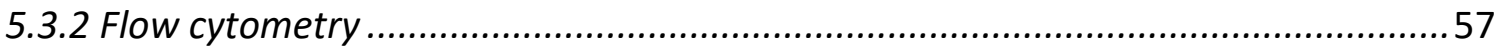

6 Results IV: In vivo characterization of reporter construct function in response to $R A$

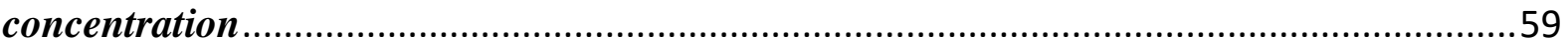

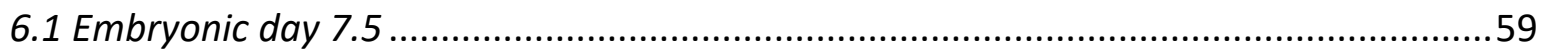

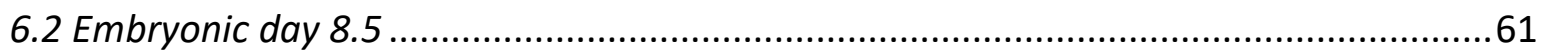

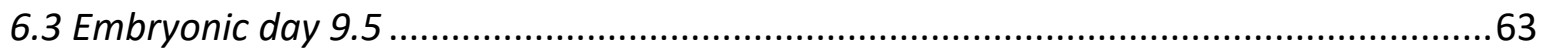

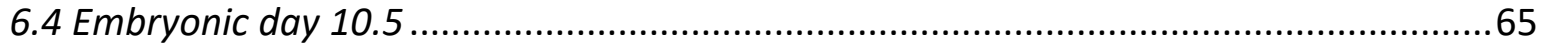

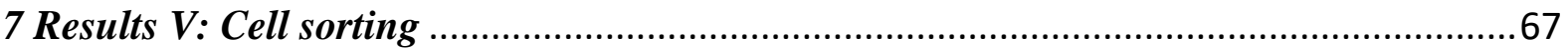

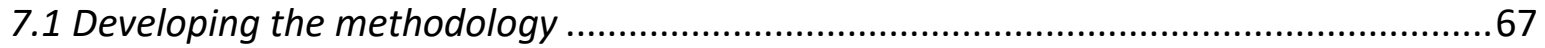

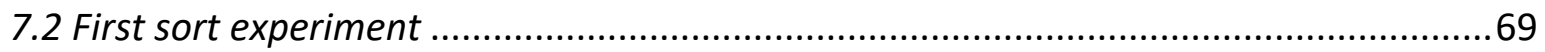

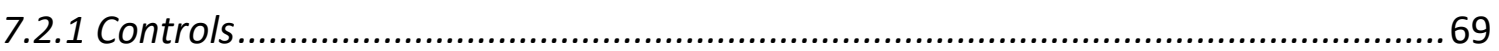

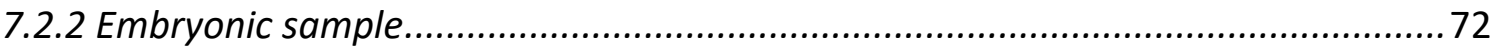

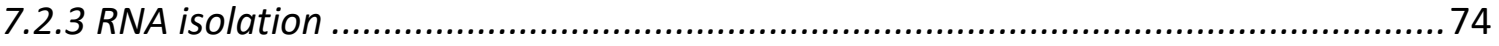

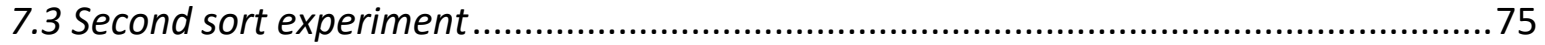

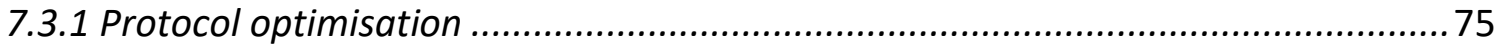

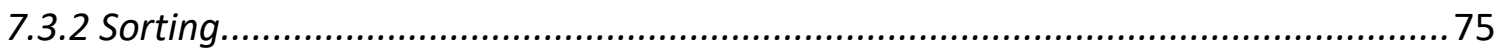

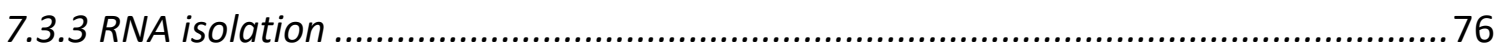

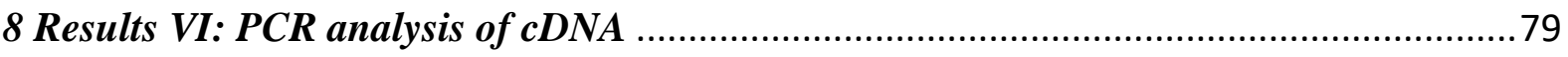

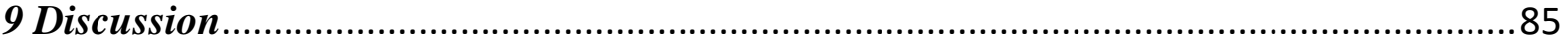

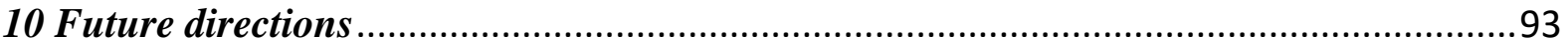

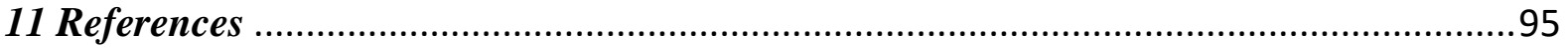

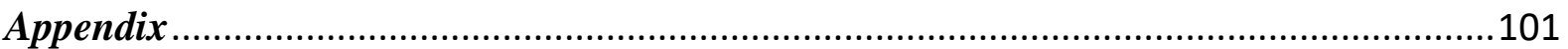

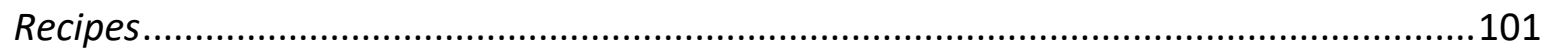

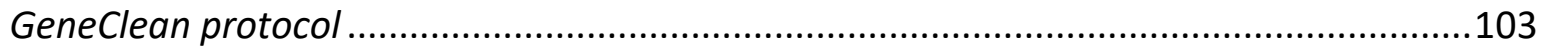

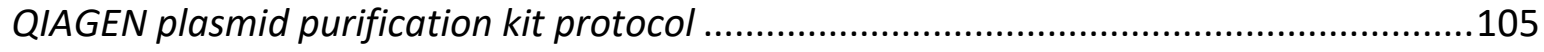

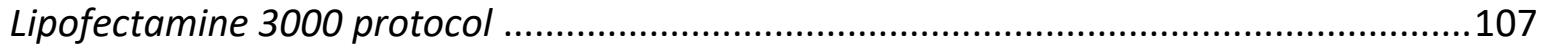




\section{List of Figures}

Figure 1 The three major retinoids

Figure 2 The mechanism of action of retinoic acid for controlling the transcription of target genes

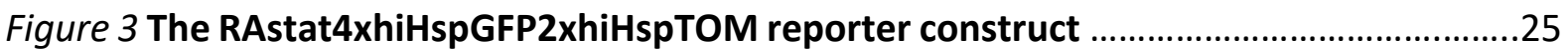

Figure 4 The plasmids used in the creation of a TOMATO-protein expressing plasmid ..........29

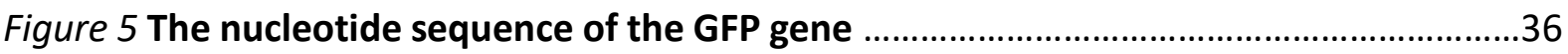

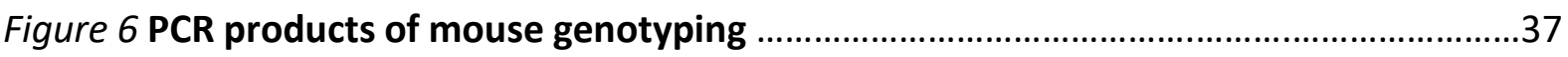

Figure 7 The pPyCAGIPmod plasmid with dTOMATO insert ................................................43

Figure 8 Restriction digest products run on 1\% agarose gel ................................................44

Figure 9 Restriction digest products of test for correct insertion of dTOMATO fragment into

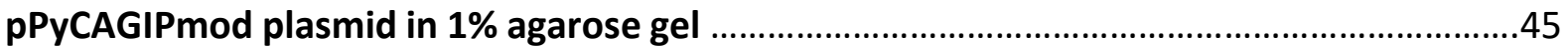

Figure 10 Transfection of cells with dTOMATO plasmid .....................................................46

Figure 11 Fluorescent protein expression in NIH3T3 cells transfected with Rasta4xhiHspGFP2xhiHspTOM construct .48

Figure 12 The gating strategy used for analyzing the FCS files obtained from flow cytometry of cells

Figure 13 The median fluorescence intensity of transfected NIH3T3 cells exposed to

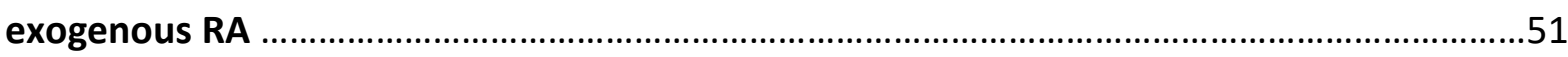

Figure 14 Result of production of primary embryonic cell lines ............................................53

Figure 15 Fluorescent protein expression in RAstat4xhiHspGFP2xhiHspTOM primary

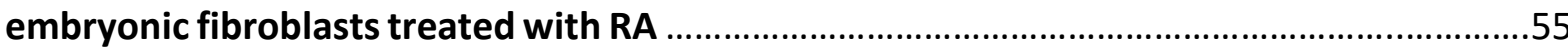

Figure 16 The median fluorescence intensity of RAstat4xhiHspGFP2xhiHspTOM primary

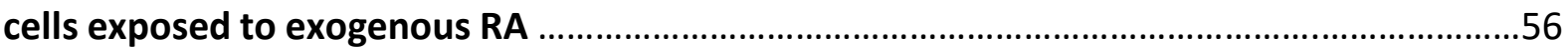

Figure 17 GFP expression in RAstat12xhiHspGFP primary embryonic fibroblasts treated with RA

Figure 18 The median fluorescence intensity of RAstat12xhiHspGFP primary cells exposed to exogenous RA .58

Figure 19 Embryonic day 7.5 embryos showing RA distribution .60

Figure 20 Embryonic day 8.5 embryos viewed under 10x magnification .62

Figure 21 Embryonic day 9.5 embryo viewed under 1.25x magnification .63 
Figure 22 Embryonic day 9.5 embryos viewed under 5x magnification

Figure 23 Embryonic day 10.5 embryos viewed under 1.25x magnification .65

Figure 24 Embryonic day 10.5 embryos viewed under 5x magnification .66

Figure 25 Identification of transgenic embryos .69

Figure 26 The dot-plots of the single stained controls for each of the four fluorophores and DAPI .70

Figure 27 The dot-plots of the fluorescence-minus-one controls .71

Figure 28 Gating around the single and live cells . .72

Figure 29 Gating the two tissue types .73

Figure 30 Gating the populations of paraxial mesoderm cells to be sorted .74

Figure 31 Gating the two tissue types in the second experiment .76

Figure 32 Gating around the populations of paraxial mesoderm cells to be sorted in the second experiment

Figure 33 The normalised fluorescence of the real time PCR and the melt curve of the PCR products of cDNA with GAPDH primers

Figure 34 PCR products of 1:15 DNA dilution

Figure 35 PCR products of 1:45 DNA dilution

Figure 36 Testing the primers on two types of cDNA .84

Figure 37 Embryonic turning between E8.5 and E.9.5 


\section{List of Tables}

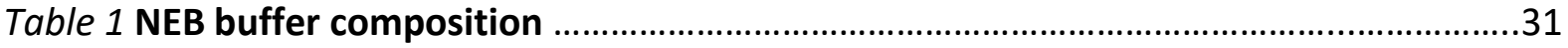

Table 2 The PCR cycling parameters for identifying GFP presence in transgenic mice .........36

Table 3 The DNA yield from cells obtained during the first sort experiment ..........................75

Table 4 The DNA yield of cells obtained during second sorting experiment ........................77

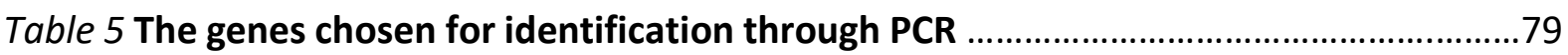

Table 6 PCR cycling parameters for identification of genes of interest .................................80 


\section{$\underline{1 \text { Introduction }}$}

\subsection{Biochemistry}

The majority of animals must derive retinoids from their diet, as they are unable to be synthesised de novo (Rhinn \& Dollé, 2012). Embryos of placental species receive maternal retinol through trans-placental transfer, whereas oviparous species store vitamin A within the egg yolk (Rhinn \& Dollé, 2012). Precise control of RA distribution throughout different regions of the developing embryo is achieved through the dynamic expression patterns of specific enzymes involved in synthesis and metabolism pathways (Rhinn \& Dollé, 2012).

Vitamin A (retinol) is acquired through the diet and absorbed in the small intestine. Here, it is esterified into a retinyl ester for transport through the blood stream (Kam et al., 2012). These retinyl esters are hydrolysed to retinol in the liver. Retinol is able to bind retinol binding proteins (RBPs) and this complex is the major form in which retinol is transported through the body (Kam et al., 2012). The most common retinoid in circulation is retinol bound to RBP4 (Rhinn \& Dollé, 2012). Target organs take up this retinol/RBP and it is either re-esterified into a retinyl ester or it is bound to a cellular retinol binding protein (CRBP). CRBPs can protect retinol from premature oxidation, facilitate storage, or present retinol to the retinol dehydrogenases for oxidation. (Kam et al., 2012).

The first step in vitamin A metabolism for the synthesis of retinoic acid is the oxidisation of retinol to retinaldehyde. This reaction is catalysed by several alcohol dehydrogenases (ADHs) as well as retinol dehydrogenases (RDHs) (Duester, 2008). There are several forms of each enzyme. ADHs that play a role in retinol metabolism are the forms $A D H 1, A D H 2$ and $\mathrm{ADH} 3$, and RDH forms involved are RDH1 and RDH10. All of these enzymes are expressed widely and their expression domains overlap (Duester, 2008).

The next step is the oxidation of retinaldehyde to retinoic acid (Kam et al., 2012). This reaction is catalysed by three retinaldehyde dehydrogenases: RALDH1, RALDH2 and RALDH3. These enzymes show tissue specific expression during embryogenesis (Duester, 2008). RALDH2 is the first to be expressed. It is found in the primitive streak as well as 
mesodermal cells and is the sole RALDH present until E8.5 in the mouse. Later, RALDH1 and RALDH3 are involved in RA synthesis in the eyes and olfactory system (Rhinn \& Dollé, 2012). The result of this step is all-trans-RA (atRA), the major active form of retinoic acid (Ross et al., 2000; Kam et al., 2012) (Figure 1).

Control of RA concentration is achieved through tissue-specific oxidation by members of the cytochrome P450 26 enzyme subfamily (Kam et al., 2012). Similar to the RALDHs mentioned above, the three enzymes involved (CYP26A1, CYP26B1 and CYP26C1) are each found within discrete, specific tissue groups during embryogenesis in the mouse (Duester, 2008). These enzymes catalyse the conversion of RA to metabolites that are more polar, preventing inappropriate or undesired RA signalling in specific cell populations and preventing the detrimental and teratogenic effects of excess endogenous RA (Rhinn \& Dollé, 2012).
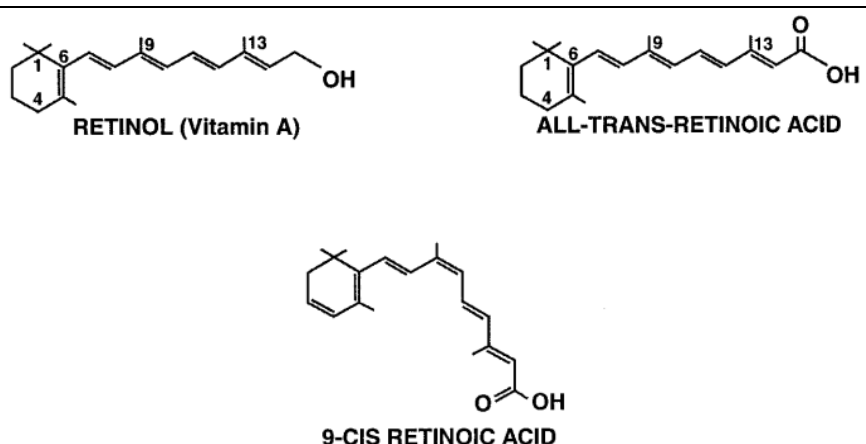

Figure 1| The three major retinoids. Vitamin A, all-trans-RA and 9-cis-RA. Image adapted from Ross et al., 2000.

\subsection{Retinoic acid mechanism of action}

Retinoic acid is released by cells which synthesise RA and enters the surrounding tissues. If the RA enters a cell expressing any of the Cyp26 gene, the RA is degraded and has no effect on the cell (Duester, 2008). Should it enter a cell not expressing Cyp26 genes, RA is able to exert its effects on gene expression through retinoic acid receptors (RARs) (Mark et al., 2009). Cellular retinoic acid binding protein II (CRABPII) carries newly synthesised RA to the nucleus where it can interact with RARs on the nuclear membrane (Kam et al., 2012). As RA binds to its receptor, the RAR dimerises with a retinoid $X$ receptor (RXR), forming a heterodimer which is then able to move into the nucleus where it binds to a retinoic acid 
response element (RARE) in the promoter of target genes (Duester, 2008) (Figure 2). RXRs themselves can only bind the retinoid 9-cis-RA (Huang, 2006) and act as scaffolding proteins to facilitate the binding of the RAR/RXR complex to the DNA (Chambon, 1996). These heterodimers bind preferentially to direct repeats of the sequence AGGTCA separated by 1 , 2, or 5 base pairs (Oosterveen et al., 2003). This binding causes release of co-repressors a cascade of events follows that will ultimately lead to the recruitment of transcriptional activators and the commencement of gene transcription (Duester, 2008).

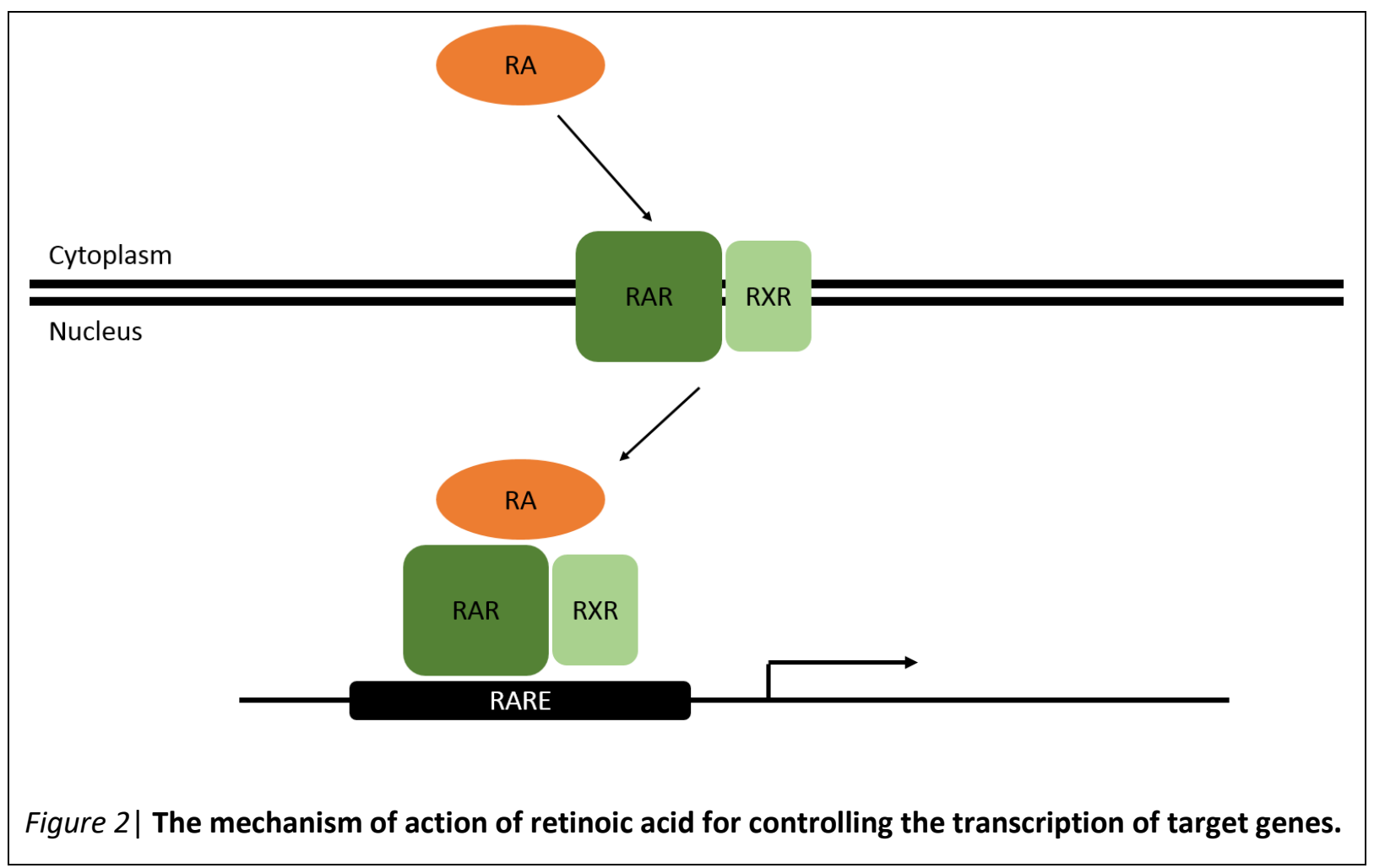

\subsection{Genetics and function of the retinoic acid receptors}

Retinoic acid receptors are part of the nuclear receptor superfamily (Mangelsdorf et al., 1995). The RAR subfamily has three members - RAR $\alpha, R A R \beta$ and RAR $($ Mark et al., 2009). These receptors show dynamic expression, changing as the embryo develops. In E6.5 mouse embryos, RAR $\alpha$ is expressed ubiquitously throughout embryonic and extraembryonic tissues, while RARy is found only in embryonic tissues (Dollé, 2009). At E7.5, RAR $\beta$ is expressed in posterior midline tissues and in the lower regions of the head fold. 
Single knockout mutants in mice are not lethal (Mark et al., 2009) and display only minor effects such as reduced body weight in $\mathrm{RAR}^{-1-}$ mutants and vertebrate malformation in $\mathrm{RAR}^{-/-}$mutants (Kam et al., 2012), suggesting there is functional redundancy. No effect has been seen in RAR ${ }^{-/-}$knockout strains.

Similarly, the RXR family also has three members - RXR $\alpha, R X R \beta$ and RXRY (Kam et al., 2012). These receptors facilitate RA binding to the RAR, and also increase the efficiency of the RA/RAR complex binding to promoters on the DNA (Chambon, 1996). Knockout experiments by Kastner et al. (1997) showed embryonic lethality due to malformation in the heart in mouse embryos with a mutation in the RXR $\alpha$ gene. RXR $\beta$ mutant embryos show $50 \%$ lethality for unknown reasons, and those that do survive are morphologically normal apart from the fact that males are sterile due to abnormal germ cell maturation (Kastner et al., 1995). RXRy mutants are indistinguishable from wild type embryos (Krezel et al., 1996). RXRs have also been identified has having roles in the signalling pathways of other molecules including thyroid hormone and vitamin D3 (Zhang et al., 1994).

\subsection{Effects during development}

Discussed below are a range of the effects that RA has on the developing embryo. Unless specified otherwise, all findings come from studies on murine embryos.

Vitamin $\mathrm{A}$ is unique among vitamins, in that its concentration must be maintained within a specific range, where deficiency is just as serious as toxicity (Duester, 2008). It regulates important embryonic patterning and growth events through its derivative, RA (Niederreither \& Dollé, 2008). In humans, vitamin A and RA have functions that extend into adulthood, including maintaining healthy vision and fertility and prevention of neurodegenerative disease (Niederreither \& Dollé, 2008), however here, only their effects on embryonic development will be discussed.

The signalling activity of RA is first seen at embryonic day (E) 7.5 and RALDH2 is first seen expressed at E7.5 as well (Duester, 2008). The node has been identified as the structure which is the major source of RA at this stage of development, as shown by experiments 
where the node was transplanted to another area of the embryo where it was able to induce a second embryonic axis (Conlon, 1995). This RA signalling is essential for accurate patterning of developing embryonic structures (Oosterveen et al., 2003). Normal physiological concentrations of RA in the developing embryo range from $10^{-7} \mathrm{M}$ to $10^{-11} \mathrm{M}$, with dose dependent effects being seen in the embryo when RA concentration is between $5 \times 10^{-7} \mathrm{M}$ and $10^{-3} \mathrm{M}$ (Huang et al., 2006). Different species show differing physiological RA concentrations. Stage 10-15 Xenopus embryos show mean endogenous RA concentrations of $1.5 \times 10^{-7} \mathrm{M}$ (Durston et al., 1989), and the chick limb bud shows a concentration of $5 \times 10^{-8}$ M (Thaller \& Eichele, 1987).

Embryos at different stages show different sensitivities to changes in RA concentration and the effect that these changes have vary greatly in severity, depending on the developmental stage of the embryo (Huang et al., 2006).

\subsubsection{Axis formation}

Body axis formation in vertebrates begins with creation of the future head during gastrulation, followed by extension along the length of the embryo (Berenguer, 2018). RA is important for the establishment of the anterior-posterior axis (Durston et al., 1989). RA itself has a posteriorising effect (Simeone et al., 1995), meaning that it is necessary to tightly control the concentration of RA along the embryo. RALDH and CYP26 enzymes create this balance. RALDHs synthesise RA in the posterior regions of the embryo, while CYP26s expressed in the anterior of the embryo ensure that RA is restricted to the posterior (Kam et al., 2012). While the concentration of RA shows a gradient with higher levels at the posterior and low levels in the anterior regions, an opposing FGF8 gradient is found during axis formation (Rhinn \& Dollé, 2012). RA and FGF8 are antagonising signals, each able to inhibit signalling by the other (Wilson et al., 2009). These opposing gradients provide important information about positional identity along the anteroposterior axis. The most posterior part of the tail end of the embryo is kept free of RA signalling through expression of FGFs and Cyp26a, to ensure that axis extension is not prematurely terminated (Cunningham et al., 2011) and that caudal progenitor cells are preserved (del Corral et al., 2003). 
In addition to specifying the direction of the axis, RA is also involved in cell fate specification of cell populations on the embryonic axis (Berenguer, 2018). A population of stem cells adjacent to the regressing primitive streak is required for the generation of trunk tissues along the axis as is extends (Niederreither \& Dollé, 2008). These cells - neuromesodermal progenitors - require the absence of FGF8 in order to differentiate into neural tissues and presomitic mesoderm, meaning that RA is essential for ensuring that progenitor tissues differentiate correctly (Berenguer, 2018). As the body of the embryo grows, the point at which the RA gradient and the expression boundary of posterior FGF8 meet becomes the point at which these cells differentiate, creating a wave of cell differentiation from anterior to posterior (del Corral et al., 2003). As structures develop, newly formed somites (discussed below in 1.4.2) begin to express RA, helping to move the RA boundary along the extending axis (Harrison et al., 2011).

\subsubsection{Somites}

Somites, segmented epithelial structures that sit along the neural tube, form sequentially along the length of the embryonic axis (Gibb et al., 2010) in a process called somitogenesis. Somites form from mesodermal tissue. Embryonic mesoderm is found as four different types: the intermediate, axial, paraxial and lateral plate mesodermal layers (Christ \& Ordahl, 1995). Somites arise from the paraxial mesoderm. Somitogenesis commences at E8.0 and continues until E14.0, with around 65 somite pairs formed (Hogan et al., 1994). They are the precursor structures of many different tissues including muscle, dermis, the vertebral column and the ribs (Burgess et al., 1996). Somites are formed as bilateral pairs in a rhythmic process termed a "clock and wave front" mechanism (Duester, 2008). In this process, Notch and Wnt signalling generate waves of gene expression that move through the presomitic mesoderm (PSM) (Rhinn \& Dollé, 2012) and interact with the regressing Fgf8 expression domain, controlled by the antagonistic action of RA, to form a so-called somite determination front where new somites are formed (Gibb et al., 2010). As the embryonic axis extends, this determination front moves posteriorly along the axis, forming new somites just anterior of the Fgf8 expression domain as it does (Duester, 2008). The anteroposterior position of this determination front is controlled by RA, as mentioned above in 1.4.1. 
RA deficiency causes anteriorisation of the $F g f 8$ expression domain, changing the intersomitic boundary and causing forming somites to be smaller than normal (Niederreither \& Dollé, 2008). The symmetry of the bilateral formation can also be effected by deficiency in RA. Too low levels of RA during somitogenesis cause the gene expression waves to become desynchronised, due to the asymmetric expression of Hes 7 and $L f n g$, which are both required for the Notch-dependent function of the oscillator (Duester, 2008). This allows for asymmetry in the forming somites (Niederreither \& Dollé, 2008), resulting in fewer somites forming one side, often the right, than the other (Rhinn \& Dollé, 2012).

\subsubsection{Hox genes}

The Hox gene family is a group of genes that is highly conserved within metazoans (Ruddle et al., 1994). Their existence was first found in the fruit fly Drosophila melanogaster, where they are termed HOM genes (Favier \& Dollé, 1997). They were identified as being genes whose mutation led to a transformation of one body part to another in specific segments of the anterior-posterior (A-P) body axis.

Vertebrates have four clusters of Hox genes: Hoxa, Hoxb, Hoxc and Hoxd (Shimeld, 1996). It is believed that these clusters evolved by gene duplication of an ancestral Hox cluster over the last 500 million years (Ruddle et al., 1994). These clusters are able to be aligned is such a way that related genes sit in a similar position in each cluster. As such, there are 13 of these positions, termed paralogy groups, although not all clusters have genes occupying each group (Shimeld, 1996). Humans and mice possess 38 Hox genes (Krumlauf, 1994), each around $10 \mathrm{~kb}$ in length (Ruddle, 1994), making each Hox gene cluster approximately $120 \mathrm{~kb}$ long (Favier \& Dollé, 1997).

Hox genes are expressed in confined domains along the A-P axis of the developing embryo and display sharp expression boundaries (Favier \& Dollé, 1997). This expression pattern is closely linked to the physical order of the genes along the chromosome (Krumlauf, 1994), with the genes that lie at the $3^{\prime}$ end of the cluster being expressed anteriorly and those at the $5^{\prime}$ end being expressed posteriorly (Geada et al., 1992). 
RA diffusion from the node is thought to drive the transcription of RA-inducible Hox genes, especially those found in the posterior of the embryo (Conlon, 1995). Evidence for this comes from several sources. Functional RAREs, necessary for expression, have been found in the promoter regions of Hoxa1, Hoxb1 and Hoxd4 (Conlon, 1995). Hoxa1, Hoxb1, Hoxb2, Hoxb3 and Hoxd1, all of which normally show distinct anterior expression boundaries in the hindbrain, show anterior expansion when the embryo is treated with RA (Shimeld, 1996). Cell culture studies have shown time and dose dependent effects of RA on the expression of Hox genes (Simeone et al., 1995).

\subsubsection{Brain development}

RA has the ability to induce specification alterations in the rostral developing central nervous system. These alterations result in three distinct areas - fore-, mid- and hindbrain (Simeone et al., 1995).

Early hindbrain development involves the generation of tissue segments called rhombomeres. These segments, of which there are seven (Kam et al., 2012), have a distinct spatial identity along the anteroposterior axis and will eventually give rise to structures including the brain stem, the heart and large vessels, the inner ear and the branchial arches (Rhinn \& Dollé, 2012). An important role for RA in the development of the hindbrain involves controlling Hox gene expression (Dupé \& Lumsden, 2001). Hox genes, whose expression is controlled by RA as discussed above in 1.4.3, are responsible for controlling the positional identities of rhombomeres on the A-P axis, as well as the location of the boundaries between them (Kam et al., 2012). An example of such a gene is Hoxb1 which is required for facial motor neuron differentiation and is specific to rhombomere 4 (Simeone et al., 1990). Although initially expressed throughout the posterior hindbrain, as rhombomere formation begins, Hoxb1 is restricted to rhombomere 4 through a RARE $5^{\prime}$ to the promoter which represses Hoxb1 found in rhombomeres 3 and 5, but not rhombomere 4 (Duester, 2008).

RA produced in the presomitic mesoderm by RALDH2 diffuses towards the developing hindbrain and provides a signal for anteroposterior positioning to regulate the patterning and location of the rhombomeres (Grandel et al., 2002) with the highest concentrations in 
the posterior and a complete lack of RA the rostral brain due to the activity of CYP26 enzymes (Niederreither \& Dollé, 2008). This graded distribution of RA is vital for specification of rhombomere identity (Oosterveen et al., 2003). Dysregulation of this signal can have drastic consequences for rhombomere development. Exposing the embryo to excess RA at the late gastrula to early neurula stages, occurring between embryonic day 7 and 7.5 (Hogan et al., 1994), results in the anterior shift in the boundaries between the hind- and midbrain, as well as between the anterior and posterior hindbrain (Conlon, 1995). This leads to an anterior expansion of the hindbrain and a reduction in size of everything rostral to the midbrain-hindbrain border (Conlon, 1995). Other conditions such as microcephaly and anencephaly may also occur (Niederreither \& Dollé, 2008), and sense organs formed from the forebrain, such as the nasal pits and eyes, may also be lost (Durston et al., 1989). Similarly, treating amphibian embryos with RA results in the anterior advance of the hindbrain and loss of the fore- and midbrain (Duester, 2008). Treatment at later stages of development causes rhombomere-specific posteriorisations of rhombomere 2-3 to rhombomere 4-5 (Rhinn \& Dollé, 2012). Low levels and lack of RA also effect rhombomere development (Duester, 2008). Mouse mutants lacking Raldh2 lose segmentation and show a reduction in the size of the hindbrain. These patterning defects can have drastic consequences for later developmental events including the patterning of the inner ear, cranial nerve differentiation and migration of neural crest cells (Rhinn \& Dollé, 2012). Although RA is detrimental during the initial phase of the development of the forebrain, it becomes essential for the proper growth of the forebrain at later stages (Niederreither \& Dollé, 2008). Vitamin A deficiency (VAD) mouse models have shown that Raldh2 and Raldh3 are both active within the embryonic head and forebrain (Rhinn \& Dollé, 2012). Raldh2 can be found transiently expressed in the rostral neural plate and the optic vessels and Raldh3 is found expressed in the ectoderm overlaying the anterior forebrain (Rhinn \& Dollé, 2012).

\subsubsection{Organogenesis}

Changes in retinoic acid concentration can have drastic effects on the outcome of key developmental processes during organogenesis. Depending on the organ, effects can range from a complete lack of development, to issues such as incorrect patterning resulting in 
abnormal structures. Discussed below are the effects of varying RA concentration on several organ systems.

RA is one of the signals required for anteroposterior patterning of the heart tube (Duester, 2008). However, it is most likely that the effect of RA on heart development is not due to direct induction of target genes, rather, it acts to repress Fgf8 expression in the posterior region of the developing heart (Duester, 2008). A reduction of RA concentration causes severe defects in the structure of the heart. The looping morphogenesis of the heart tube which results in the basic structure of the heart is interrupted (Niederreither \& Dollé, 2008) and the atria is greatly reduced in size and the ventricles form abnormal cavities, often lacking distinct left and right ventricles (Duester, 2008). Another function of RA is to restrict the pool of cardiac progenitor cells (Niederreither \& Dollé, 2008). Without adequate levels of RA, the population of lateral mesodermal cells destined to become myocardial progenitors is expanded, reducing the number of cells left to become progenitor for pharyngeal, pancreatic and, in zebrafish, fin structures (Niederreither \& Dollé, 2008).

RA concentration effects the patterning of the developing limb buds. RA synthesis in the limb bud is regulated by RALDH2 expression in the flank mesoderm, adjacent to the limb bud (Duester, 2008). While RA expression along the anteroposterior axis of the limb bud is uniform, it is found expressed at high levels in the proximal limb bud and decreases towards the distal end (Duester, 2008). This gradient is likely regulated by the expression of Fgf8 in the apical ectodermal ridge of the distal limb bud, opposing the gradient of RA forming from the proximal regions (Duester, 2008). Forelimb buds develop hypoplastically or fail to develop altogether in the absence of RA (Rhinn \& Dollé, 2012), and RA deficient mouse models cease to develop before the stages where hindlimb buds begin to develop (Duester, 2008). RA deficiency also effects the expression of Shh, which is an important regulator of forelimb bud outgrowth (Rhinn \& Dollé, 2012). Rescue of $R A L D H^{-/}$embryos with maternal RA supplementation reduces the lethality and is able to induce limb budding. While the forelimb buds are smaller than is normal, the hindlimb buds develop as expected, suggesting that RA only effects forelimb development and not that of the hindlimbs (Duester, 2008). Although RA is essential during some stages of forelimb bud patterning and development, eventually the limb bud cells require an environment devoid of RA to 
continue proper growth, and this is regulated through the expression of Cyp26b1 (Rhinn \& Dollé, 2012).

The lung also requires RA signalling for organogenesis. The lungs derive from the posterior foregut endoderm and RA signalling from the mesoderm stimulates this tissue into a lung fate at E9.5 in mice (Duester, 2008). In the context of lung development, RA works to induce the expression of Hoxa5, which is essential for correct tracheal formation as well as the lung branching required to develop the large surface area of the lungs (Costa et al, 2001), as well as inhibiting TGF- $\beta 1$ signalling (Duester, 2008). Inhibition of TGF- $\beta 1$ is important as Fgf10, which is essential for the expansion of the lung bud as well as branching, is supressed by TGF- $\beta 1$ signalling (Duester, 2008). RA deficient embryos have a specified lung bud, but do not express Hoxa5 and lack FGF10 signalling in the lung epithelium (Duester, 2008).

\subsection{Research aims}

Previous to this project, a RA reporter system, RAstat4xhiHspGFP2xhiHspTOM (Figure 3), was created. This reporter system is based on the work carried out by Rossant et al. (1991), where they created a transgenic mouse line expressing a plasmid containing RAREs upstream of the lacZ gene. This plasmid allowed for visualisation of RA expression through the RA-mediated expression of the enzyme $\beta$-galactosidase. Embryos were stained with Xgal - the substrate of $\beta$-galactosidase - and regions of RA expression appeared blue through the product of cleavage of X-gal. Our reporter uses the same principle of RA binding elements upstream of a gene that allows for visualisation, however here, fluorescent proteins have been used in the place of lacZ.

The other way in which this reporter differs from that used by Rossant et al. is that it possesses dual activity. There are two fluorescent proteins - green fluorescent protein (GFP) and TOMATO-fluorescent protein - which are each preceded by a different number of RA binding elements. GFP follows four binding elements, while TOMATO-fluorescent protein follows two. This makes the GFP expression response more sensitive to RA concentration than that of TOMATO, and is therefore indicative of low concentrations of RA. TOMATOfluorescent proteins are only expressed at higher RA concentration as the sensitivity of this 
reporter is lower, requiring a higher concentration to drive protein expression. This dual activity reporter allows for visualisation of varying concentrations of RA, with areas of low RA concentration expressing only GFP and areas of high RA concentration expressing both GFP and TOMATO-fluorescent proteins. The distance between the emission wavelengths of these two fluorescent proteins lie far enough apart from each other that there is minimal overlap.

The two portions of the reporter system are each preceded by a $\beta$-globin insulator sequence derived from chicken DNA. Insulator sequences are regions of DNA that protect transgenes from genomic enhancer or silencer sequences, as well as from the spread of hetero- and euchromatin (Kuhn \& Geyer, 2003). Expression of transgenes is often affected by changes in chromatin structure and epigenetics (Aker et al, 2007). One such problem is that nearby enhancer or silencer sequences have undesired effects on the expression of the reporter construct. By inserting an insulator sequence 5' of the reporter construct, the sequence is protected from repressive or enhancing effects of the surrounding genomic area.

Previous to this project, a transgenic mouse line was created using this plasmid. This was done by injecting the plasmid into the fertilised egg of a mouse. 


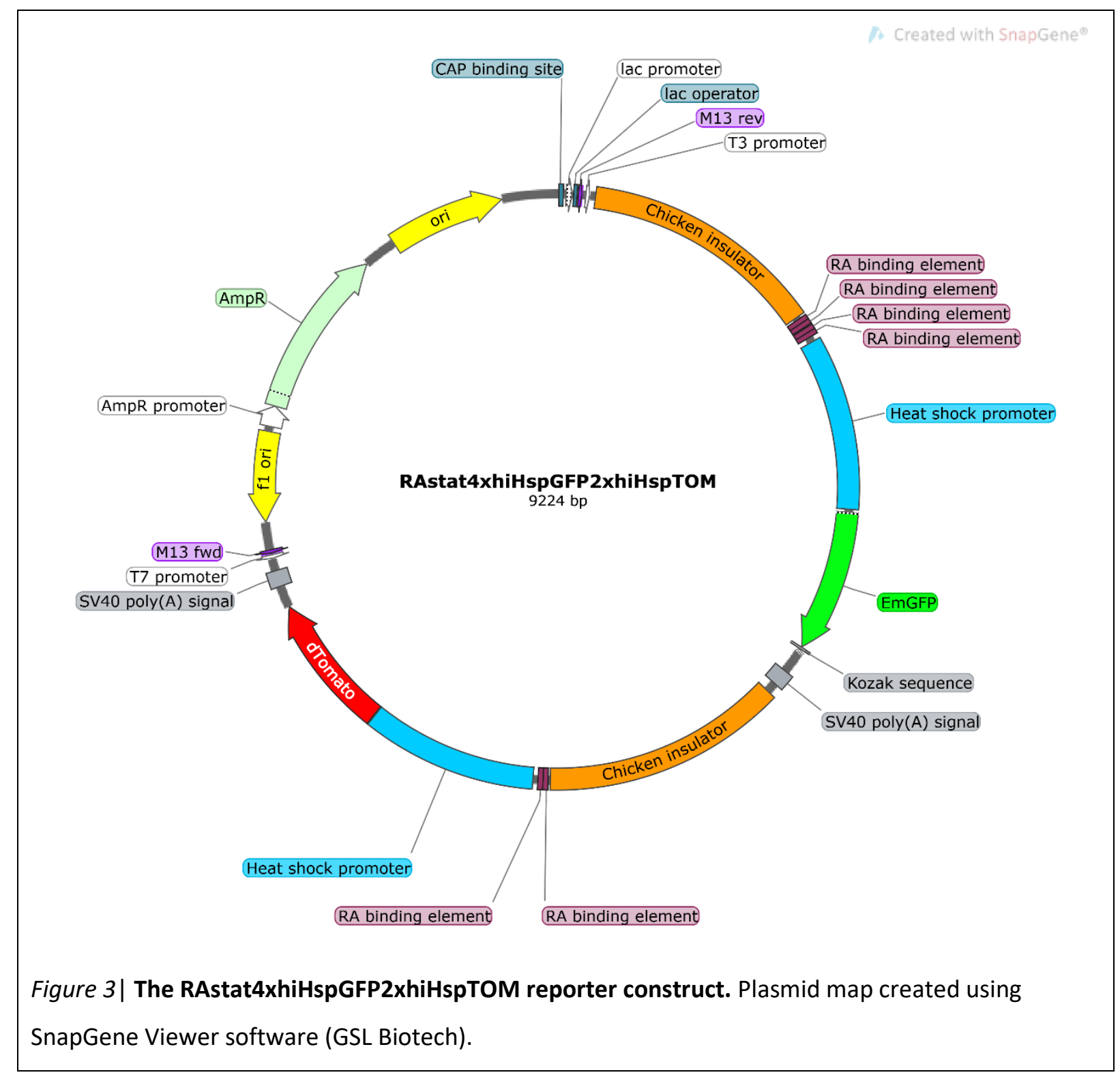

In these experiments, we aim to characterise the activity of this reporter construct and then use it to isolate discrete populations of embryonic cells that are found in areas of varying RA concentration.

To do this, we will transfect immortalised cell lines (NIH3T3) with the plasmid and supplement their growth media with varying concentrations of RA. This will allow us to see the fluorescent protein expression levels as well as a first test that the reporter works. The next step will be to create primary embryonic cell lines from the embryos of the transgenic mouse line and to test the reporter activity in those. Similarly to the immortalised cell lines, RA will be added to the growth media at various concentrations and 
the fluorescent protein expression will be analysed by fluorescence microscopy as well as flow cytometry.

The RA distribution will also be assessed in vivo using transgenic embryos at varying developmental stages, beginning at E7.5 and up to E10.5. This will involve isolating the embryos, identifying those that are transgenic and using a fluorescent microscope to visualise the distribution of the fluorescent proteins.

Finally, we will be using the information gathered in the experiments mentioned above to dissociate transgenic embryos into single cells and sort those cells based on their levels of fluorescent proteins, as an indicator of the concentration of RA they were exposed to in the embryo. Subsequently, mRNA analysis will be carried out in order to gauge the effect RA has on gene expression. 


\section{$\underline{2 \text { Methods }}$}

\subsection{Cell culture}

\subsubsection{Media}

Before any cell culture work was done, growth media - consisting of DMEM (Thermo Fisher) containing $1 \mathrm{mM}$ sodium pyruvate, $2 \mathrm{mM}$ glutamine and supplemented with $1 \%$ penicillinstreptomycin (10,000 units $/ \mathrm{mL}$ penicillin-10,000 $\mathrm{gg} / \mathrm{mL}$ streptomycin) (Thermo Fisher) and $10 \%$ fetal calf serum (FCS) (Thermo Fisher) - was warmed to $37^{\circ} \mathrm{C}$ in an incubator.

\subsubsection{Thawing cells}

Cells were cultured from frozen stocks stored in liquid $\mathrm{N}_{2}$ at $-196^{\circ} \mathrm{C}$. Cell vials were removed from the liquid $\mathrm{N}_{2}$ and rapidly thawed in a water bath at $37^{\circ} \mathrm{C}$. As soon as the cells thawed, prewarmed growth media was added to dilute the toxic dimethyl sulfoxide (DMSO) in the freezing media. Cells were spun down in a centrifuge at 1,000xg for 3 minutes. The supernatant was removed and replaced with 7-10 $\mathrm{mL}$ fresh growth media. The cells were resuspended in this and transferred to a T25 growth flask (Thermo Fisher). The culture was incubated at $37^{\circ} \mathrm{C}$ with $5 \% \mathrm{CO}_{2}$ until fully confluent.

\subsubsection{Passaging cells}

When cells became $>90 \%$ confluent, they were passaged. Growth media was aspirated, and the cells gently washed with warm phosphate buffered saline (PBS), which was then discarded. $1 \mathrm{~mL}$ TrypLE (Thermo Fisher) was added and the cells left to incubate at $37^{\circ} \mathrm{C}$ for 3-4 minutes until the cells appeared rounded under the microscope. Growth media was added and used to flush the cells off the surface of the growth flask. The cells in media were transferred to a $15 \mathrm{~mL}$ Falcon tube (Fisher Scientific) and centrifuged at 1,000xg for 3 minutes. The supernatant was aspirated, the cells resuspended in fresh media and returned to a new growth flask at a concentration of $1 / 6^{\text {th }}$ of the original culture. 


\subsubsection{Freezing cells}

Cells were lifted from their growth flask in the same way as in 2.1.3 and resuspended in freezing media which consisted of $40 \%$ growth media, 50\% FCS and 10\% DMSO (Sigma). Working quickly so as to not allow the cells to be in DMSO at room temperature for more than 10 minutes, $1 \mathrm{~mL}$ aliquots were transferred to cryotubes and stored overnight at $-80^{\circ} \mathrm{C}$ inside a pre-cooled "Mr. Frosty" box (a container that cools down by $1^{\circ} \mathrm{C}$ per minute in the freezer). Once frozen, tubes were transferred to, and stored in, liquid $\mathrm{N}_{2}$.

\subsection{Creating a TOMATO-protein-expressing expressing plasmid}

A TOMATO fluorescent expressing plasmid was created to use as a positive control for transfection experiments as there were none available in house. A green fluorescent protein (GFP)-fluorescing plasmid was available, hence it was not necessary to create one for this project.

\subsubsection{Plasmids}

A pPyCAGIPmod plasmid was used as the vector backbone and a dTOMATO gene fragment was cut from a Brainbow1-L-CMV plasmid as the insert. Using the Geneious software (version 8.0.5, http://www.geneious.com, Kearse et al., 2012), restriction sites were identified on both plasmids that would be compatible for ligations. Not1 (Not1-HF) and Bgl2 were identified as being suitable (Figure 4). 

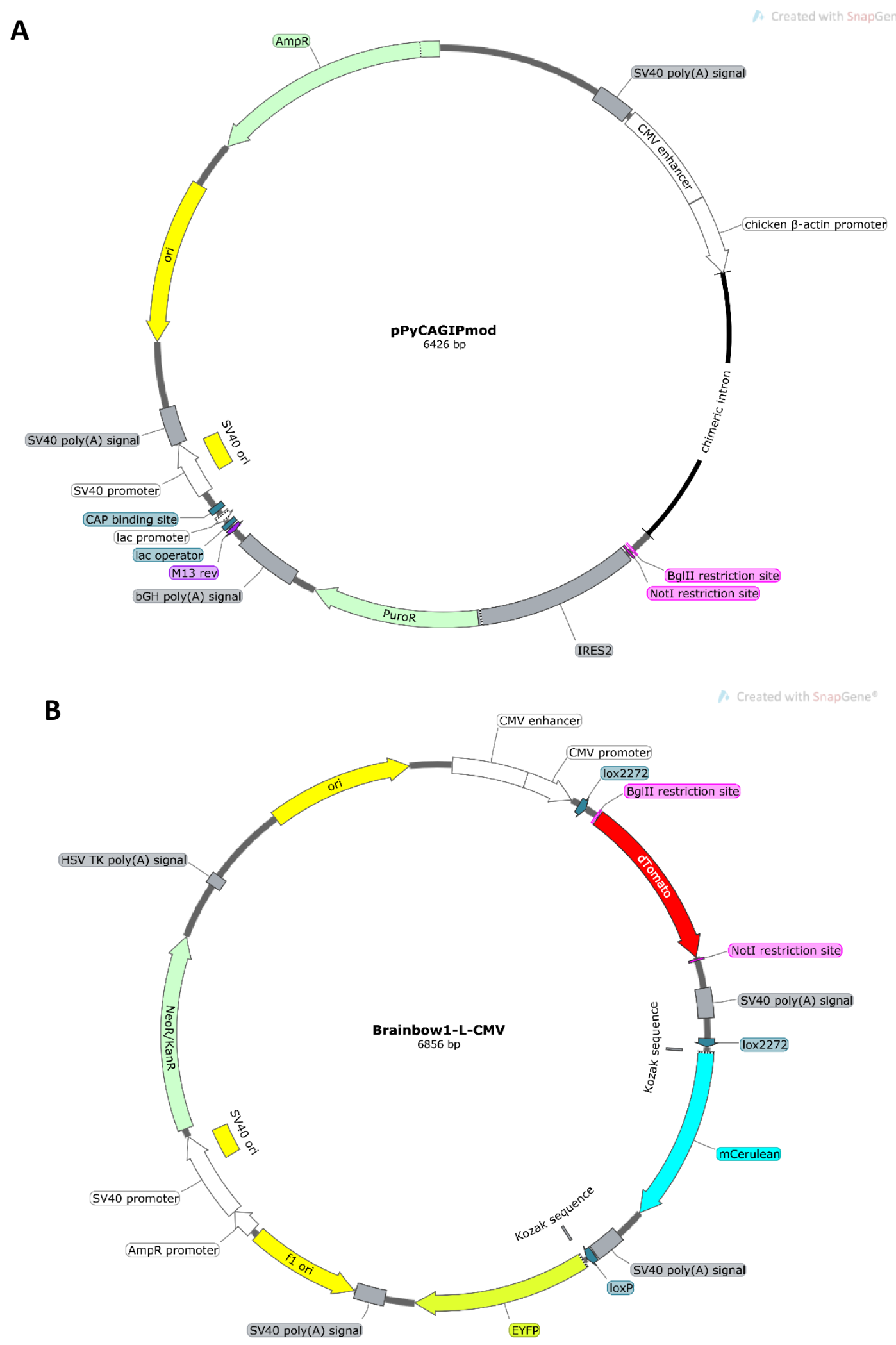

Figure $4 \mid$ The plasmids used in the creation of a TOMATO-protein expressing plasmid. $A \mid$ The pPyCAGIPmod vector backbone. B| The Brainbow1-L-CMV plasmid from which the dTOMATO gene fragment was cut. Restriction digest sites are shown in pink. Plasmid maps created using SnapGene Viewer software (GSL Biotech). 


\subsubsection{Restriction digestion}

A sequential restriction digest was used as Not1 and Bg/2 require different digestion buffers (Not1-HF requires NEB buffers 2.1 or CUTSMART for optimal activity and Bg/2 has optimal activity in NEB buffer 3.1). First, the Not1-HF digestion was carried out in the following digestion mix:

- For the digestion of the pPyCAGIPmod plasmid
○ $12.7 \mu \mathrm{L}$ water
$\circ 2 \mu \mathrm{L}$ NEB buffer 2 (New England Biolabs)
○ $1.5 \mu \mathrm{L}$ Not1-HF (New England Biolabs)
○ $\quad 3.8 \mu \mathrm{L}$ plasmid $(5 \mu \mathrm{g})$

- For the digestion of the Brainbow1-L-CMV plasmid
○ $15.5 \mu \mathrm{L}$ water
○ $2 \mu \mathrm{L}$ NEB buffer 2
○ $1.5 \mu \mathrm{L}$ Not1-HF
$\circ 1 \mu \mathrm{L}$ plasmid $(1 \mu \mathrm{g})$

After 3 hours incubation at $37^{\circ} \mathrm{C}$, the samples were placed into water bath at $65^{\circ} \mathrm{C}$ for 30 minutes to denature the enzymes. NEB buffer 3.1 and $\mathrm{NaCl}$ were added to the above digests in order to convert the existing buffer 2.1 into a more 3.1-like buffer (see Table 1 for the composition of the buffers). The following mix was made up twice (once for each plasmid) and then added to the digestion mixes above:
○ $6.5 \mu \mathrm{L}$ water
- $1 \mu \mathrm{L} 1 \mathrm{M} \mathrm{NaCl}$
○ $1 \mu \mathrm{L}$ NEB buffer 3.1 (New England Biolabs)
○ $1.5 \mu \mathrm{L} \mathrm{Bg/2}$ (New England Biolabs)

The samples were then incubated for a further 3 hours at $37^{\circ} \mathrm{C}$. 


\begin{tabular}{|l|l|l|}
\hline Ingredients & $\mathbf{2 . 1}$ & $\mathbf{3 . 1}$ \\
\hline Tris- $\mathrm{HCl}(\mathrm{mM})$ & 10 & 50 \\
\hline $\mathrm{MgCl}_{2}(\mathrm{mM})$ & 10 & 10 \\
\hline $\mathrm{NaCl}(\mathrm{mM})$ & 50 & 100 \\
\hline $\mathrm{BSA}(\mathrm{\mu g} / \mathrm{mL})$ & 100 & 100 \\
\hline
\end{tabular}

Table 1| NEB buffer composition. Comparison of the ingredients of NEB buffers 2.1 and 3.1 .

\subsubsection{Dephosphorylation of vector fragment}

After restriction digestion, the pPyCAGIPmod plasmid required dephosphorylation to ensure that the $5^{\prime}$ overhanging ends could not ligate to each other. The sample was mixed with $8 \mu \mathrm{L}$ water, $1 \mu \mathrm{L}$ NEB CUTSMART buffer and $1 \mu \mathrm{L}$ calf intestinal alkaline phosphatase (CIP). The mixture was incubated for 60 minutes at $37^{\circ} \mathrm{C}$.

\subsubsection{Electrophoresis}

A 1.5\% agarose-TAE (see Appendix) gel (containing $2 \mu \mathrm{L}$ ethidium bromide per $40 \mathrm{~mL}$ agarose gel) was cast and the two samples (vector and insert) were run on the gel to separate the DNA.

\subsubsection{Isolation of DNA from gel}

Bands of DNA were visualised under UV light and the desired DNA bands were cut out of the gel using a scalpel blade. DNA was isolated using the GeneClean kit (MP Biomedicals): The slices of gel were weighed and $4 x$ volume of sodium iodide was added (i.e. if gel weighed $100 \mu \mathrm{g}, 400 \mu \mathrm{L} \mathrm{Nal}$ solution was added). The samples were incubated at $55^{\circ} \mathrm{C}$ for 5 minutes until the gel was fully dissolved. The glass milk was vortexed vigorously and $5 \mu \mathrm{L}$ added to each sample. The samples sat at room temperature for 5 minutes and were then centrifuged for 1 minute. The supernatant was aspirated and discarded. $700 \mu \mathrm{L}$ of cold WASH solution was added and the beads resuspended. The samples were spun down again for 1 minute and the supernatant removed. The wash, spin and aspiration were repeated. 5 $\mu \mathrm{L}$ water were added, the beads resuspended and incubated at $55^{\circ} \mathrm{C}$ for 5 minutes. The samples were spun down and the supernatant retrieved and kept. 


\subsubsection{Ligation of fragments}

The two fragments (backbone and insert) were mixed on ice and an equal volume of Mighty Mix $2 x$ ligation mixture (TaKaRa) was added. The mix was left at $15^{\circ} \mathrm{C}$ for 30 minutes to allow the fragments to ligate.

\subsubsection{Transformation of competent cells}

$25 \mu \mathrm{L} \mathrm{DH} 5 \alpha$ competent $E$. coli cells (Life Technologies) were thawed and $2 \mu \mathrm{L}$ of newly ligated plasmid diluted 1:100 in Tris-EDTA (TE) buffer (see Appendix). The cells were incubated on ice for 30 minutes, heat shocked at $42^{\circ} \mathrm{C}$ for 45 seconds and plunged back into ice for 2 minutes. $1 \mathrm{~mL}$ LB broth (see Appendix) with no ampicillin was added and the samples incubated in a shaking incubator at $37^{\circ} \mathrm{C}$ for 30 minutes. The cells were spun down for 1 minute and $900 \mu \mathrm{L}$ of supernatant removed. The cells were resuspended in the remaining supernatant, spread onto a LB agar (see Appendix) plate containing $100 \mathrm{mg} / \mathrm{mL}$ ampicillin and incubated overnight at $37^{\circ} \mathrm{C}$. In the morning, 8-12 individual colonies were picked off the plate with an inoculation loop and grown over night in culture tubes with 3 $\mathrm{mL} \mathrm{LB}$ broth $+100 \mathrm{mg} / \mathrm{mL}$ ampicillin in a $37^{\circ} \mathrm{C}$ shaking incubator.

\subsubsection{Miniprep protocol}

$1.5 \mathrm{~mL}$ of the overnight cultures were transferred to Eppendorf tubes. The cells were spun down for 1 minute and the supernatant removed. $100 \mu \mathrm{L}$ of alkaline lysis solution I (see Appendix) was added and vortexed until the pellet was dissolved. $200 \mu \mathrm{L}$ alkaline lysis solution II (see Appendix) was added and mixed well by inverting the tubes sharply 5-6 times. $150 \mu \mathrm{L}$ of cold alkaline lysis solution III (see Appendix) was added and vortexed briefly. The samples were spun down for 5 minutes and the supernatant transferred to a fresh tube. $1 \mathrm{~mL}$ ethanol was added, the samples vortexed and spun down for 5 minutes. The majority of the supernatant was aspirated off and $700 \mu \mathrm{L}$ of cold $70 \%$ ethanol added carefully. All ethanol was aspirated off and the DNA pellet allowed to air dry for 3 minutes. $30 \mu \mathrm{L}$ of TE containing a 1:200 dilution of $10 \mathrm{mg} / \mathrm{mL}$ DNase-free-RNaseA was added and incubated for 30 minutes at $37^{\circ} \mathrm{C}$. 


\subsubsection{Checking correct insertion orientation}

The samples were analysed by restriction digest with Nco1 (New England Biolabs) to check for correct insertion of the insert into the vector. The samples were electrophoresed on an agarose gel to separate the resulting DNA fragments. Glycerol stocks (see Appendix) were made from the cultures that showed the correct combination of DNA bands, and therefore contained the correct version of the plasmid, and stored at $-80^{\circ} \mathrm{C}$.

\subsubsection{Midiprep}

A Midiprep was prepared from one of the overnight cultures that showed the correct restriction map. Cells from the suspension left over from the miniprep were plated onto LB agar + ampicillin plates and allowed to grow overnight at $37^{\circ} \mathrm{C}$. A single colony was picked and used to inoculate $25 \mathrm{~mL}$ of LB broth + ampicillin. This culture was grown overnight at $37^{\circ} \mathrm{C}$ in a shaking incubator. A Midiprep kit (QIAGEN, Bio-Strategy) was used to isolate DNA. The culture was centrifuged for 15 minutes at the maximum speed of the centrifuge. The supernatant was removed, and the bacterial pellet resuspended in $4 \mathrm{~mL}$ of Buffer P1. $4 \mathrm{~mL}$ of Buffer P2 was added, mixed thoroughly and incubated at room temperature for 5 minutes. $4 \mathrm{~mL}$ of pre-chilled Buffer P3 was added and the sample chilled on ice for 15 minutes. The sample was centrifuged at maximum speed for 30 minutes at $4^{\circ} \mathrm{C}$ and the supernatant was re-centrifuged for a further 15 minutes. A QIAGEN-tip 100 column was equilibrated by allowing $4 \mathrm{~mL}$ of Buffer QBT to pass through. The supernatant from the centrifugation steps was applied to the column and allowed to pass through. The column was washed twice with $10 \mathrm{~mL}$ of Buffer QC. DNA was eluted into a $15 \mathrm{~mL}$ Falcon tube with 5 $\mathrm{mL}$ Buffer QF. 3.5 mL isopropanol was added to precipitate the DNA, and centrifuged for 30 minutes at $4^{\circ} \mathrm{C}$. The supernatant was carefully removed, the DNA pellet washed with $2 \mathrm{~mL}$ room temperature $70 \%$ ethanol and centrifuged for 10 minutes. The supernatant was discarded, and the DNA pellet allowed to air dry for 5-10 minutes. The DNA was then dissolved in $100 \mu \mathrm{L}$ TE buffer and its concentration measured on a NanoDrop ND-1000 spectrophotometer (Thermo Fisher). The DNA in TE buffer was stored at $-20^{\circ} \mathrm{C}$, ready to be used for transfection. 


\subsection{Transfection}

Transfection was carried out with Lipofectamine 3000 (Thermo Fisher) as explained below.

\subsubsection{Plating cells}

Cells were lifted and resuspended as described in section 2.1.3 and cell concentration was calculated by counting cells using a hemocytometer. The cells were diluted to a concentration of $10^{5}$ cells $/ \mathrm{mL}$. $500 \mu \mathrm{L}$ cells were plated into a 24 -well plate, such that each well contained $0.5 \times 10^{5}$ cells. The cells were incubated overnight.

\subsubsection{Transfection mix}

For each well to be transfected, $500 \mathrm{ng}$ of DNA was mixed with $1 \mu \mathrm{L}$ P3000 reagent and enough Opti-MEM (reduced serum media) (Thermo Fisher) to bring the volume to $25 \mu \mathrm{L}$. In a separate tube, $1.5 \mu \mathrm{L}$ of Lipofectamine 3000 was mixed with $23.5 \mu \mathrm{L}$ of Opti-MEM for each well. The contents of the two tubes were mixed and left to incubate at room temperature for 10-15 minutes.

\subsubsection{Transfection}

The growth media was removed from the cells and into each well $50 \mu \mathrm{L}$ of transfection mix was added as well as $50 \mu \mathrm{L}$ Opti-MEM to prevent the well from drying out. Plates were returned to the incubator for 6 hours, after which the transfection mix was discarded and replaced with complete growth medium containing serial dilutions of retinoic acid (RA). The plate was again returned to the incubator and cells left to grow for $\sim 48$ hours. The following controls were used: untransfected cells, cells transfected with the RAstat4xhiHspGFP2xhiHspTOM construct incubated in the absence of RA, and cells transfected with a modified plasmid lacking RAREs (RAstat0xHspGFP0xHspTOM) as negative controls; and cells transfected with constitutively expressed GFP and TOMATO vectors as positive transfection controls, as well as for establishing compensation settings for flow cytometry experiments.

For the purposes of fluorescence microscopy, the media was removed and replaced with warm PBS as the media caused a very high amount of background fluorescence. 


\subsection{Flow cytometry}

After photos were taken of the cells, they were prepared for flow cytometry. The PBS was removed and a drop of TrypLE added to each well. After an incubation of 3 minutes, depending on the confluence of the cells, $200-300 \mu \mathrm{L}$ of FACS media (PBS $+2 \%$ FCS) was added to each well and the cells were flushed off the surface by pipetting up and down. The cells were transferred into FACS tubes (Fisher Scientific), passing them through a $40 \mu \mathrm{m}$ cell strainer (Corning, Sigma-Aldrich) to avoid clumping. Flow cytometry was carried out on a BD FACSCanto II flow cytometer (BD Biosciences) and the results interpreted using Flowing Software (Cell Imaging Core, Turku Centre for Biotechnology, Finland). The two positive controls were used to set the voltages on the flow cytometer and to set up compensation controls. These were required as the FACSCanto II is limited in the number of lasers it has, and so uses a filter, rather than a laser to excite TOMATO proteins. 100,000 cells were counted from each sample and each experimental condition was done in duplicate.

\subsection{Genotyping mice}

All mouse work was carried out using FVB/Swiss cross mice under the VUW Animal Ethics Committee application number 25317. These were housed in the Victoria University of Wellington Small Animal Facility where they were kept on a schedule of 12 hours light (7 am-7 pm) and 12 hours darkness ( $7 \mathrm{pm}-7 \mathrm{am})$. Mice had constant access to water and Mouse Feed Diet 86 food pellets (Sharpes Stock Feeds). Mouse pups $<3$ weeks old were ear punched for identification and a small tail clipping $(2-3 \mathrm{~mm})$ was taken (mice older than 3 weeks were only ear punched and the piece of ear that was taken out was used for genotyping).

\subsubsection{Digestion}

Tail clippings were digested in $200 \mu \mathrm{L}$ Proteinase K buffer (see Appendix) containing 0.2 $\mathrm{mg} / \mathrm{mL}$ Proteinase $\mathrm{K}$ (Roche) in a Thermomix (Hangzhou Allsheng Instruments) at $55^{\circ} \mathrm{C}$, shaking at $900 \mathrm{rpm}$, for 2 hours until all tissue was digested. The lysate was diluted 1:3 with water and boiled for 5 minutes to avoid digestion of PCR enzymes by Proteinase K. 


\subsubsection{PCR}

Samples were amplified by polymerase chain reaction (PCR) using GFP primers (Figure 5) and the products run on a $1.5 \%$ agarose gel to determine the presence of GFP. The PCR mix was made up as follows:

Per reaction:
○ $20 \mu \mathrm{L}$ water
○ $2.5 \mu \mathrm{L}$ 10x PCR buffer (Bioline)
○ $\quad 0.5 \mu \mathrm{L} 10 \mathrm{mM}$ dNTPs (Sigma)
○ $\quad 0.5 \mu \mathrm{L} 10 \mu \mathrm{M}$ GFP Vienna forward primer (Sigma)
○ $\quad 0.5 \mu \mathrm{L} 10 \mu \mathrm{M}$ GFP Vienna reverse primer (Sigma)
○ $0.2 \mu \mathrm{L}$ Taq polymerase (Bioline)
- $1 \mu \mathrm{L}$ diluted template DNA

The samples were run in an Eppendorf Mastercycler Pro PCR machine (Eppendorf) following the protocol outlined in Table 2.

\begin{tabular}{|c|c|c|}
\hline Temperature $\left({ }^{\circ} \mathbf{C}\right)$ & Time & Cycles \\
\cline { 1 - 2 } 95 & $5^{\prime}$ & 1 \\
\hline 94 & $30^{\prime \prime}$ & \multirow{2}{*}{35} \\
\cline { 1 - 2 } 60 & $45^{\prime \prime}$ & \multirow{2}{*}{1} \\
\hline 72 & $1^{\prime}$ & \\
\hline 72 & $7^{\prime}$ & 1 \\
\hline 4 & $\infty$ & 1 \\
\hline
\end{tabular}

Table 2| The PCR cycling parameters for identifying GFP presence in transgenic mice. 
CATGGTGAGATCTATGGTGAGCAAGGGCGAGGAGCTGTTCACCGGGGTGGTGCCCATCC TGGTCGAGCTGGACGGCGACGTAAACGGCCACAAGTTCAGCGTGTCCGGCGAGGGCGAG GGCGATGCCACCTACGGCAAGCTGACCCTGAAGTTCATCTGCACCACCGGCAAGCTGCC CGTGCCCTGGCCCACCCTCGTGACCACCTTCACCTACGGCGTGCAGTGCTTCGCCCGCTA CCCCGACCACATGAAGCAGCACGACTTCTTCAAGTCCGCCATGCCCGAAGGCTACGTCCA GGAGCGCACCATCTTCTTCAAGGACGACGGCAACTACAAGACCCGCGCCGAGGTGAAGT TCGAGGGCGACACCCTGGTGAACCGCATCGAGCTGAAGGGCATCGACTTCAAGGAGGAC GGCAACATCCTGGGGCACAAGCTGGAGTACAACTACAACAGCCACAAGGTCTATATCAC CGCCGACAAGCAGAAGAACGGCATCAAGGTGAACTTCAAGACCCGCCACAACATCGAG GACGGCAGCGTGCAGCTCGCCGACCACTACCAGCAGAACACCCCCATCGGCGACGGCCC CGTGCTGCTGCCCGACAACCACTACCTGAGCACCCAGTCCGCCCTGAGCAAAGACCCCA ACGAGAAGCGCGATCACATGGTCCTGCTGGAGTTCGTGACCGCCGCCGGGATCACTCTC GGCATGGACGAGCTGTACAAGTAAGCGGCCGC

Figure 5| The nucleotide sequence of the GFP gene. The primers used for genotyping mice are indicated in red.

\subsubsection{Gel electrophoresis}

The PCR product was run on a $1.5 \%$ agarose gel containing ethidium bromide at $90 \mathrm{~V}$ for $\sim 30$ minutes and the DNA bands visualised under UV light. An example of the samples run on an agarose gel is shown below in Figure 6. The samples in lanes 2, 3, 5, 6, 7 and 8 were deemed to be positive for GFP and lanes 4, 10, 11, 12, 13 and 14 were deemed to be negative for GFP. 


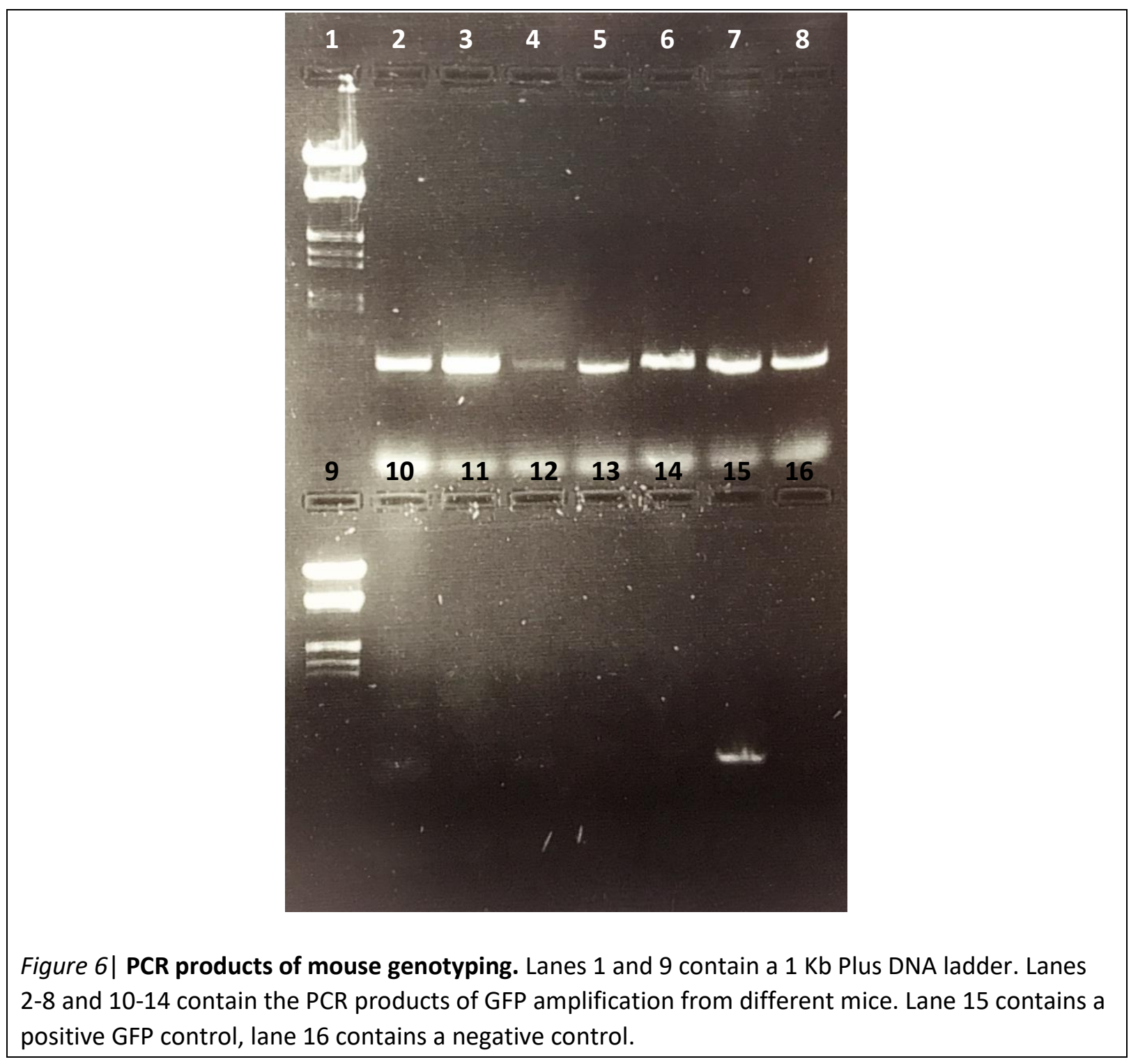

\subsection{Embryo recovery}

A transgenic male and a wild type female were placed together into a cage and the female checked each morning for a copulation plug. Once a plug was seen, this was taken as E0.5. Once the desired day of gestation was reached, the pregnant female was sacrificed through asphyxiation with a mixture of $\mathrm{O}_{2}$ and $\mathrm{CO}_{2}$ until unconscious, followed by pure $\mathrm{CO}_{2}$ for 5 minutes. After death, the cervical vertebrae were broken. The abdominal cavity was opened, the uterine horns were removed and transported back to the lab in cold PBS. Under a dissecting microscope, the embryos were removed from the uterus and placed into 
fresh, cold PBS. Once all were removed, a fluorescent microscope was used to identify transgenic embryos and non-transgenic embryos were discarded.

\subsection{Preparation of primary mouse embryonic fibroblasts}

The protocol outlined by Bryja et al. (2006) was used to create a primary embryonic cell line. Complete growth media was placed in the incubator with the lid slightly loosened 1-2 hours prior to embryo retrieval.

\subsubsection{Embryo recovery}

A 14.5 days post coitum (dpc) female mouse was sacrificed and the uterine horns removed. After briefly rinsing in $70 \%$ ethanol, the uterine horns were placed in cold PBS for transport back to the laboratory. At this point, around six $35 \mathrm{~mm}$ Petri dishes were prepared with 1 $\mathrm{mL}$ TrypLE in each (enough for 2 embryos per dish) and placed in the $37^{\circ} \mathrm{C}$ incubator. Working inside a laminar flow hood and using autoclaved tools, the decidua were removed from the uterus and embryos separated from the placenta and amniotic membranes (roughly 10 embryos were recovered from each female). Heads and abdominal organs (liver, digestive system, etc.) were removed and discarded. The remaining tissues were minced as finely as possible using scalpel blades.

\subsubsection{Tissue dissociation}

The tissue was divided evenly between the dishes containing TrypLE and returned to the incubator for 3-4 minutes. For the cells of 10 embryos, two $50 \mathrm{~mL}$ Falcon tubes were prepared with $\sim 50 \mathrm{~mL}$ complete growth media. $1 \mathrm{~mL}$ of media was added to each of the dishes to stop the digestion by trypsin. The contents of the Petri dishes was homogenised by pipetting up and down with a P1000 filter tip and transferred to the prepared Falcon tubes. The larger clumps of tissue were left to settle for $\sim 5$ minutes and the supernatant containing the cell suspension was collected and transferred to T75 growth flasks (5-6 flasks were used, i.e. 2 embryos per dish). 


\subsubsection{Cell growth}

The flasks were placed in the incubator at $37^{\circ} \mathrm{C}$ with $5 \% \mathrm{CO}_{2}$ for $4-5$ hours, after which the culture medium was discarded and replaced. After this, they were treated as any other cell culture and passaged as described above in 2.1.3.

\subsection{Flow sorting:}

\subsubsection{Embryo recovery}

Embryos were recovered at E8.5, dissected out of the uterine horns and transferred to cold PBS on ice. Transgenic embryos were separated from non-transgenic embryos using a fluorescent microscope.

\subsubsection{Embryo dissection}

A transverse cut at the anterior-most somite was made to remove any head tissue.

\subsubsection{Dissociation}

The embryos were transferred to the well of a 4-well plate containing prewarmed TrypLE. After 5 minutes incubation at room temperature, the cells were gently pipetted up and down until mainly single cells were left. $1 \mathrm{~mL}$ DMEM/FCS was added to stop the trypsinisation. The cells were filtered through a $70 \mu \mathrm{m}$ cell strainer and collected in a $1.5 \mathrm{~mL}$ Eppendorf tube.

\subsubsection{Centrifugation}

The cells were centrifuged at 10,000xg for 5 minutes and the supernatant discarded. The cell pellet was resuspended in cold flow cytometry staining buffer ( $2 \%$ FCS and 2 mM EDTS in 1x PBS) (FCSB) and centrifuged again. The supernatant was discarded, and the cell pellet resuspended in $400 \mu \mathrm{L}$ of cold FCSB. 


\subsubsection{Antibodies}

CD49 antibodies conjugated to efluor450 were added to the cells at a 1:500 dilution and incubated at $4^{\circ} \mathrm{C}$ for 30 minutes. $1 \mu \mathrm{L}$ of the antibody was also added to a drop of compensation beads and incubated the same way as the cells for use as a control. $1 \mathrm{~mL}$ of FCSB was added and the cells/beads were centrifuged at 10,000xg for 5 minutes and the supernatant discarded. The wash was repeated. Cells were resuspended in $400 \mu \mathrm{L}$ FCSB. DAPI (Sigma) was added as the viability marker at a concentration of $3 \mu \mathrm{M}$. The cells were transferred to $5 \mathrm{~mL}$ round bottom polypropylene tubes (provided by Malaghan Institute of Medical Research). Although initially CD394 antibodies conjugated to Cy5 were to be used as well, these proved unsuccessful and therefore were not used.

\subsubsection{Cell sorting}

The cells were sorted using a BD Influx cell sorter (located at the Malaghan Institute of Medical Research). The following gates were set up for sorting:

- Live (DAPI'), paraxial mesoderm (eFluor450+), GFP-, TOM $^{-}$

- Live (DAPI-), paraxial mesoderm (eFluor450+), GFPintermediate, TOM$^{-}$

- Live (DAPI-), paraxial mesoderm (eFluor450+), GFPhigh, TOM $^{-}$

- Live (DAPI'), paraxial mesoderm (eFluor450+), GFPhigh, TOM $^{+}$

Cells were collected into $200 \mu \mathrm{L}$ PBS in $1.5 \mathrm{~mL}$ LoBind RNAse free Eppendorf tubes (Eppendorf). The cells from each gate were collected into separate tubes, with 300 cells collected into each. After one tube contained 300 cells, a new tube was used until 3 repeats of each cell population had been obtained.

\section{9 mRNA amplification}

Immediately after sorting, the cells were transferred to $0.2 \mathrm{~mL}$ PCR tubes (Axygen) and spun down at 1,000xg for 2 minutes and the supernatant discarded. The pellet was resuspended in $7 \mu \mathrm{L}$ of ultra-pure $\mathrm{H}_{2} \mathrm{O}$. 
RNA was converted to cDNA and amplified using the QIAseq FX Single Cell RNA Library kit (QIAGEN), following the manufacturer's instructions for the amplification of poly $A^{+}$mRNA.

A Qubit 3.0 fluorometer (Life Technologies) was used to measure the DNA yield. Samples were prepared for measurement according to the manufacturer's instructions.

\subsection{GeneClean}

The $8 \mu \mathrm{L}$ of the amplified cDNA samples were purified using the GeneClean kit as described in 2.2.5 in order to remove the components of the kit, which may interfere with PCR. The DNA was eluted into $30 \mu \mathrm{L} \mathrm{H}_{2} \mathrm{O}$ with $3 \mu \mathrm{L}$ TE buffer.

\subsection{PCR analysis}

The cDNA samples were diluted 1:15 and 1:45 and analysed through PCR to test for the presence of genes of interest to show the differential function of RA based on concentration. 


\section{Results I: Creation of dTOMATO expressing plasmid}

So as to have a positive control for detecting and measuring the red fluorescence emitted by the TOMATO fluorescent protein used in the RAstat reporter construct, constitutively TOMATO-expressing cells were needed. To this end it was decided to create a plasmid containing a strong enhancer-promoter element driving TOMATO expression. pPyCAGIPmod (Figure 4A) was chosen as the vector because the CAG promoter (the cytomegalovirus enhancer fused to a chicken beta-actin promoter) is able to efficiently drive high levels of gene expression (Wang et al., 2017). The TOMATO DNA cassette was obtained from a Brainbow1-L-CMV plasmid (Figure 4B). The resulting plasmid can be seen in the plasmid map in Figure 7.

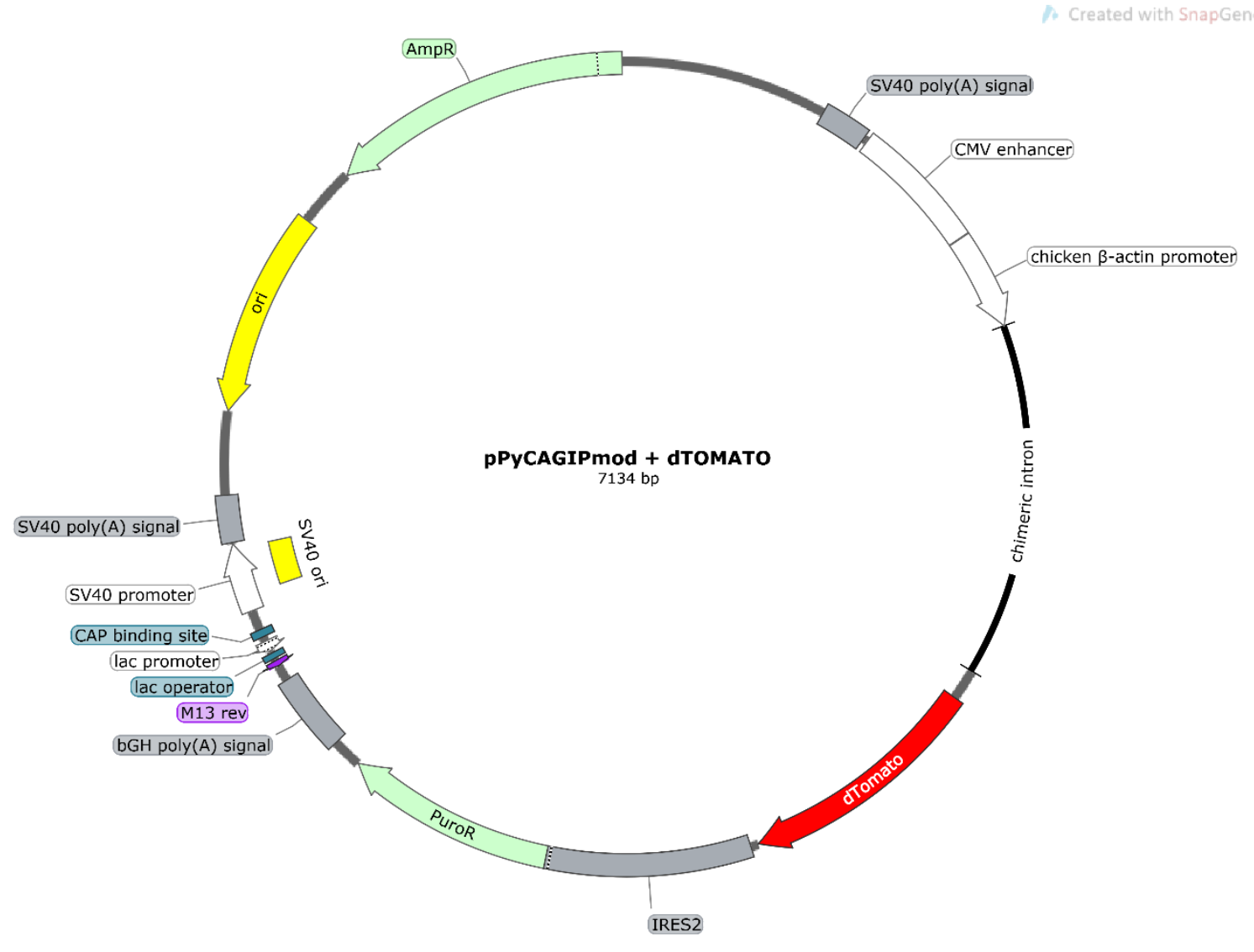

Figure 7| The pPyCAGIPmod plasmid with dTOMATO insert. Plasmid map created using SnapGene Viewer (GSL Biotech). 


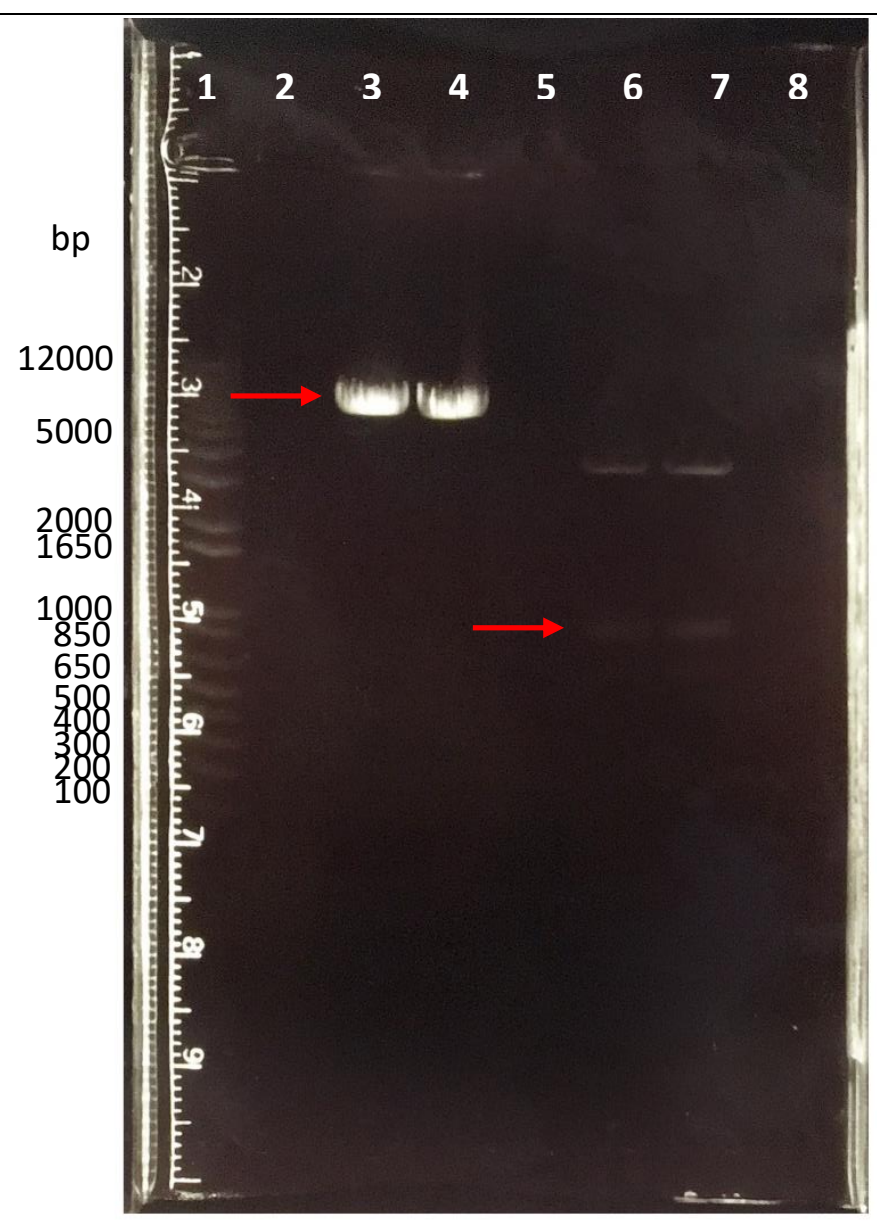

Figure $8 \mid$ Restriction digest products run on $1 \%$ agarose gel. Lane 1 contains a $1 \mathrm{~Kb}$ Plus DNA ladder. Lanes 3 and 4 contain the pPyCAGIPmod vector at $6411 \mathrm{bp}$, and lanes 6 and 7 contain the dTOMATO portion of the Brainbow1-L-CMV plasmid at $723 \mathrm{bp}$. Red arrows indicate the bands of interest. 


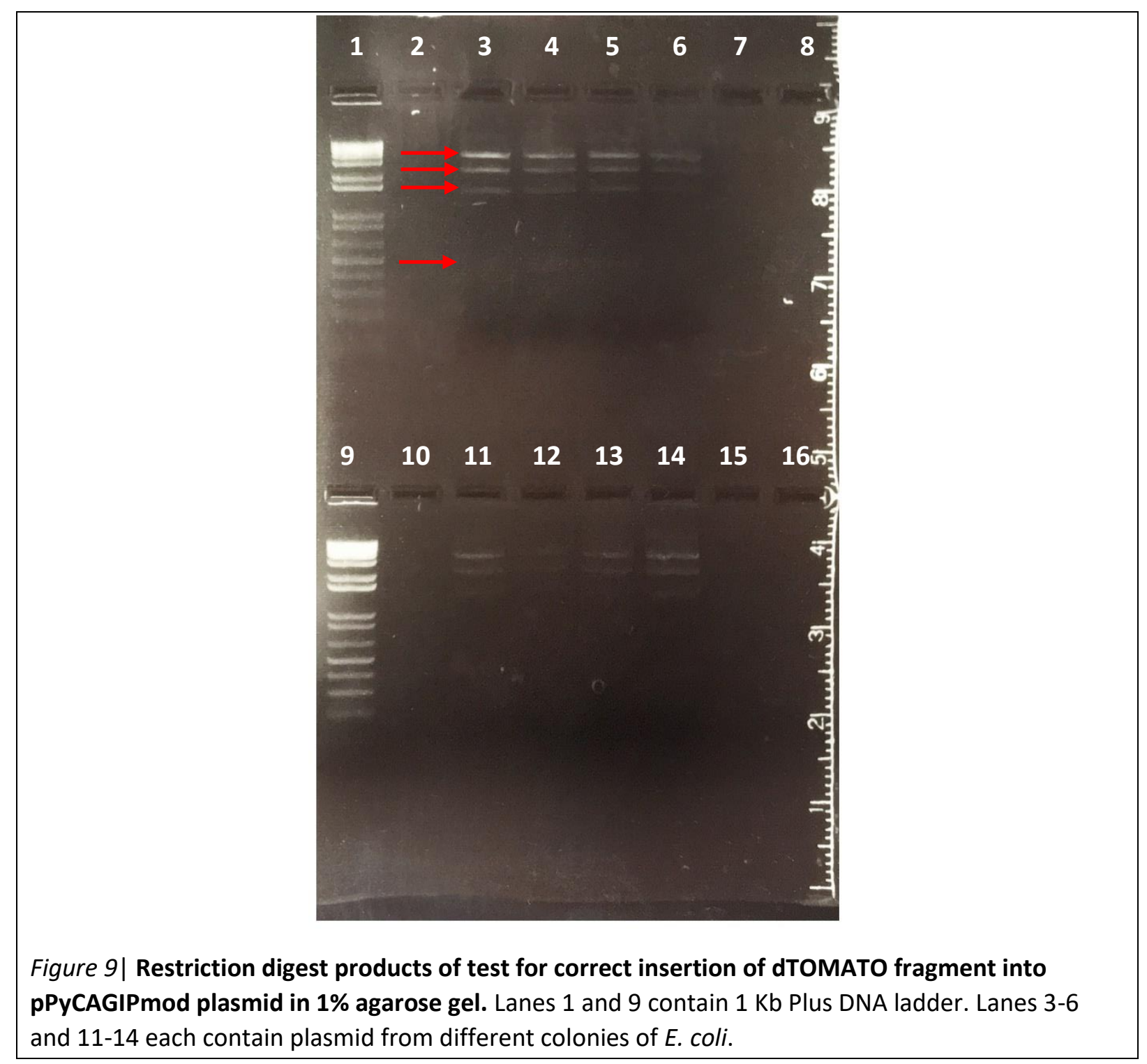

The result of the restriction digest of the two plasmids are shown in Figure 8.

The final ligated product was digested with restriction enzymes to test for correct insertion of the TOMATO cassette and run on a gel in Figure 9. This shows insertion of the insert fragment into the vector plasmid as expected. The restriction digest with Nco1 was expected to produce four bands - 3222 bp, 2017 bp, 1382 bp and $423 \mathrm{bp}$. These are indicated by red arrows in Figure 9. 
To test the function of the new plasmid, NIH3T3 and HEK293T/17 cells were transfected with the plasmid. The results after 24 hours incubation time are shown in Figure 10. A strong signal was observed in both cell lines, indicating the production of dTOMATO and that the plasmid was functioning as expected.
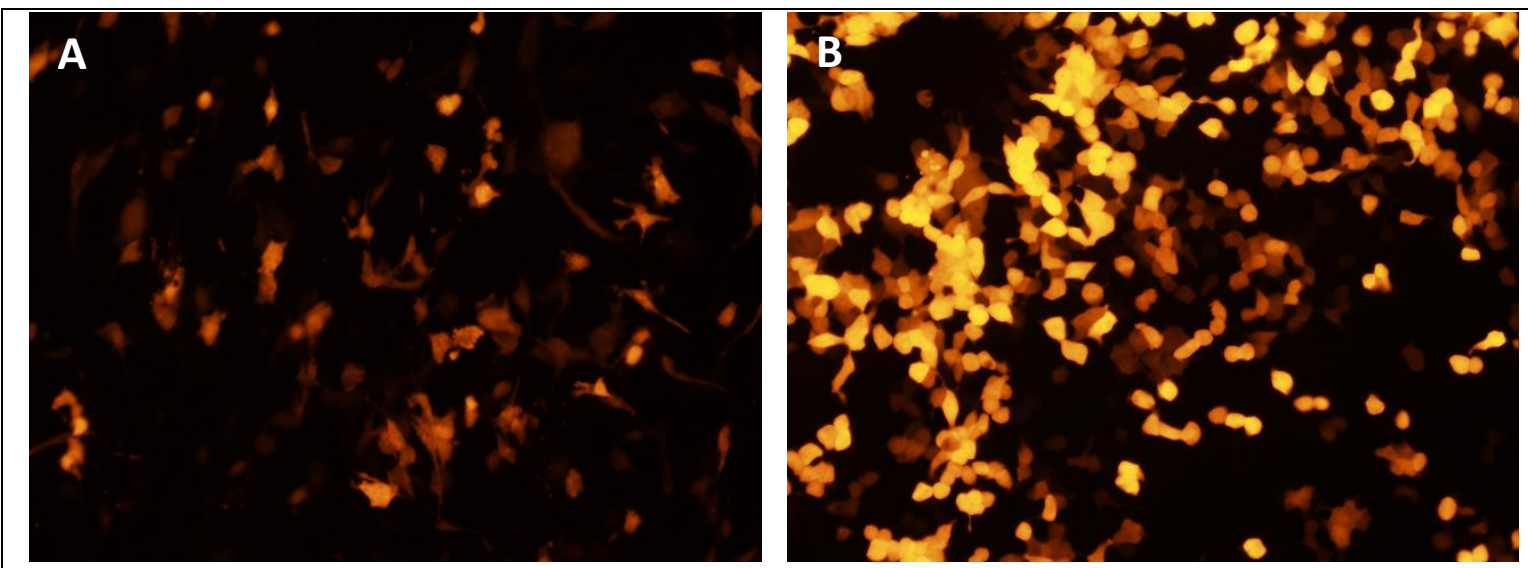

Figure 10| Transfection of cells with dTOMATO plasmid. A| Transfected NIH3T3 cells under the Texas red filter B | Transfected HEK293T/17 cells under the Texas red filter. 


\section{Results II: Testing functionality of the dual retinoic acid reporter RAstat4xhiHspGFP2xhiHspTOM in vitro}

Previous work done in our lab had shown that the 4xhiHspGFP portion of the reporter system was able to respond to differing concentrations of RA, but the 2xhiHspTOM portion had not been tested. Here we continued on with that work, with the aim to characterize the eGFP as well as the dTOMATO expression by cells transfected with the RAstat4xhiHspGFP2xhiHspTOM reporter plasmid in response to different RA concentrations.

\subsection{Microscopy}

Fluorescent imaging of the transfected cells showed the fluorescent protein expression in these transfected cells (Figure 11). As expected, the cells exposed to the highest concentrations of RA showed both GFP and TOMATO positive cells (Figure 11A, 11B, 11F, 11G). The cells exposed to the lower concentrations of RA showed only low levels of GFP and no TOMATO fluorescence (Figure $11 C-E, 11 \mathrm{H}-J$ ). Based on these images, it appears that rather than showing a dose-dependent response with fluorescence levels gradually decreasing with decreasing RA concentration, there is a threshold at which the response to RA (represented by production of fluorescent proteins) is induced. This threshold appears to be at $10^{-7} \mathrm{M}$ RA for both GFP and TOMATO. 


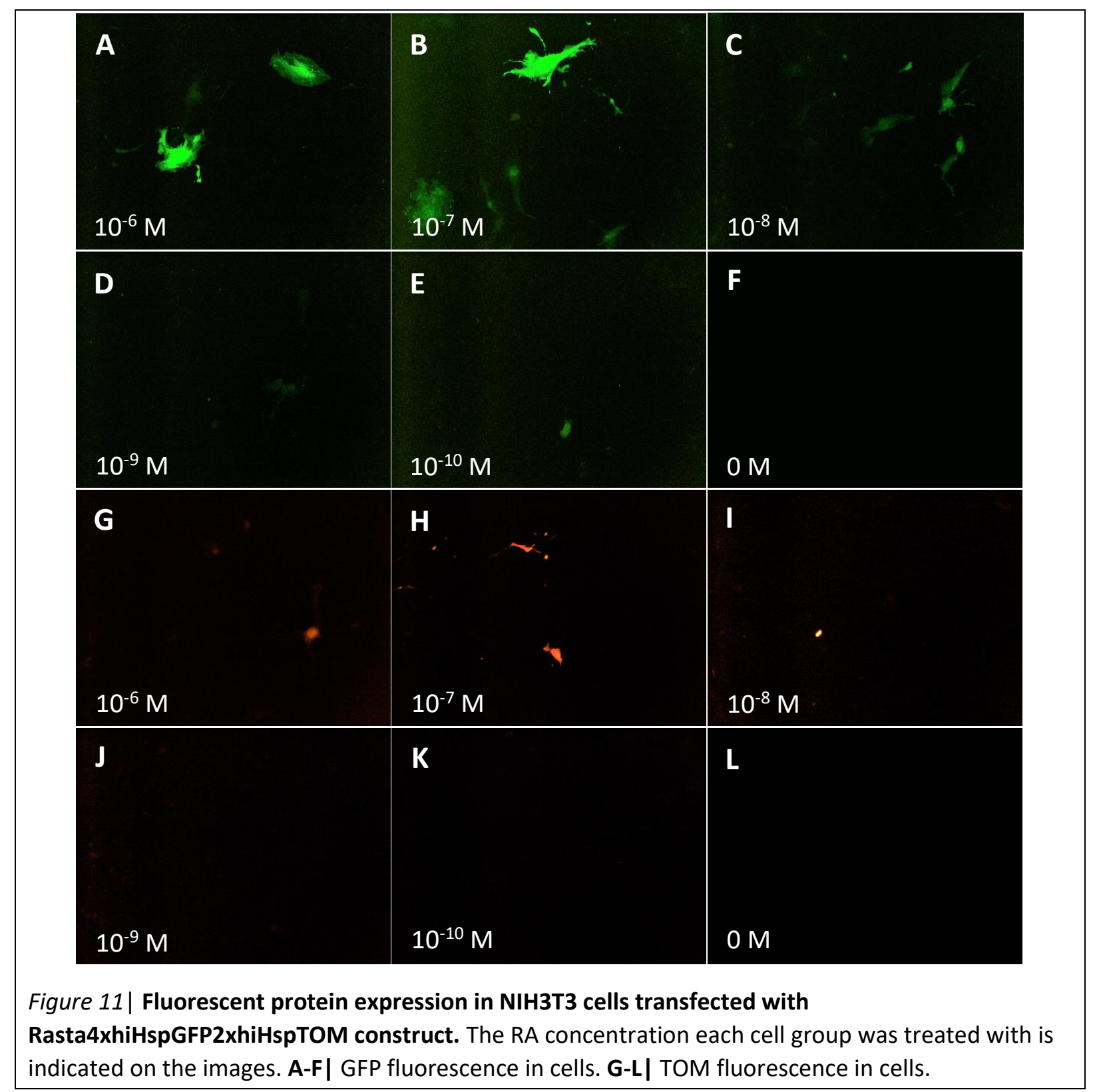

\subsection{Flow cytometry}

Flow cytometry of these cells provided more information on the expression levels of fluorescent proteins. The FCS files were analysed with Flowing Software and the cell populations were gated as shown in Figure 12. Forward scatter area and side scatter area were used to find live cells, and then, to remove any bias that doublets may have given, forward scatter area and height were compared (Figure 12C), followed by side scatter area and height (Figure 12D). In each of these cases, the densest population was the one of interest. 


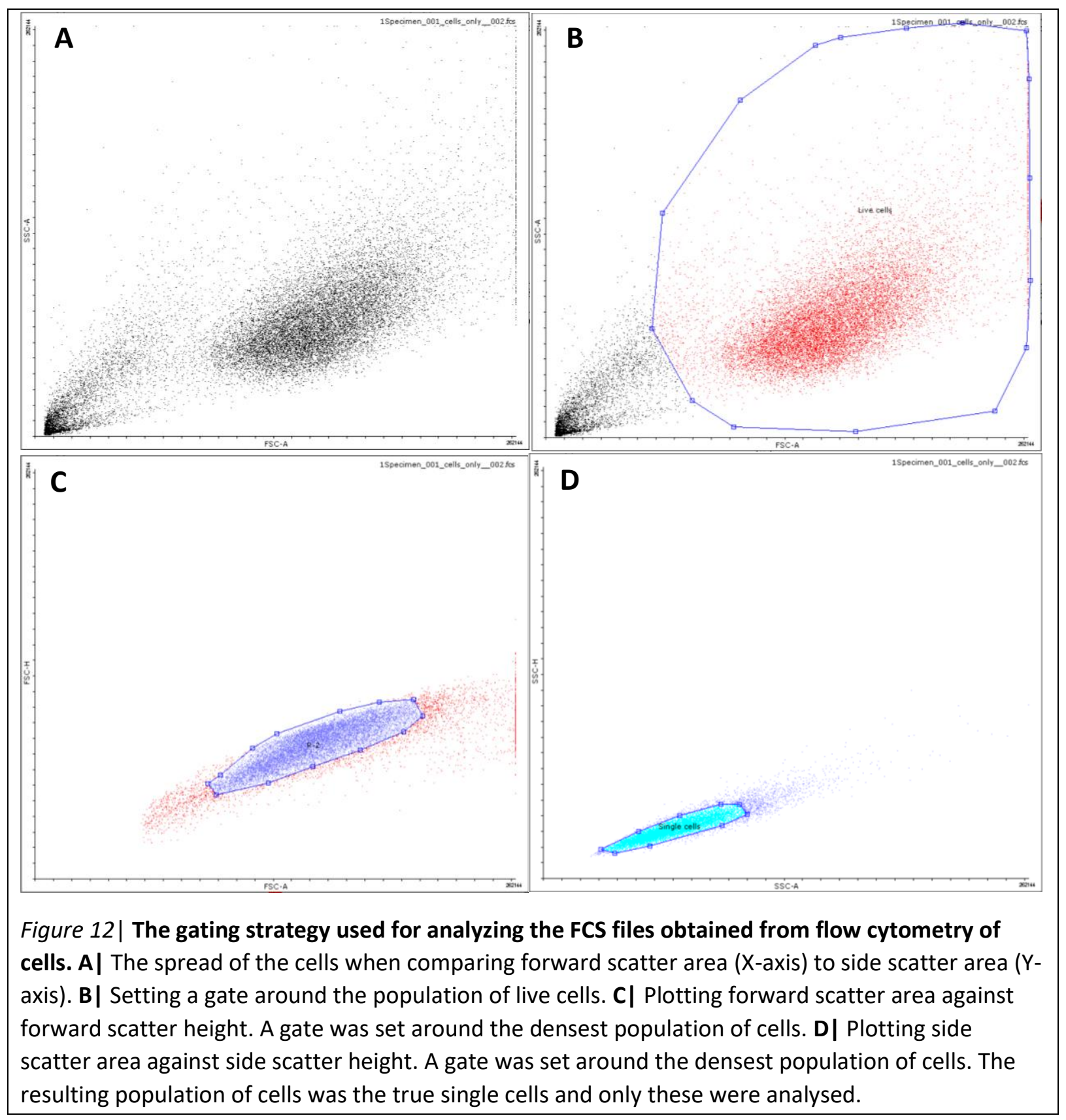

The results of the analysis of the flow cytometry results is shown in Figure 13. Several controls were required for this experiment: a group of cells that remained untransfected in order to be able to gate out background fluorescence; a GFP single-positive population and a TOMATO single-positive population to calculate compensation controls as well as test for transfection efficiency; and a population of cells transfected with a version of the RAstat4xhiHspGFP2xhiHspTOM construct that lacked the RA binding elements to control for random firing of the reporter. 
Compensation controls were required as the FACSCanto II used for this experiment lacked the appropriate laser to excite the dTOMATO. Of the three lasers it possesses $-405 \mathrm{~nm}, 488$ $\mathrm{nm}$ and $633 \mathrm{~nm}$ - the $488 \mathrm{~nm}$ laser is best able to excite the dTOMATO protein, whose maximum excitation wavelength is $554 \mathrm{~nm}$. As this is also the laser used to excite the eGFP, whose excitation maximum is $484 \mathrm{~nm}$, the same laser had to be used to excite both proteins. Two filters were used in order to detect the different emission wavelengths. A FITC filter was used for GFP emission ( $510 \mathrm{~nm}$ ) and a PE filter was used for TOMATO emission $(581 \mathrm{~nm})$. The maximum emission wavelengths for these two fluorescent proteins lie close together, and therefore it was necessary to apply compensation controls before recording data. These controls allow the FACS software calculate the mathematical adjustment necessary to remove any fluorescent spill-over from one channel to the other.

The cells transfected with the RAstat4xhiHspGFP2xhiHspTOM construct showed a somewhat dose-dependent response to the RA treatment (Figure 13), however, similarly to what can be seen in Figure 11, this may be a threshold response above $10^{-7} \mathrm{M}$ RA. Those cells that were not exposed to any RA in the growth media showed no meaningful response in either of the proteins. The levels of GFP fluorescence generally increased with an increase in RA concentration, however there was no clear increasing step up in fluorescence between each of the treatment concentrations. TOMATO fluorescence was very minimal, with the low levels that were recorded most likely being background fluorescence. The reporter is designed that at high RA concentration (i.e. $10^{-6} \mathrm{M}, 10^{-7} \mathrm{M}$ ), both GFP and TOMATO proteins are expressed. The fact that no TOMATO fluorescence is seen could indicate that that portion of the reporter system is not functional in the way we expected.

Despite this, we decided to continue on with this reporter as its function in vitro may be different to its function in vivo, which was the ultimate goal of this project. 


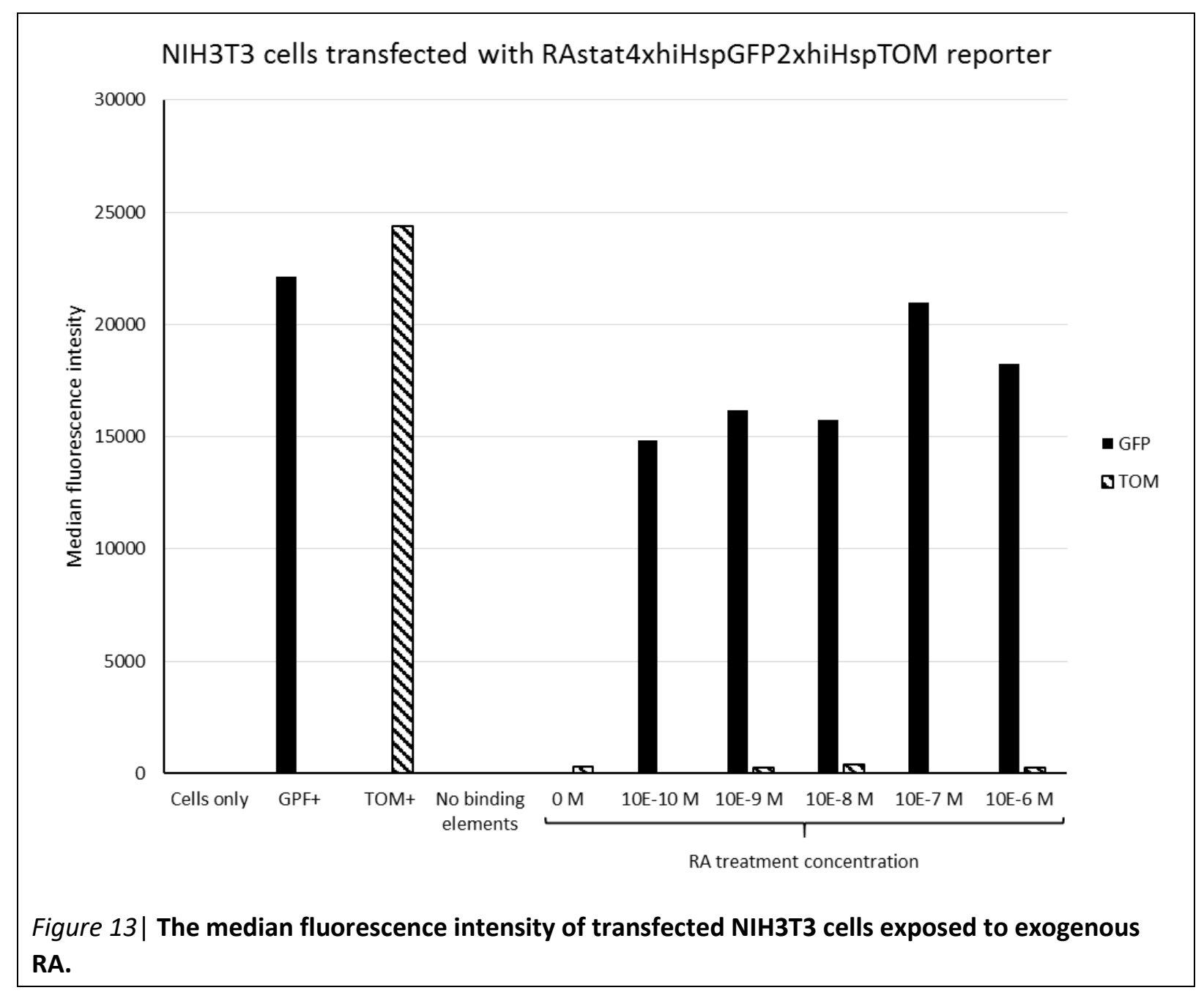




\section{Results III: Primary cell lines}

The function of the RAstat4xhiHspGFP2xhiHspTOM reporter was tested in vivo using in vitro methods in order to further try to characterize its activity after the initial cell line work did not yield expected results. This was done in the form of primary embryonic cell lines, which were specially created for this project. This approach was chosen as it eliminates the need for cell transfection, meaning there are less chances for unexpected results due to experimental error.

\subsection{Creation of cell lines}

We created these cell lines from the embryos of the transgenic mice we planned to use for the later in vivo work. Although initially more heterogeneous, after several passages the cells showed similar morphology to the embryonic fibroblasts of the NIH3T3 cells (Figure 14).
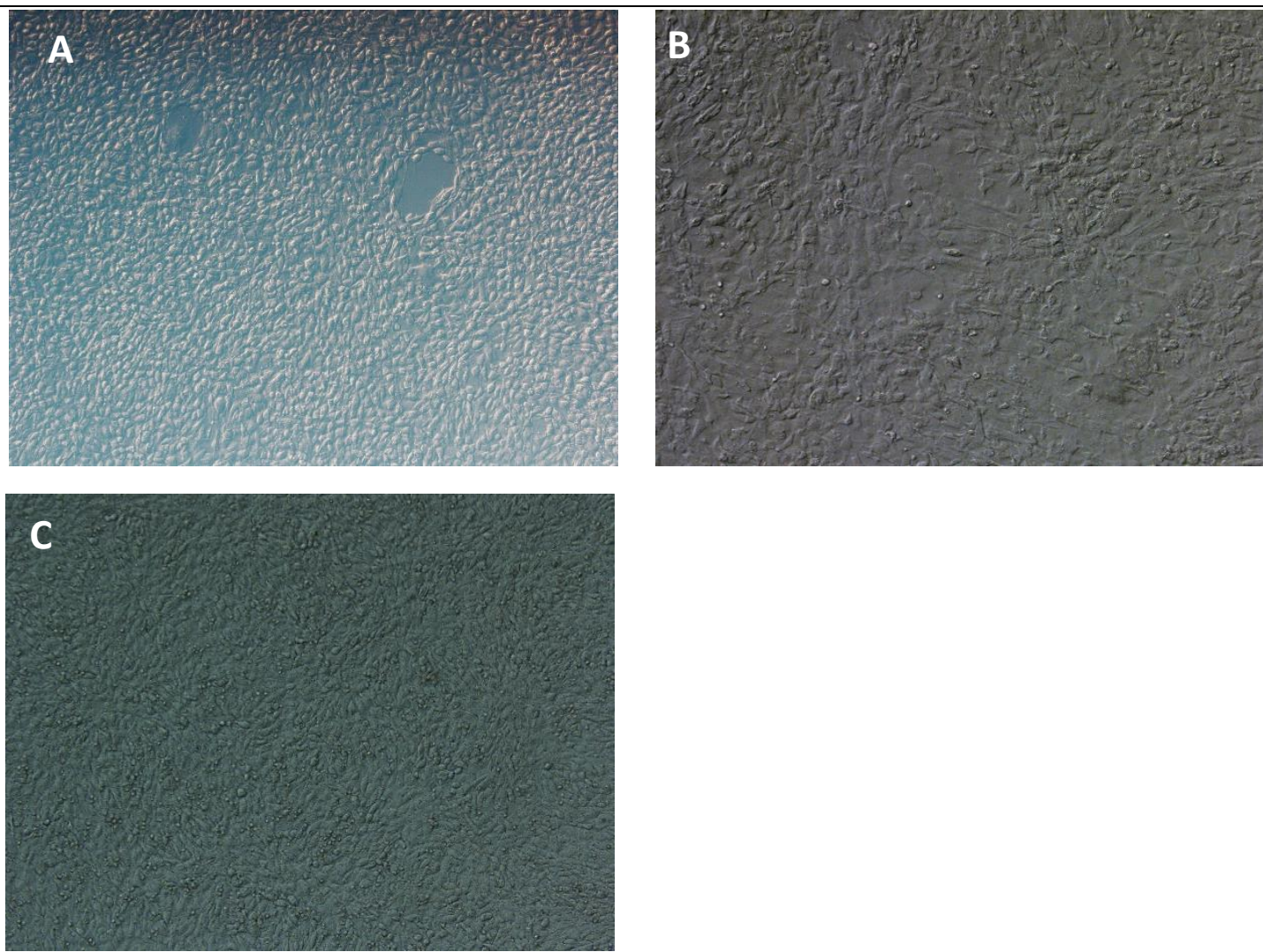

Figure 14| Result of production of primary embryonic cell lines. A| Cells of the RAstat4xhiHspGFP2xhiHspTOM primary cell line. B| Cells of the RAstat12xhiHspGFP cell line. $\mathbf{C l}$ NIH3T3 cells. 


\subsection{RAstat4xhiHspGFP2xhiHspTOM line}

\subsubsection{Microscopy}

The primary embryonic cell lines were also exposed to RA at the same concentrations as the transfected NIH3T3 cells. Overall, these cells show higher levels of GFP expression, as the advantage of working with these cells is that issues of transfection efficiency are avoided. Similarly to the transfected 3T3 cells, based on the images these cells show what appears to be a threshold reaction above $10^{-8} \mathrm{M}$ RA, with the cells exposed to lower concentrations likely just showing background or auto-fluorescence (Figure15A-E). The images showing dTOMATO expression appear to show higher numbers of fluorescent cells at the lower concentrations of RA (Figure 15F-J). However, the signal is very weak, meaning that most likely this is merely background fluorescence and not an actual signal.

\subsubsection{Flow cytometry}

To further characterize the expression of fluorescent proteins in these cells, they were analysed by flow cytometry (Figure 16). This was done at the same time as the NIH3T3 cells, so the compensation controls used for those cells were applied here. The GFP response was clearly dose-dependent with more GFP fluorescence detected with increasingly higher RA concentration. However, as was seen in the NIH3T3 cells, the TOMATO response was not as expected. 


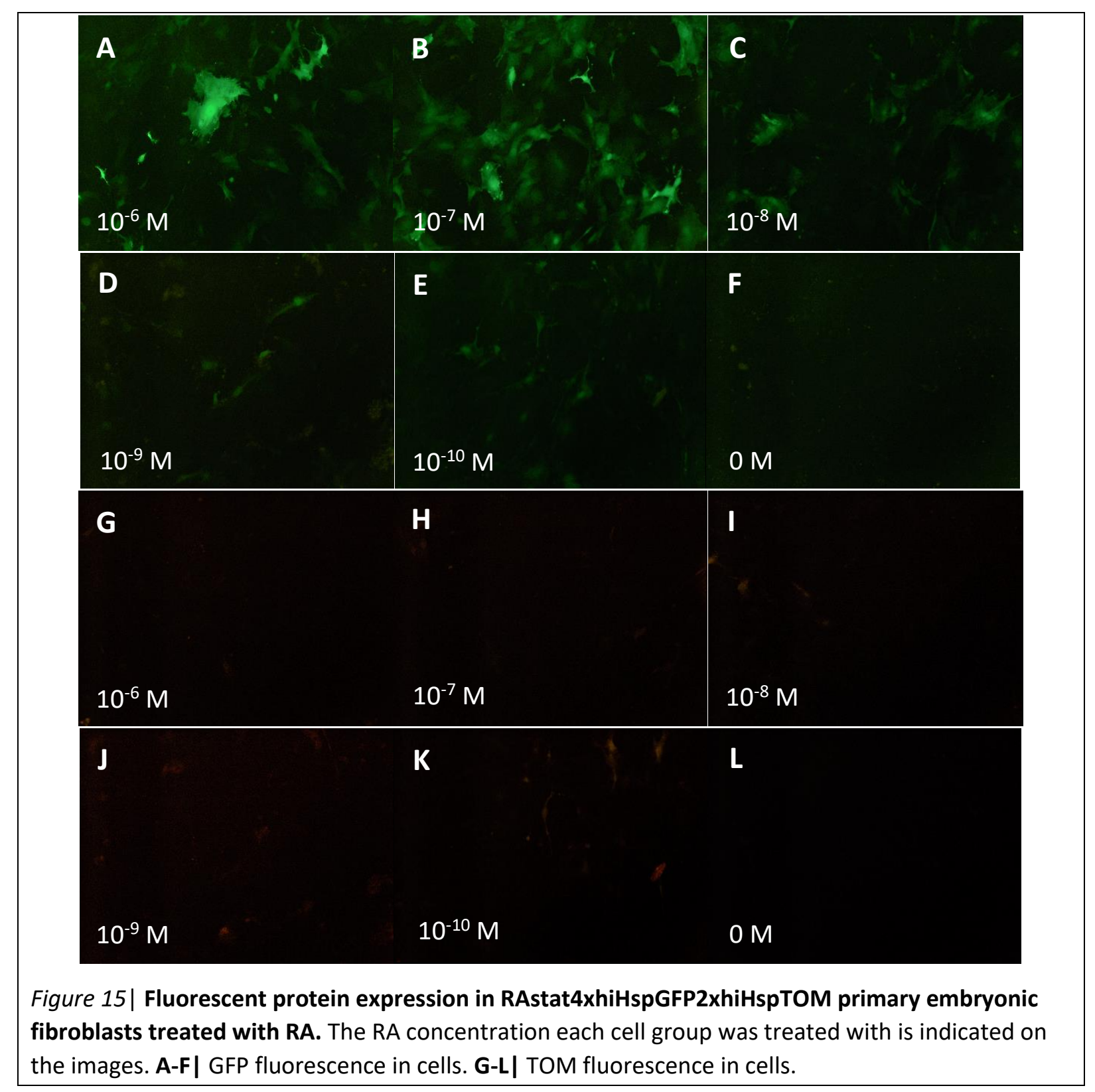




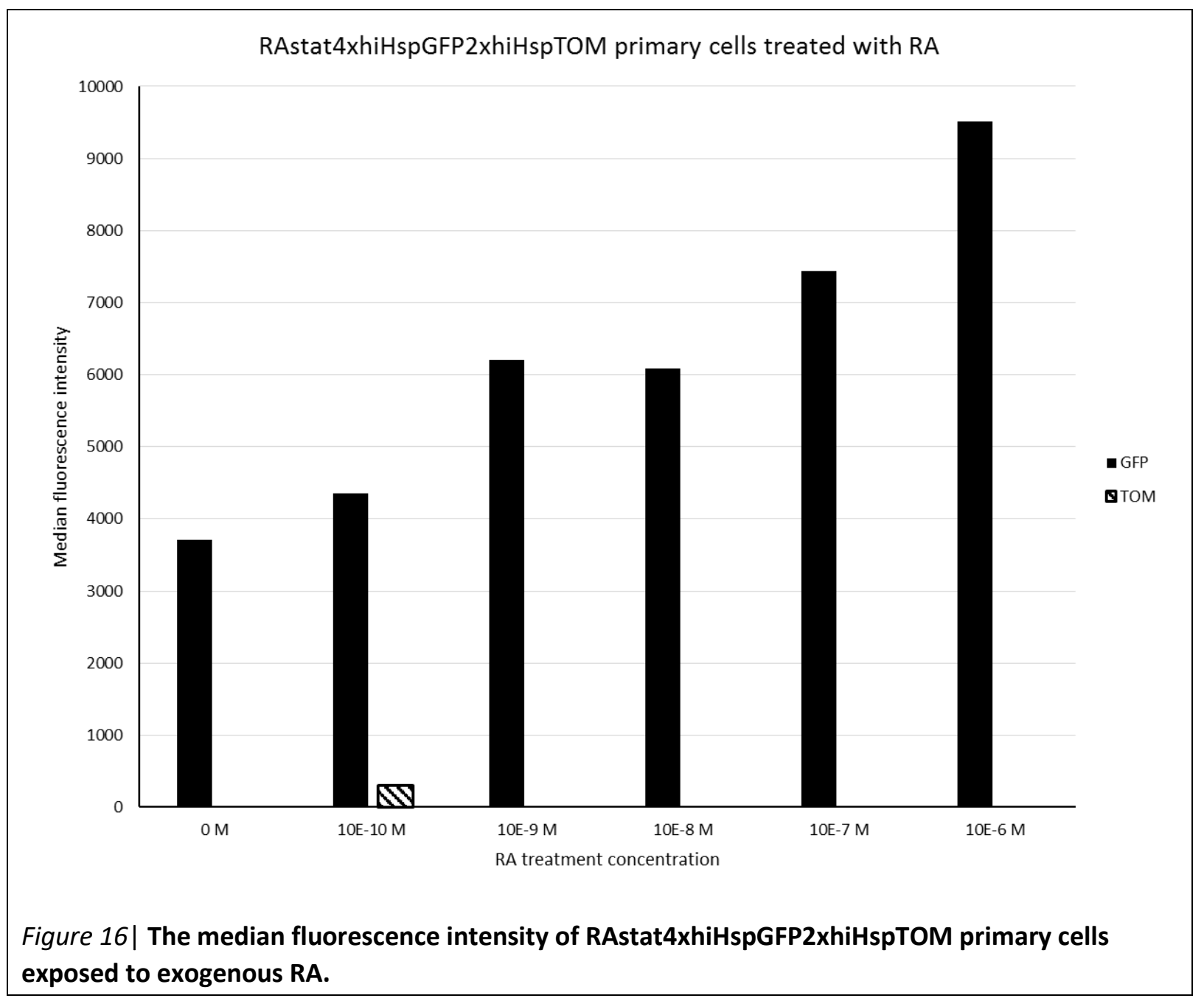

\subsection{RAstat12xhiHspGFP line}

An additional transgenic mouse line was employed for the purposes of the primary cell line work. These mice (and subsequent primary cell line) contained a reporter system similar to the RAstat4xhiHspGFP2xhiHspTOM mice, however they had twelve repeats of the RA binding elements and did not contain the second portion of the reporter with TOMATO. These cells were used determine whether the copy number of the binding elements makes the system proportionally more sensitive (i.e. $3 x$ the copy number $=3 x$ as sensitive). 


\subsubsection{Microscopy}

The RAstat12xhiHspGFP primary cell line exposed to the same levels of RA as the transfected 3T3 cells and the RAstat4xhiHspGFP2xhiHspTOM lines showed higher numbers of fluorescent cells as well as brighter fluorescence (Figure 17). This was not necessarily expected as we did not know whether the 12 RA binding elements would make this reporter three times as sensitive as the four binding elements on the RAstat4xhiHspGFP2xhiHspTOM construct, or whether binding element repeats above a certain number would have no effect. However, the images indicate that this reporter, to a certain degree, is more sensitive in comparison to the other. Again, the images show what may be a threshold response, however in these cells it may be occurring at $10^{-8-} \mathrm{M}$ RA and above.

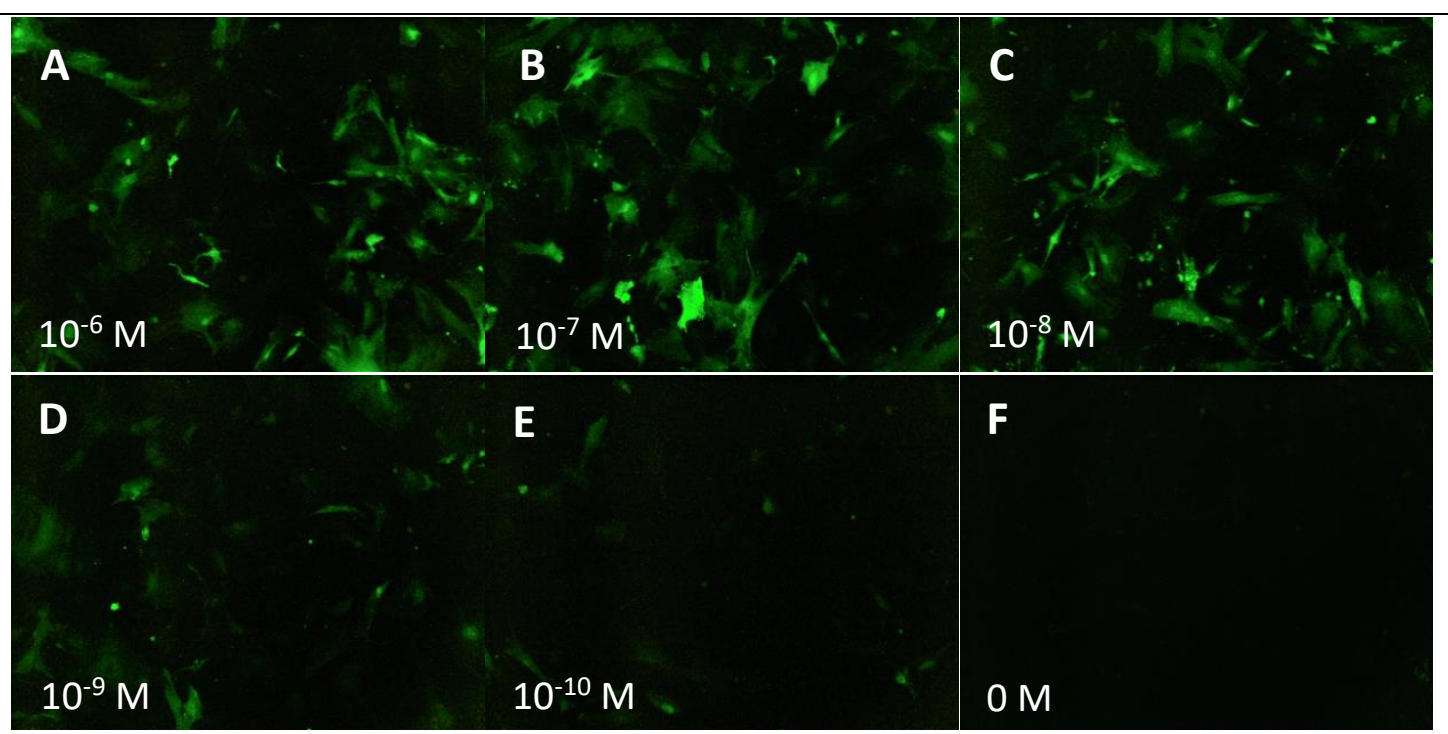

Figure 17| GFP expression in RAstat12xhiHspGFP primary embryonic fibroblasts treated with RA. The RA concentration each cell group was treated with is indicated on the images.

\subsubsection{Flow cytometry}

Flow cytometry analysis showed a dose dependent response in GFP from these cells (Figure 18). However, the cells treated with $10^{-6} \mathrm{M}$ RA showed a decreased fluorescence intensity when compared to the other treatment conditions. Some low levels of TOMATO fluorescence were detected in these cells, which is not true signal as these cells do not possess the gene for the TOMATO protein. Therefore, this is likely just a small amount of spillover of GFP emission into the PE filter. The levels of fluorescence intensity of these cells was higher than those of the RAstat4xhiHspGFP2xhiHspTOM primary cells, indicating further that this reporter is more sensitive than the one with fewer binding element repeats. 


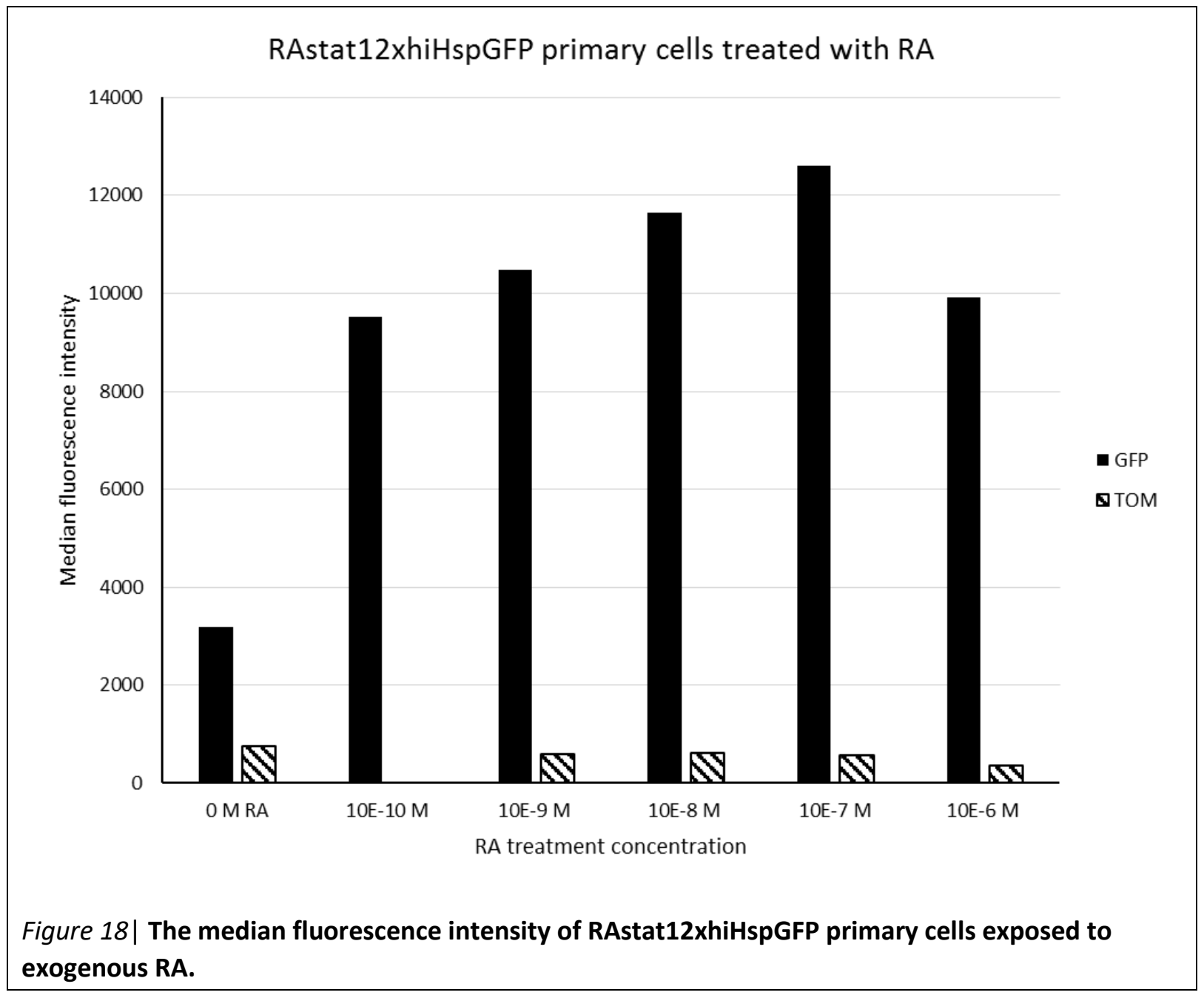




\section{Results IV: In vivo characterization of reporter construct function in response to $R A$ concentration}

We then wanted to observe the function of the reporter in vivo. To do this, we mated a transgenic mouse with a wildtype mouse. This was done to ensure that transgenic embryos were hemizygous for the RAstat4xhiHspGFP2xhiHspTOM gene. Had two transgenic mice been mated, the litter will have included transgenic embryos either with one or two copies of the gene. Those embryos carrying two copies would have shown higher levels of fluorescence than those with just one copy, making them incomparable.

The GFP fluorescence of the reporter responding to RA levels at different stages of development are shown below. Images were taken using a Leica DM6000 fluorescent microscope fitted with a blue 13 filter to measure GFP fluorescence and a green N21 filter to measure TOMATO fluorescence.

\subsection{Embryonic day 7.5}

The fluorescent protein expression in response to RA concentration at E7.5 is shown in Figure 19. RA expression begins around E7.5, therefore fluorescent protein levels are only beginning to build up and the signal is not as strong as at later stages. TOMATO signal (Figure 19C) is merely background, indicating that RA concentration has not yet reached a high enough level for the less sensitive portion of the reporter construct to respond. GFP, expressed in response to lower concentrations of RA can be detected (Figure 19B). It is localized to the posterior region of the embryo, where RA emanates from the node, and is expressed along the posterior epiblast. 


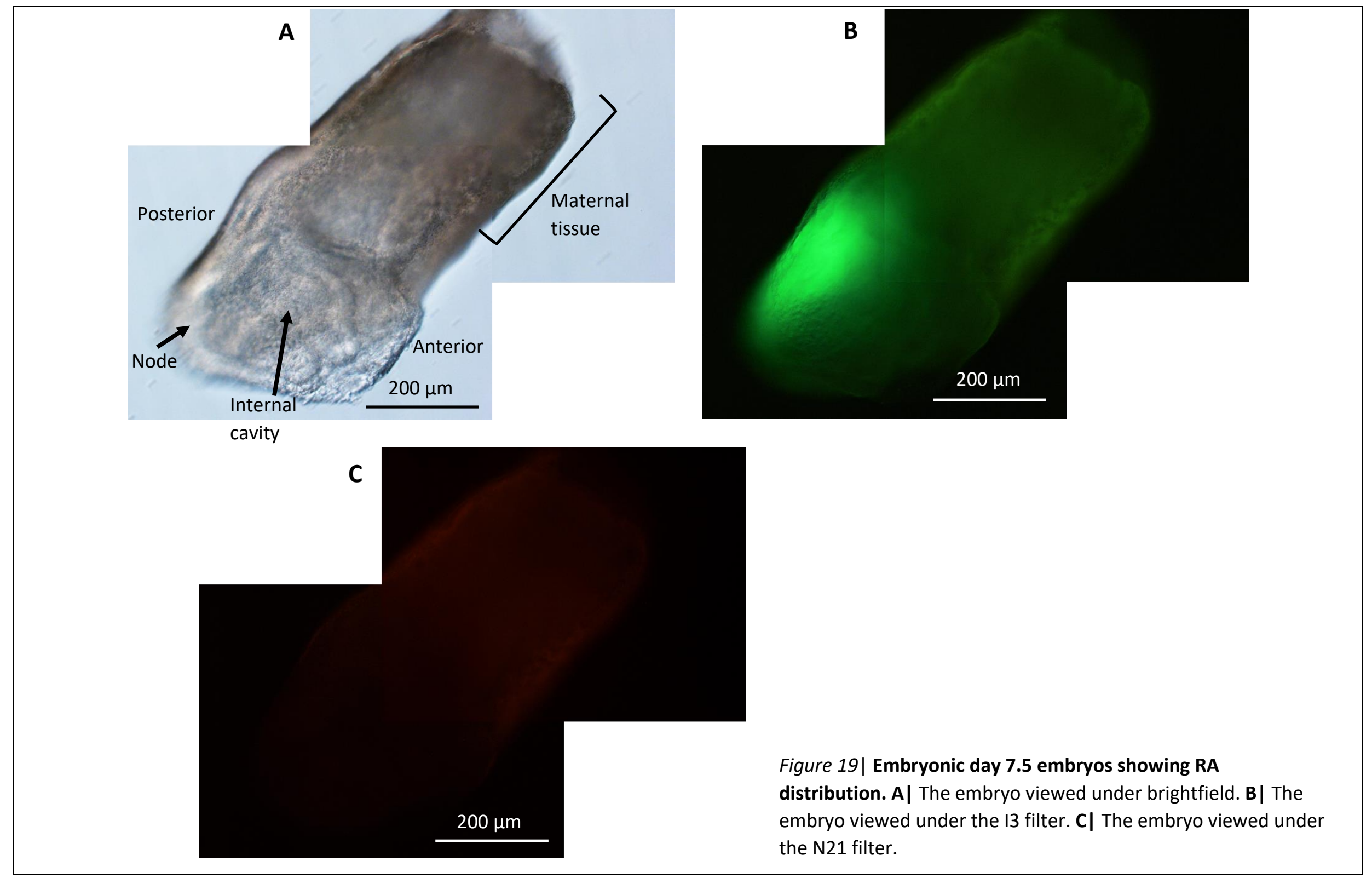




\subsection{Embryonic day 8.5}

At E8.5, the embryo has undergone noticeable developmental changes. The embryonic cylinder of E7.5 has grown and visible tissue differentiation has begun. The embryo has 7 somites, a beating heart and the head folds have formed. RA is not present in the head folds and is seen to be brightest in the midsection of the embryo (Figure 20B). There appears to be a posterior boundary of expression below the newest somite (indicated by the red arrow in Figure 20B). The tissues surround the posterior of the embryo which show brighter fluorescence are extraembryonic membranes showing auto-fluorescence. The presence of TOMATO, indicating high concentrations of RA, cannot be confirmed, as the red fluorescence seen is barely above background (Figure 20C). 


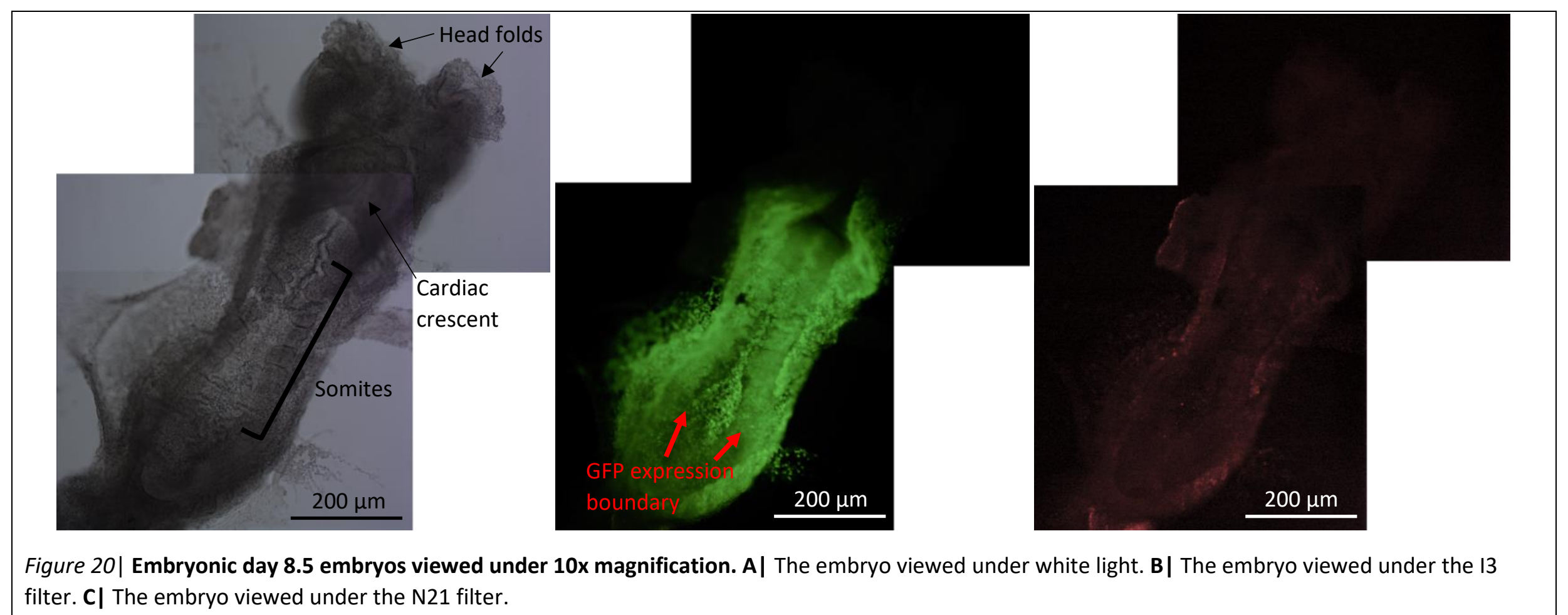




\subsection{Embryonic day 9.5}

At E9.5, the embryo has begun to develop limb buds, eyes and a distinct tail. The head folds have closed, and the embryo has developed the three regions of the brain - fore-, mid- and hindbrain. Figure $21 B$ shows that at this stage of development, the region of the embryo with RA activity begins at roughly the level of the forelimb bud and extends posteriorly to just anterior of the tip of the tail. By looking at the embryo under higher magnification (Figure 22), we see that there is some RA activity in the head region around the developing optic and ear vesicles, as well as the posterior trunk. The brightest signal comes from the midsection of the embryo, where we see both a strong GFP signal and TOMATO fluorescence.

A

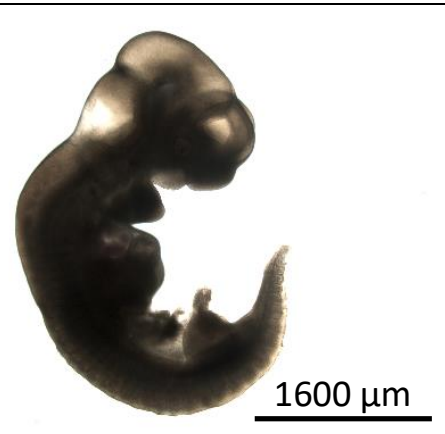

\section{B}

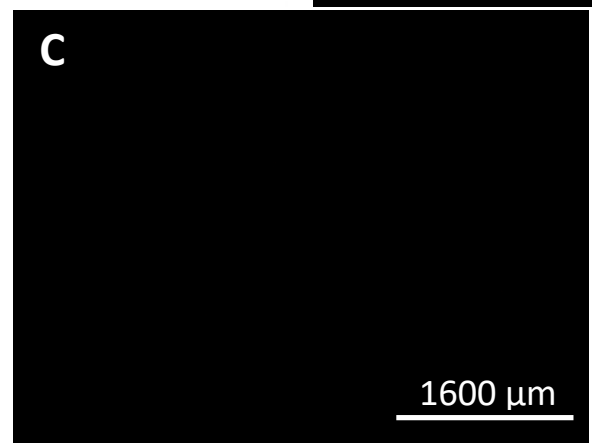

Figure 21| Embryonic day 9.5 embryo viewed under 1.25x magnification. A| The embryo under brightfield. B| The embryo under the 13 filter. $\mathbf{C l}$ The embryo under the N21 filter. 


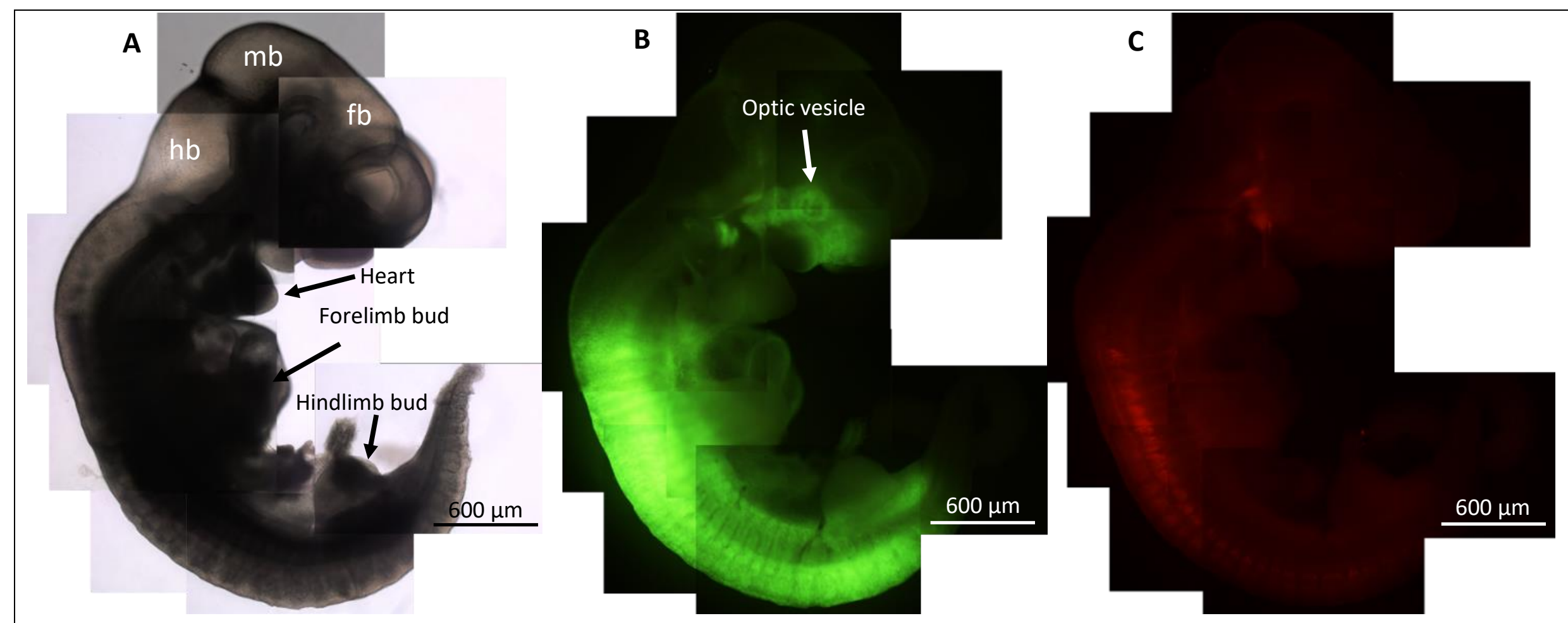

Figure 22| Embryonic day 9.5 embryos viewed under 5x magnification. A| The embryo under brightfield. B | The embryo under the $\mid 3$ filter. $\mathrm{C} \mid$ The embryo under the N21 filter. The location of the forebrain $(\mathrm{fb})$, midbrain $(\mathrm{mb})$ and hindbrain $(\mathrm{hb})$ are indicated on $\mathbf{A}$. 


\subsection{Embryonic day 10.5}

At E10.5, the embryo is significantly more complex with developing eyes, limb buds and more somites. Figure $23 B$ shows a distinct area of RA that begins around the midsection of the embryo and extends posteriorly, however it does not include the most posterior part of the tail bud. Figure $24 B$ clearly shows the area of brightest GFP signal is found in the anterior portion of the expression region, with less signal coming from the more posterior parts. There is an area that shows a stronger signal than the surrounding tissue just anterior of the posterior expression boundary. This brighter green can be seen in both Figure $23 B$ and Figure $24 B$, indicated by red arrows. Figure $24 C$ shows the TOMATO expression in the embryo and, similar to the GFP expression, hotspots can be found in the anterior portion as well as the region at the posterior, indicating that these areas do indeed show higher concentrations of RA while the surrounding tissues show lower. This is reinforced by the fact that under the N21 filter, the TOMATO protein seems to generally be confined to those two areas.

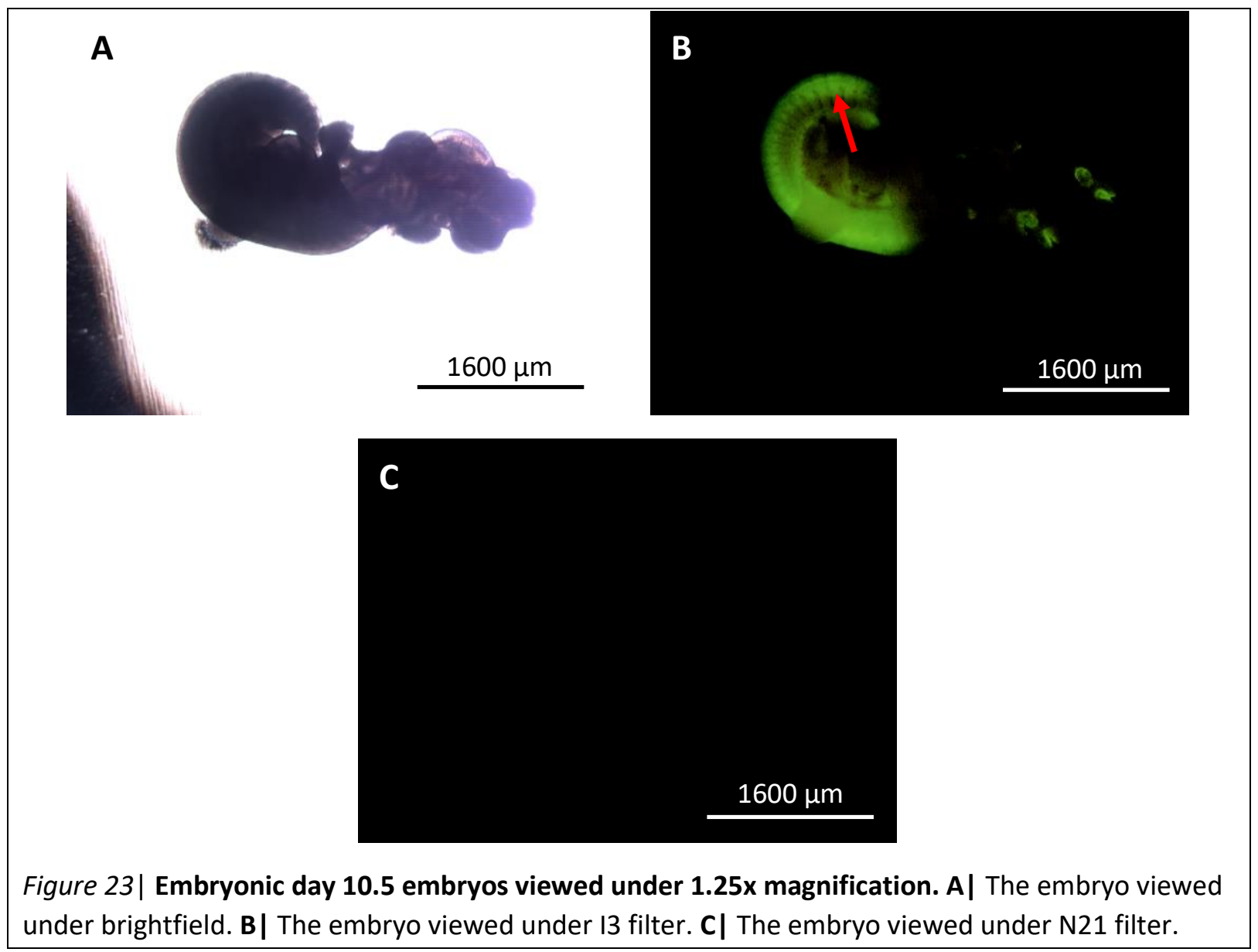




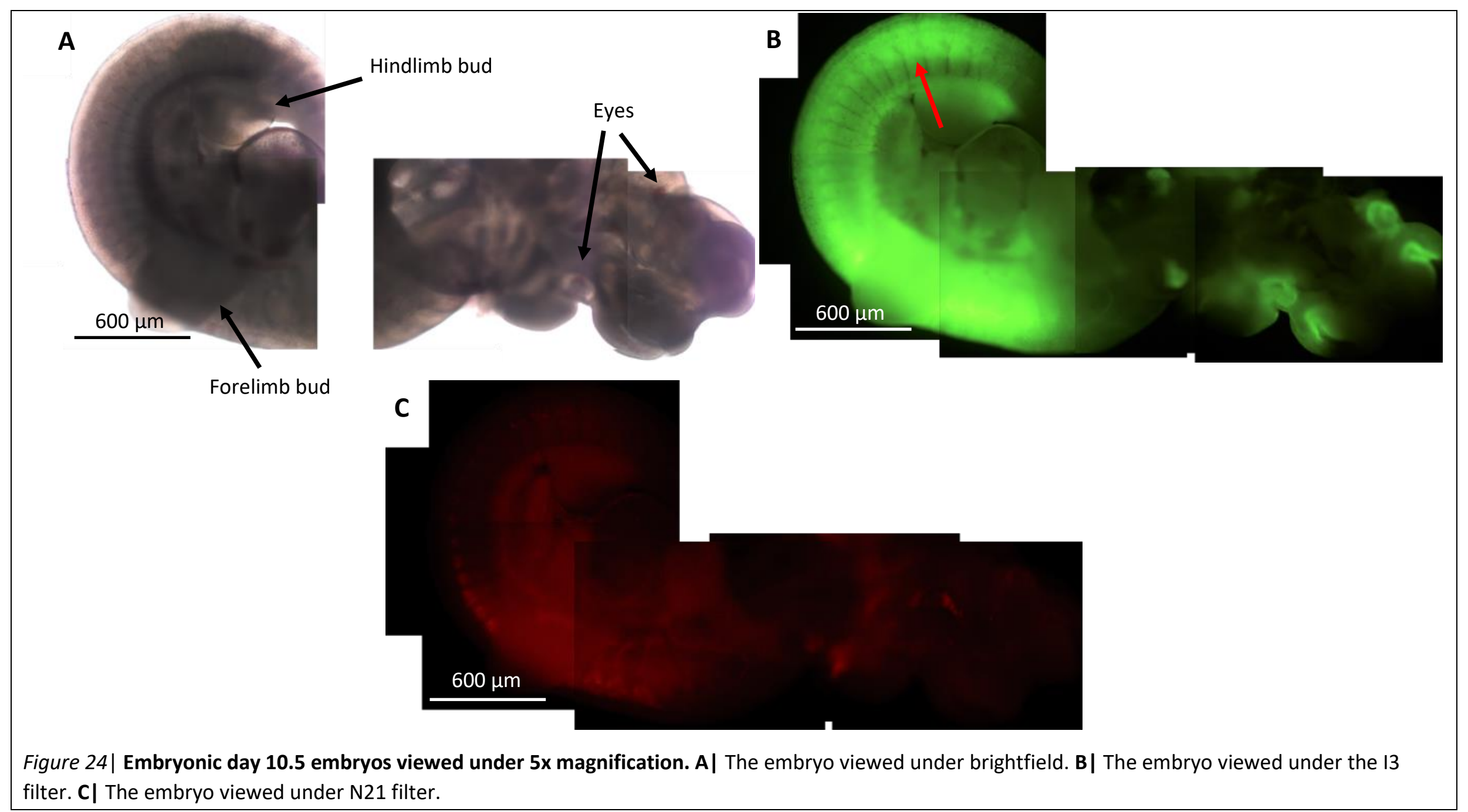




\section{Results V: Cell sorting}

Having observed the expression patterns in the embryo at different stages, we used these transgenic embryos to investigate the effect that RA has on gene expression in different tissues along its expression gradient. Our ultimate goal was to use a cell sorter to separate the cells of an embryo into those expressing either high or low levels of RA based on GFP and TOMATO signal, ideally separated into groups based on tissue type. We decided to attempt to isolate the neural tube and paraxial mesoderm for this work.

\subsection{Developing the methodology}

The methodology for doing this is not well described in the literature. To begin developing the method, we decided to work with E8.5-9.5 embryos as these show RA activity and are large enough to be able to identify distinct the neural tube and paraxial mesoderm, without having too many other tissue types. It was important to be able to fully separate the two tissue types, as we had to be sure that the two populations we were isolating were as pure as possible in order to have confidence in the results.

The first method we trialled involved removing the head and tail from the embryo, leaving only the trunk tissues. These we then attempted to separate from one another using jeweller's forceps and ophthalmic scalpels. This method involved using the scalpel to slice between the neural tube and the somites on either side, theoretically leaving three strips of tissue - one of neural tube cells and two of paraxial mesoderm cells. However, this proved difficult as the scalpels, though the blades were small, were larger than the pieces of tissue we were trying to isolate, making them clumsy to use. This made it too difficult to cleanly isolate the tissues from one another.

The next method we trialled involved using digestive enzymes to attempt to digest the paraxial mesoderm away from the neural tube. We used tested three different proteinases for this: collagenase B; papain; and trypsin in the form of TrypLE. Different times of digestion were tested, however it was difficult to find the balance between enough 
digestion of the outer layers and keeping the neural tube tissue intact. As this proved too difficult to balance, we decided not to proceed with this method.

Our next method involved the use of antibodies to label the two tissues we were interested in. Our search for appropriate markers for each tissue type began on the Mouse Genome Informatics (MGI) website (http://www.informatics.jax.org/). We used the differential expression search tool to identify genes that were expressed in the paraxial mesoderm but not the neural tube and vice versa. These were then filtered to show only genes with strong expression in the time of interest and not expressed in any other tissue types. This list of genes was entered into the Ingenuity Pathways Analysis tool (QIAGEN) where genes that did not code for membrane proteins were filtered out and the remaining list of genes was analysed for their suitability. Based on this search, we chose CD349 (FZD9) as a marker for neural cells, and CD49 (ITGA6) as the marker for paraxial mesoderm, as these are restricted to their respective tissues at E8.5. We then looked into which fluorophores would best fit into a panel with GFP and TOMATO and decided on Cy5 and eFluor450.

DAPI was chosen as the viability marker. DAPI is slow to move through the intact plasma membrane of live cells, while it easily enters dead cells. Therefore, cells positive for DAPI can be identified as dead.

I isolated E8.5 embryos, separated transgenic from non-transgenic (see Figure 25), removed the heads and the tails, dissociated the cells and stained them with our antibodies according to the protocol in 2.8 . 


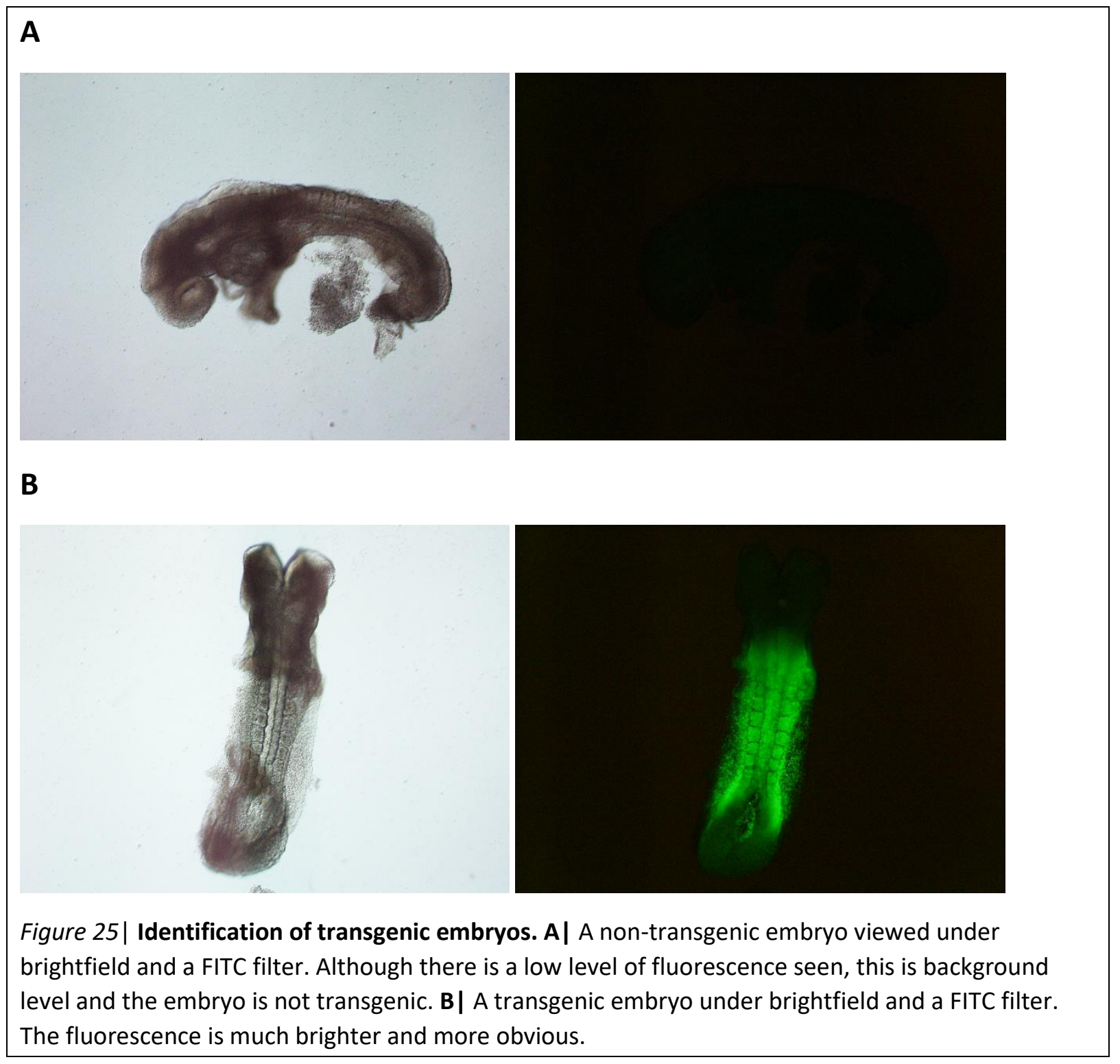

\subsection{First sort experiment}

The initial sort of these cells was to tease out any issues that may arise. These cells were stained with a 1:1000 dilution of the two antibodies.

\subsubsection{Controls}

The first step of the sort was to calculate compensation between the four fluorophores. This step was required to have absolute confidence in the results, as it allows for the machine's software to make mathematical adjustments to ensure that there is no spill over from one fluorescent channel into another. This was done with NIH3T3 cells transfected with either a constitutively expressing GFP or TOMATO plasmid, or compensation beads for the antibodies. One drop of compensation beads was mixed with $1 \mu \mathrm{L}$ of antibody and 
incubated the same amount of time as the cells. The antibodies bind to the beads which can then be used as the positive control. The dot-plots of these controls are shown in Figure 26. These plots also allow us to see where the positive signal for each of these fluorophores lies.
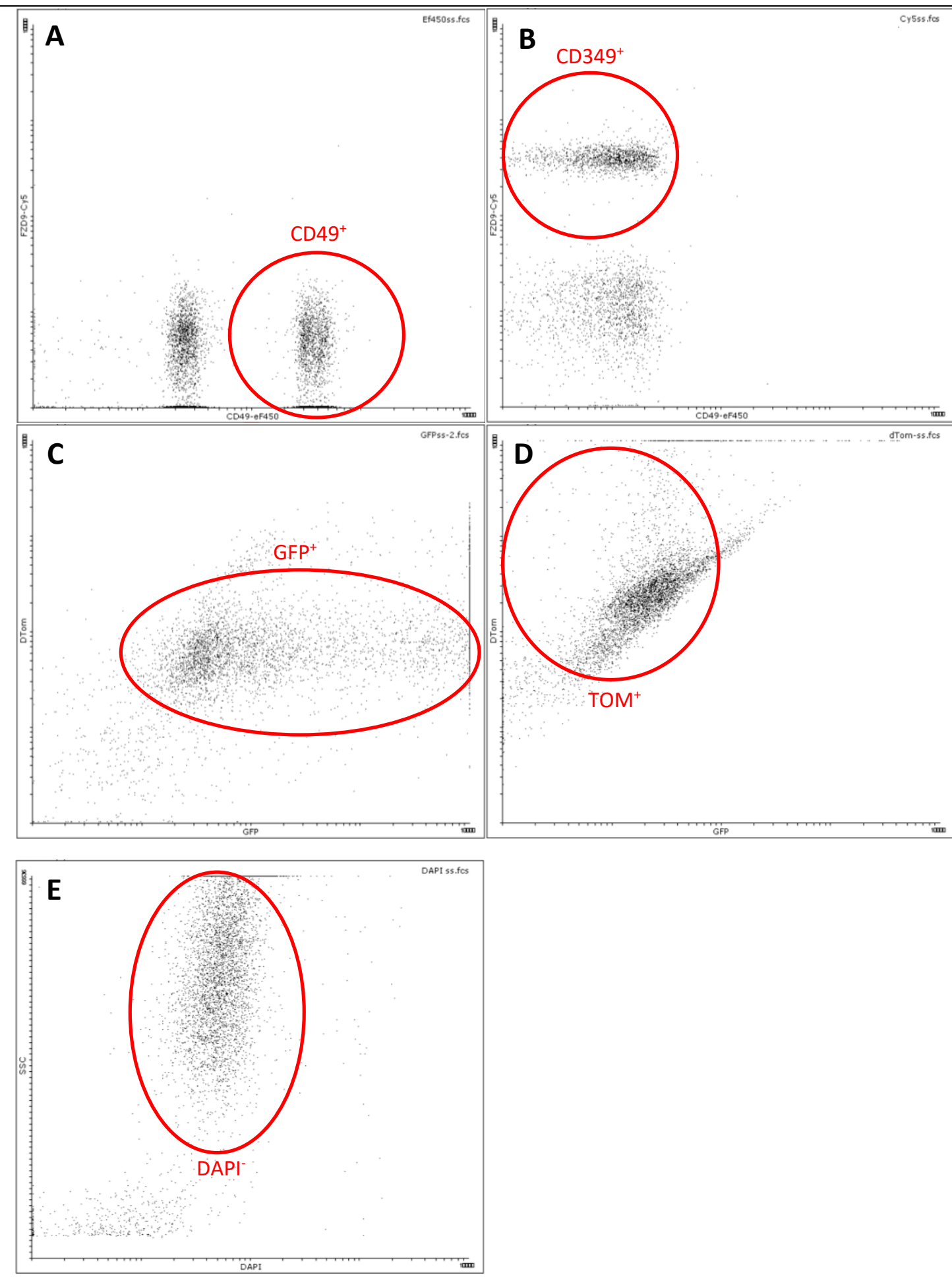

Figure 26| The dot-plots of the single stained controls for each of the four fluorophores and DAPI. A| eflour450. B| Cy5. C| GFP. D| TOMATO. E| DAPI. 
As the cells were stained with multiple fluorophores, fluorescence-minus-one (FMO) samples were also included in the controls for this experiment. These are samples stained with all but one of the fluorophores and allow for a greater level of certainty when placing the gates around positive populations. As GFP and TOMATO fluorescence were coupled to one another, we were only able to have FMOs for the two antibodies. The plots of these are shown below in Figure 27. The FMO for Cy5 (Figure 27A) shows where the combined signal of GFP, TOMATO and eFluor450 lies. When compared with the fully stained sample, the truly $\mathrm{Cy}^{+}{ }^{+}$population can be identified as the population of cells seen in the fully stained sample but not the Cy5 FMO. The same principle can be applied to the eFluor450 FMO (Figure 27B).

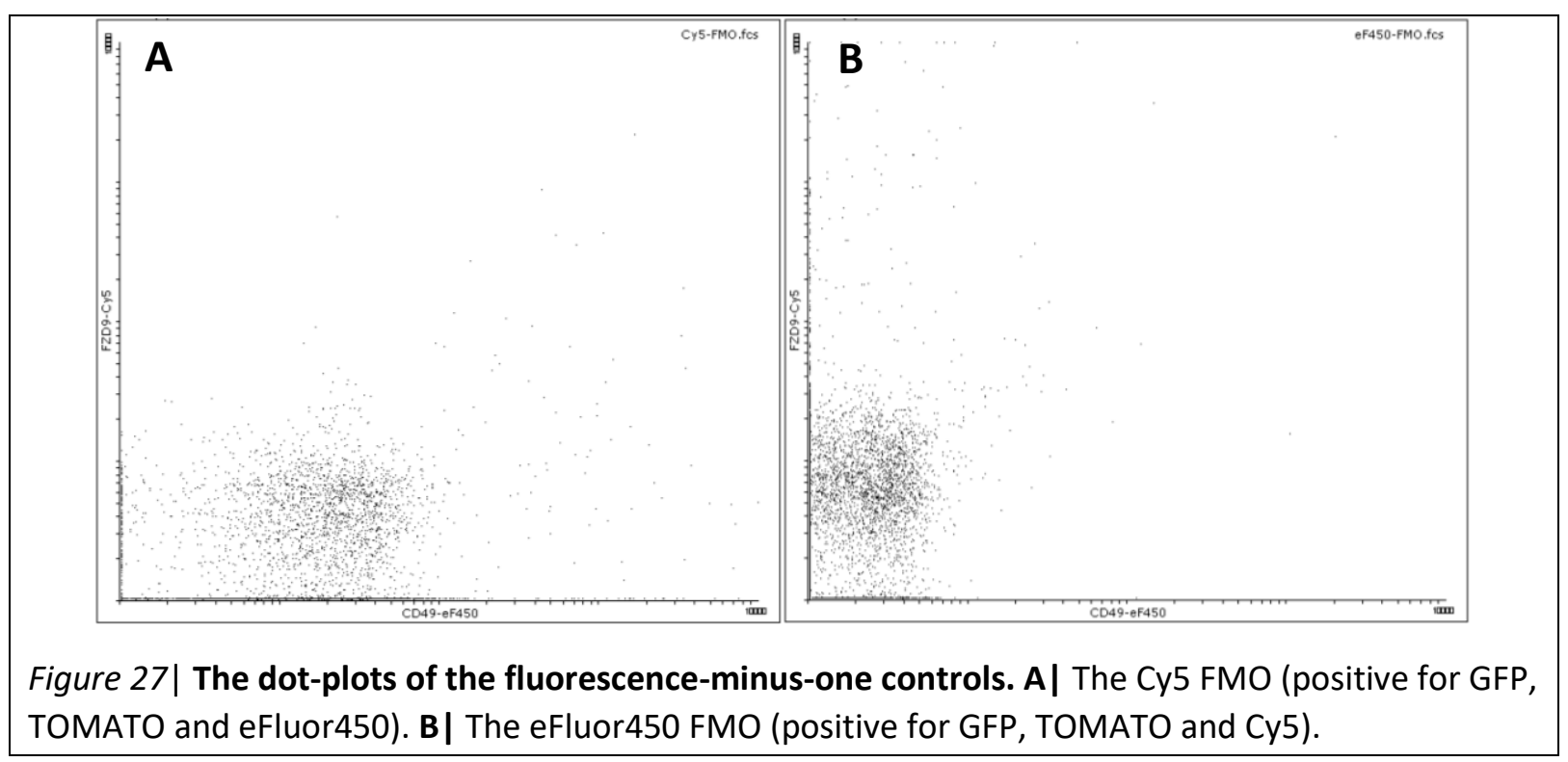




\subsubsection{Embryonic sample}

Once all the controls were set up, the fully stained embryo sample was analysed. Initially, the population of single, live cells had to be found. This was done by analysing forward scatter and side scatter (Figure 28A, 28B). In each of these cases, the main population was gated. These cells were then analysed for DAPI expression and those cells that were DAPI were gated around (Figure 28C).

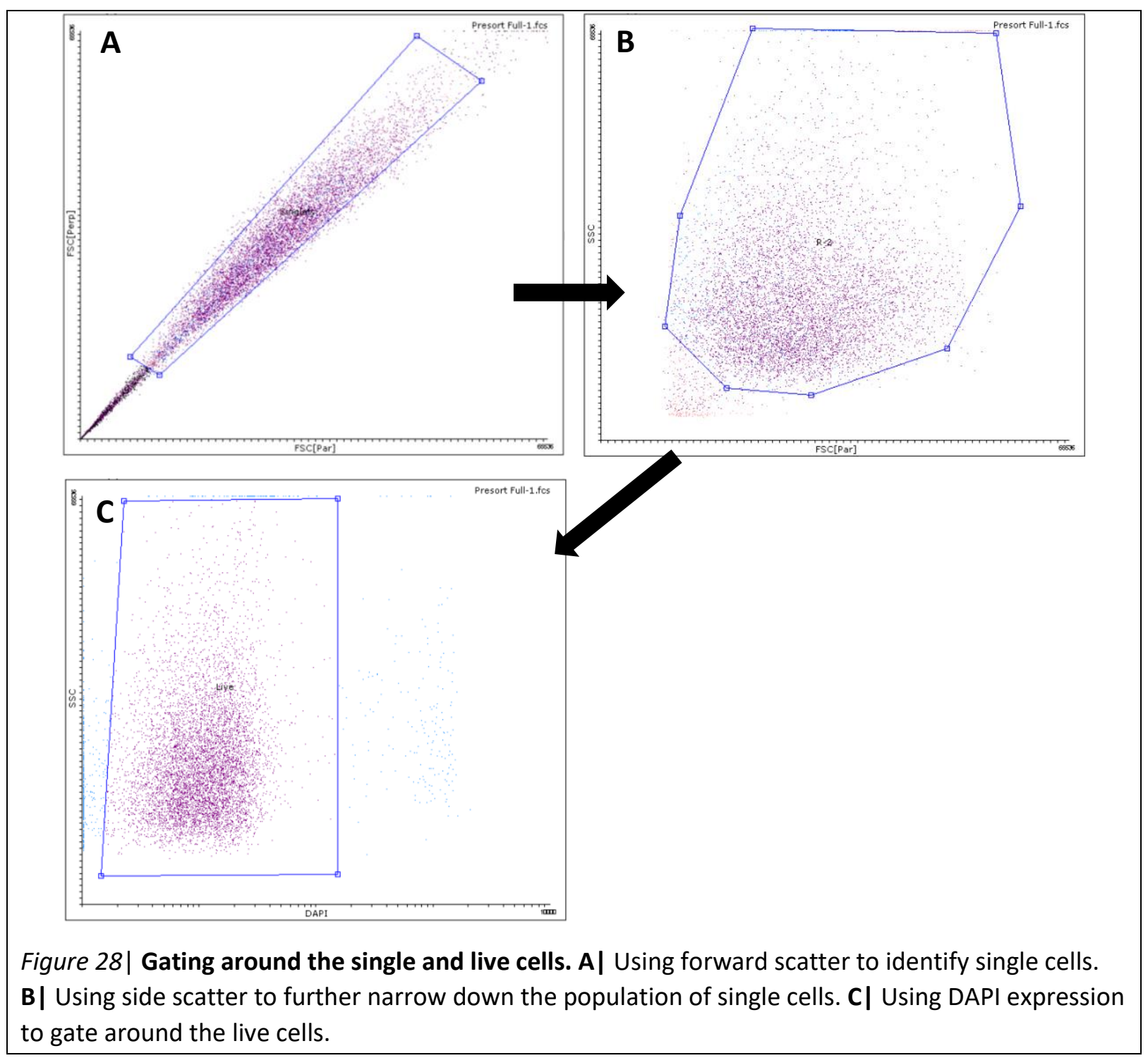


Once this population of cells had been identified, the fluorescent markers on the antibodies were looked at (Figure 29). Cy5 fluorescence was plotted against eFluor450 fluorescence and the FMO plots (Figure 27) were used to set gates around the positive populations for each fluorophore. It was decided during this process that there was not a strong enough positive signal from the Cy5 antibody (neural tissue) to base a sort on. We chose to proceed only with the tissue marked as paraxial mesoderm. After gating this population, the levels of GFP and TOMATO fluorescence were compared (Figure 30). We chose to set up gates for double negative cells, cells that showed intermediate levels of GFP but no TOMATO, cells that showed high levels of GFP but no TOMATO and double positive cells. From these populations, we collected cells in two repeats of 500, giving us 1000 cells total for each of the four populations.

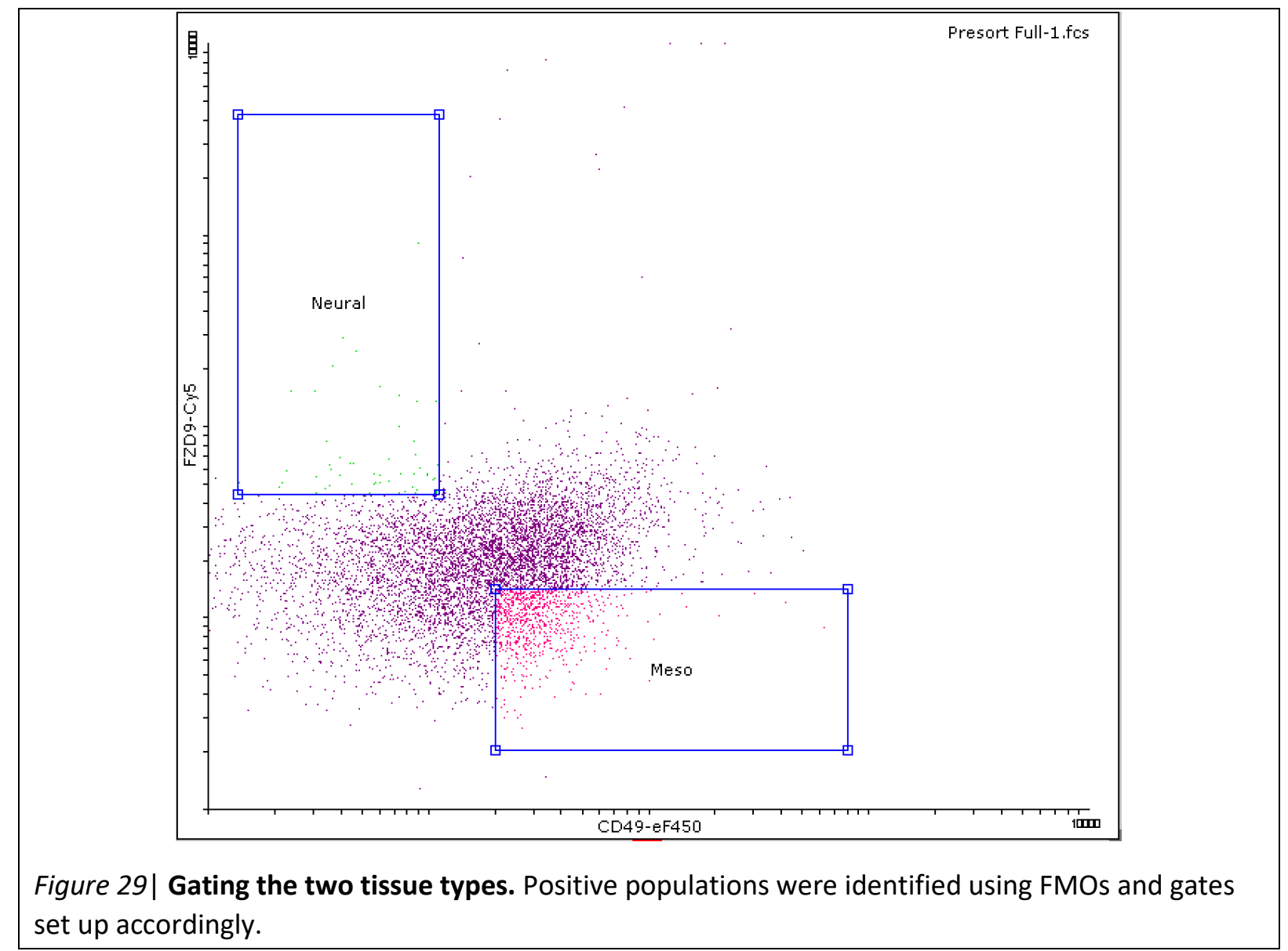




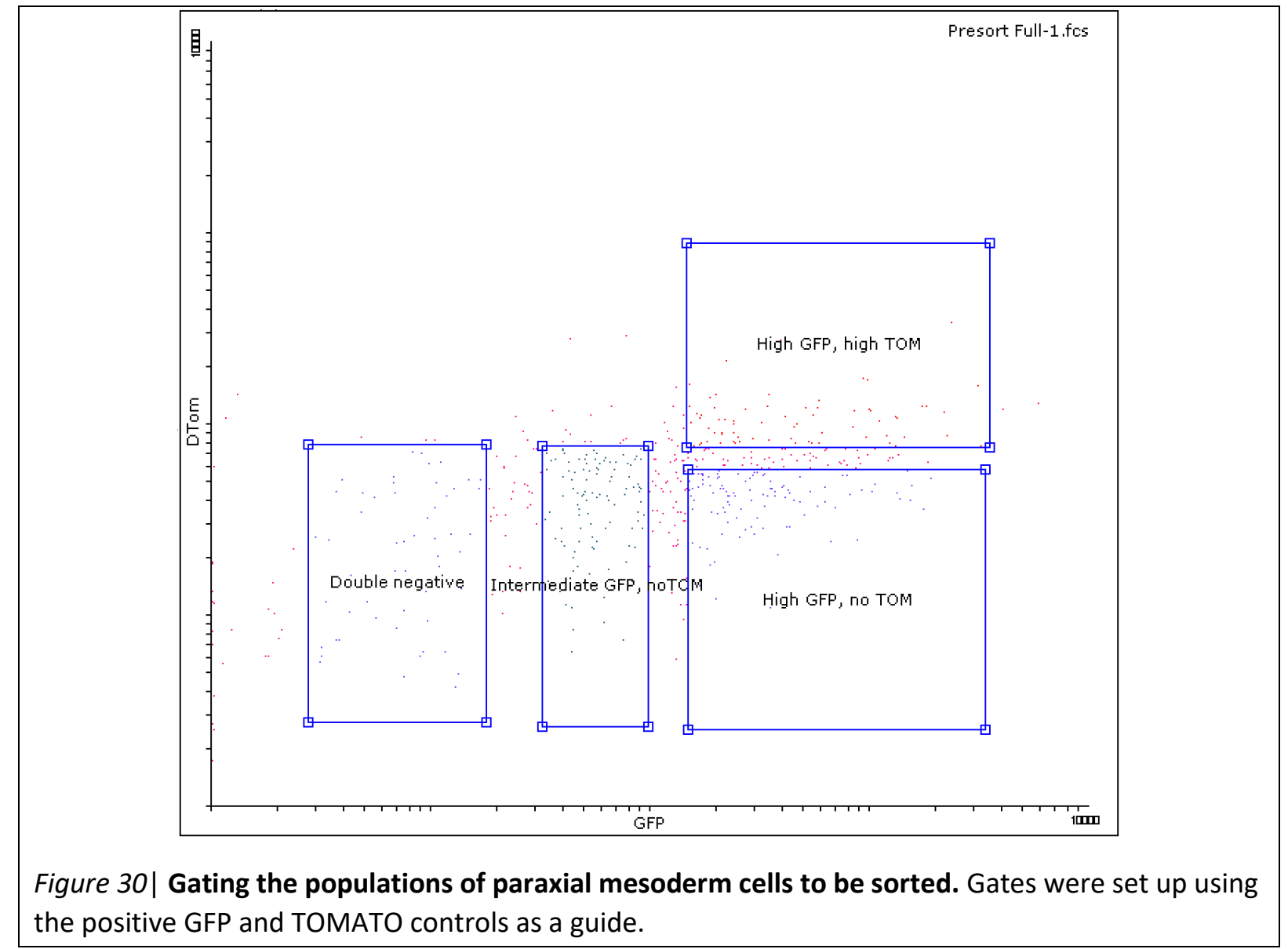

\subsubsection{RNA isolation}

Once we had these cells, we used the RNA library kit to generate cDNA. Using a Qubit fluorometer, the DNA yield was measured for each of the cell populations (Table 3). A NanoDrop was not suitable for the measurement of DNA in this instance as the sample was polluted with the ingredients of the RNA library kit. This would have given a higher reading than the actual DNA concentration on the NanoDrop. The Qubit uses a fluorescent molecule that intercalates into the dsDNA, giving an accurate DNA concentration. The expected yield for the RNA library kit is $\sim 300 \mathrm{ng} / \mu \mathrm{L}$ (QIAGEN, 2016), making these yields were very low. 


\begin{tabular}{|l|l|l|}
\hline Cell population & DNA yield repeat 1 & DNA yield repeat 2 \\
\hline Double negative & $0.29 \mathrm{ng} / \mu \mathrm{L}$ & $0.28 \mathrm{ng} / \mu \mathrm{L}$ \\
\hline Intermediate GFP, no TOM & $0.44 \mathrm{ng} / \mu \mathrm{L}$ & $0.56 \mathrm{ng} / \mu \mathrm{L}$ \\
\hline High GFP, no TOMATO & $0.70 \mathrm{ng} / \mu \mathrm{L}$ & $0.73 \mathrm{ng} / \mu \mathrm{L}$ \\
\hline Double positive & $0.57 \mathrm{ng} / \mu \mathrm{L}$ & $0.56 \mathrm{ng} / \mu \mathrm{L}$ \\
\hline
\end{tabular}

Table $3 \mid$ The DNA yield from cells obtained during the first sort experiment.

\subsection{Second sort experiment}

\subsubsection{Protocol optimisation}

After analysing the results from this experiment, some adjustments to the protocol were made. We decided not to remove the tails, leaving us with more double negative cells to work with. We increased the concentration of antibodies added from 1:1000 to 1:500 in an attempt to be able to see Cy5 fluorescence from the CD349 antibody. We also decided to collect 300 cells per tube rather than 500 , as the higher number of cells may have had a negative effect on the efficiency of the lysis buffer.

\subsubsection{Sorting}

The sorting experiment was repeated, making these adjustments. The single, live cell population was identified as before (Figure 28). Antibody expression was compared (Figure 31), however we again observed a lack of Cy5 signal. As before, only the cells expressing efluor450 were collected. The same gates were set up as in the previous sort experiment (Figure 32) and three repeats of 300 cells collected from each gate 


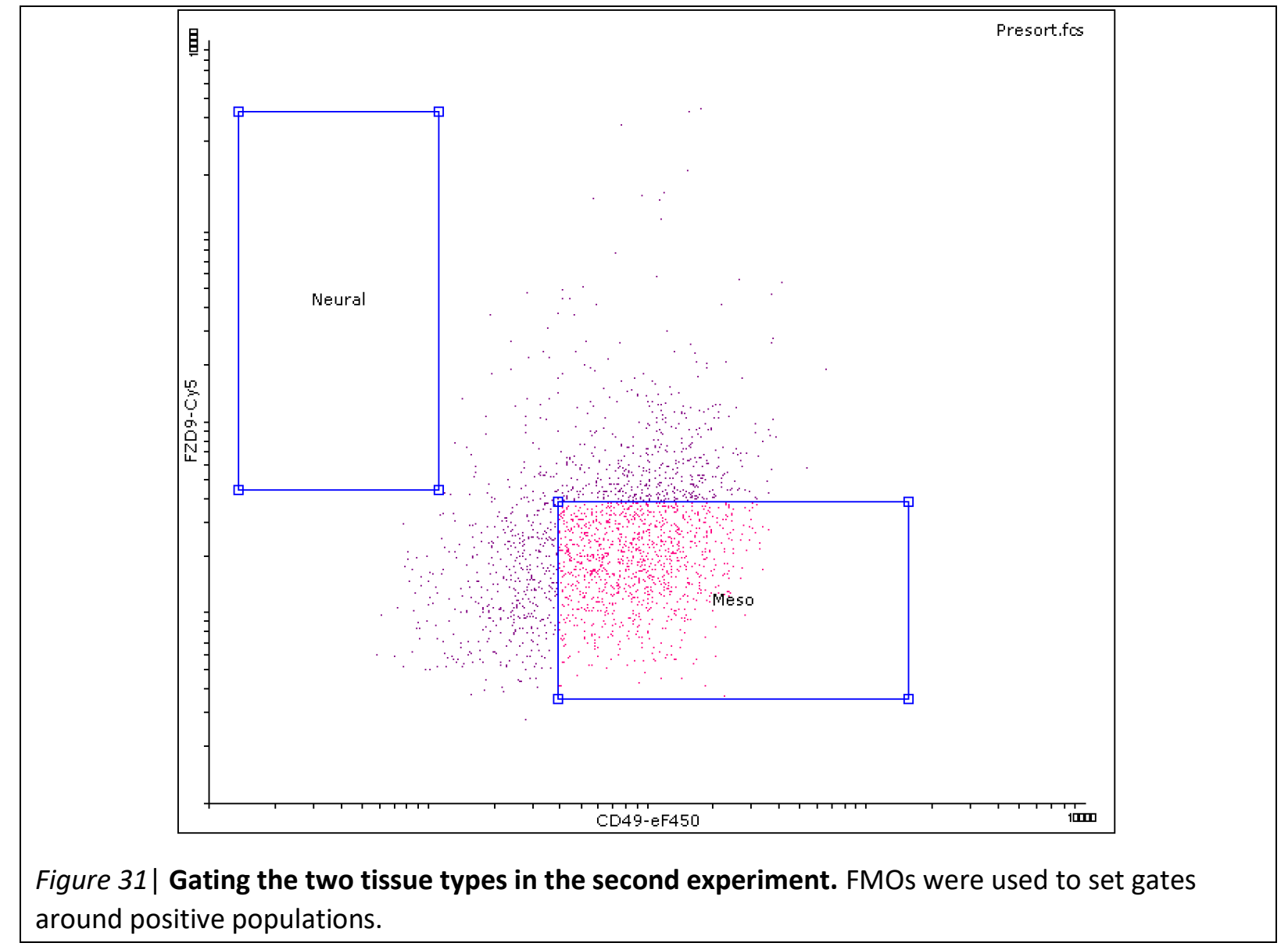

\subsubsection{RNA isolation}

Using the QIAseq RNA library kit, the RNA was isolated, converted to CDNA and amplified as before. The DNA yield of these cells is shown below in Table 4. These cells showed much higher yields than those from the previous experiment, indicating that either there was an issue during the first sort/RNA isolation experiment, or the optimisation of the protocol allowed for higher yields to be obtained. 


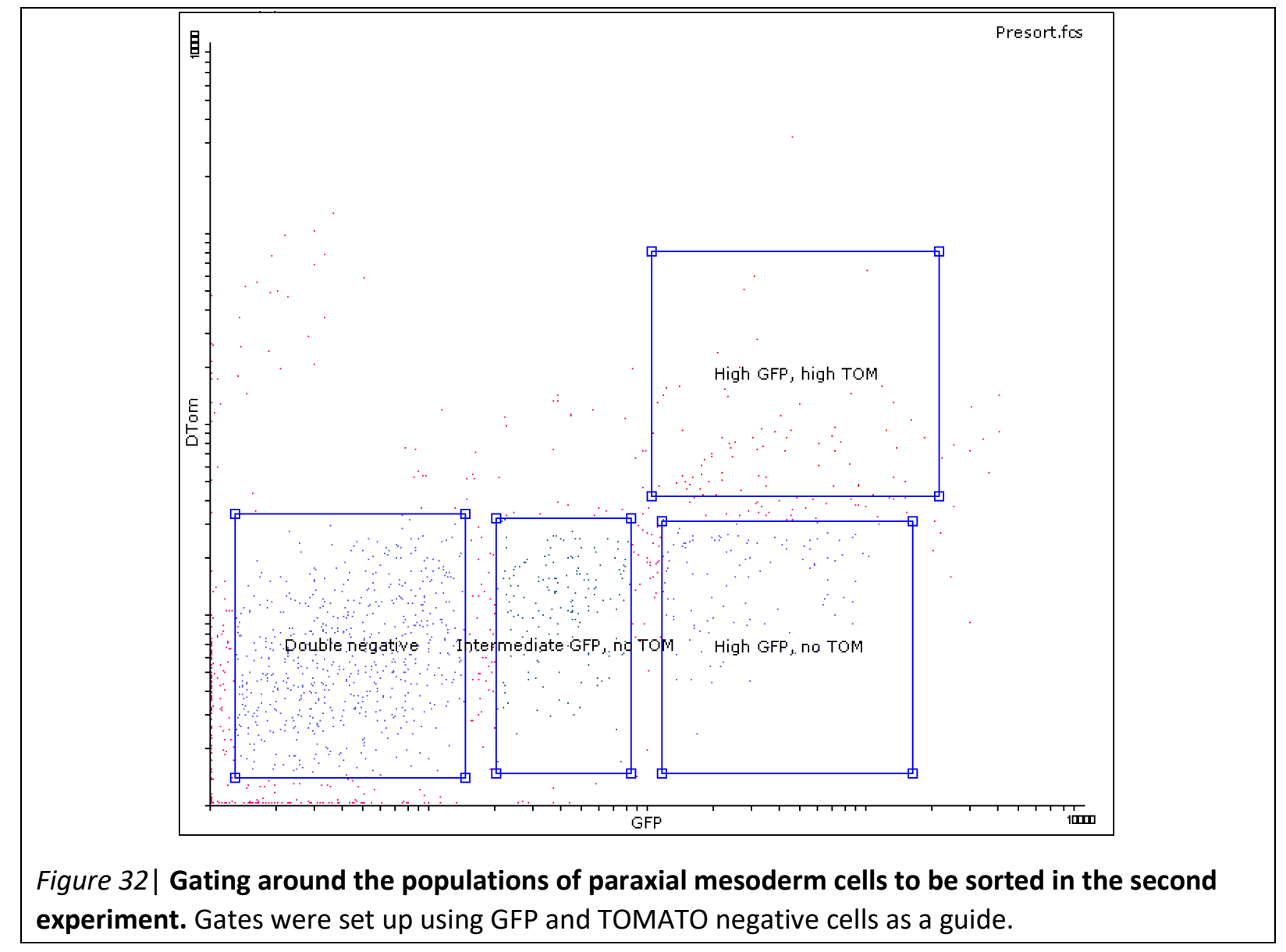

\begin{tabular}{|l|l|l|l|}
\hline Cell population & DNA yield repeat 1 & DNA yield repeat 2 & DNA yield repeat 3 \\
\hline Double negative & $312 \mathrm{ng} / \mu \mathrm{L}$ & $466 \mathrm{ng} / \mu \mathrm{L}$ & $570 \mathrm{ng} / \mu \mathrm{L}$ \\
\hline Intermediate GFP, no TOM & $566 \mathrm{ng} / \mu \mathrm{L}$ & $602 \mathrm{ng} / \mu \mathrm{L}$ & $640 \mathrm{ng} / \mu \mathrm{L}$ \\
\hline High GFP, no TOM & $512 \mathrm{ng} / \mu \mathrm{L}$ & $518 \mathrm{ng} / \mu \mathrm{L}$ & $552 \mathrm{ng} / \mu \mathrm{L}$ \\
\hline Double positive & $472 \mathrm{ng} / \mu \mathrm{L}$ & $612 \mathrm{ng} / \mu \mathrm{L}$ & $602 \mathrm{ng} / \mu \mathrm{L}$ \\
\hline
\end{tabular}

Table 4| The DNA yield of cells obtained during second sorting experiment. 


\section{Results VI: PCR analysis of cDNA}

Due to time restriction, we were not able to have the cDNA sequenced. Therefore initially, our goal was to use real-time PCR to search for specific genes and record their expression in the four cell populations. The genes chosen are shown in Table 5. However, the results indicated that this technique was not going to work for these samples (Figure 33), possibly due to the fact that the cDNA product of the library kit was long DNA strands of up to $100 \mathrm{~kb}$ (QIAGEN, 2016). This may have caused the nucleotides in the real time PCR mix to be used up in the first few cycles, meaning that no real result was able to be seen.

\begin{tabular}{|l|l|l|}
\hline Gene & Function & Size (bp) \\
\hline GAPDH & House keeper & 175 \\
\hline Beta tubulin 5 & House keeper & 200 \\
\hline Meox1 & Paraxial mesoderm marker & 306 \\
\hline ITGA6 & Paraxial mesoderm marker & 308 \\
\hline Cyp26A & No RA signal & 290 \\
\hline HoxA1 & Anterior & 317 \\
\cline { 1 - 1 } HoxA4 & & 252 \\
\hline HoxC5 & & 218 \\
\cline { 1 - 1 } HoxC8 & Posterior & 200 \\
\hline
\end{tabular}

Table 5| The genes chosen for identification through PCR.

In light of this, it was decided that standard end-point PCR would be used here to try to achieve a result. Two dilutions of DNA were tested - 1:15 and 1:45 - to provide biological repeats. The four cell populations were cycled with each of the nine primers according to the PCR parameters in Table 6. 


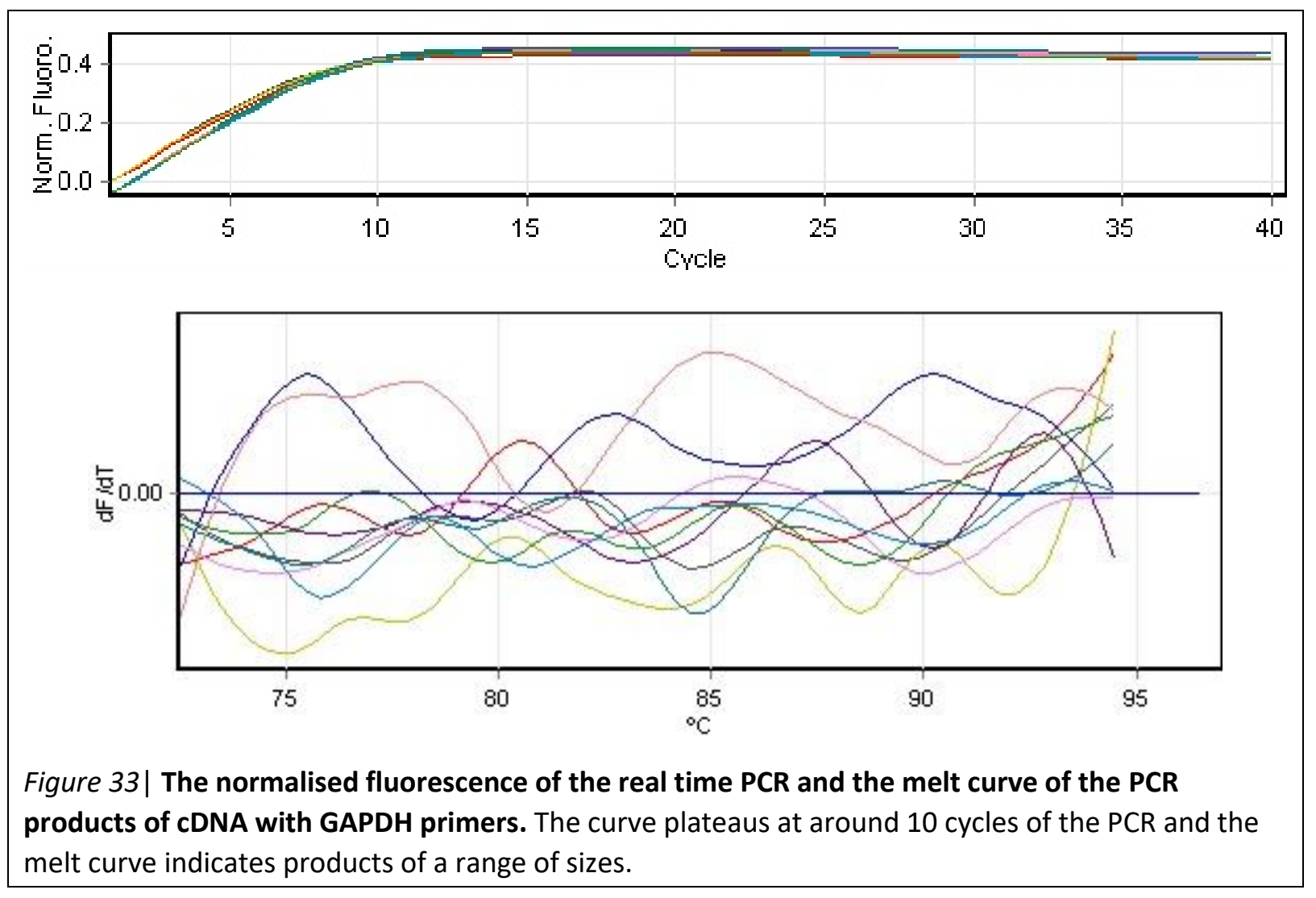

\begin{tabular}{|l|l|l|}
\hline Temperature $\left(^{\circ} \mathrm{C}\right)$ & Time & Cycles \\
\hline 95 & $5^{\prime}$ & 1 \\
\hline 95 & $30^{\prime \prime}$ & \multirow{2}{*}{35} \\
\hline 60 & $30^{\prime \prime}$ & \\
\hline 72 & $45^{\prime \prime}$ & \\
\hline 72 & $5^{\prime}$ & 1 \\
\hline 4 & $\infty$ & 1 \\
\hline
\end{tabular}

Table 6| PCR cycling parameters for identification of genes of interest.

Figure 34 shows the products of this PCR. The two housekeeper genes were present in all of the cell populations, indicating that the reverse transcription/amplification had worked. None of the cell populations showed Meox, and only the double negative population showed ITGA6, both in the 1:15 DNA dilution and 1:45 (Figure 35), indicating that it is a true band. Ideally, all populations would have been positive for these genes as they were markers for paraxial mesoderm. We expected the double negative population to show Cyp26A - the marker for no RA signal - and all other population to be negative for this marker. However, no band is seen, meaning that it was not present, even in the double negative population. We expected to see the Hox genes show differential expression 
through the different cell populations. The RA concentration gradient has the highest concentration at the posterior of the embryo and decreases along the embryonic axis to more anterior regions. Because of this, and due to the nature of the activity of the reporter activity, the double positive cells come from the posterior of the RA expression region, the high GFP, no TOMATO cells are found anterior to the double positive cells and the intermediate GFP, no TOMATO cells even more anterior. From this, we expected to see the posterior Hox genes in the double positive cells, as well as possibly in the high GFP, no TOMATO cells, and the anterior Hox genes in the intermediate GFP, no TOMATO population. Unfortunately, none of the Hox genes were amplified during the PCR process. The double negative sample with the HoxC5 primer shows a band, however this is seen at $\sim 1000 \mathrm{bp}$, while the product was expected to be $218 \mathrm{bp}$ (Table 5). This indicates that this is not an actual result and may just be an artefact of the PCR. 


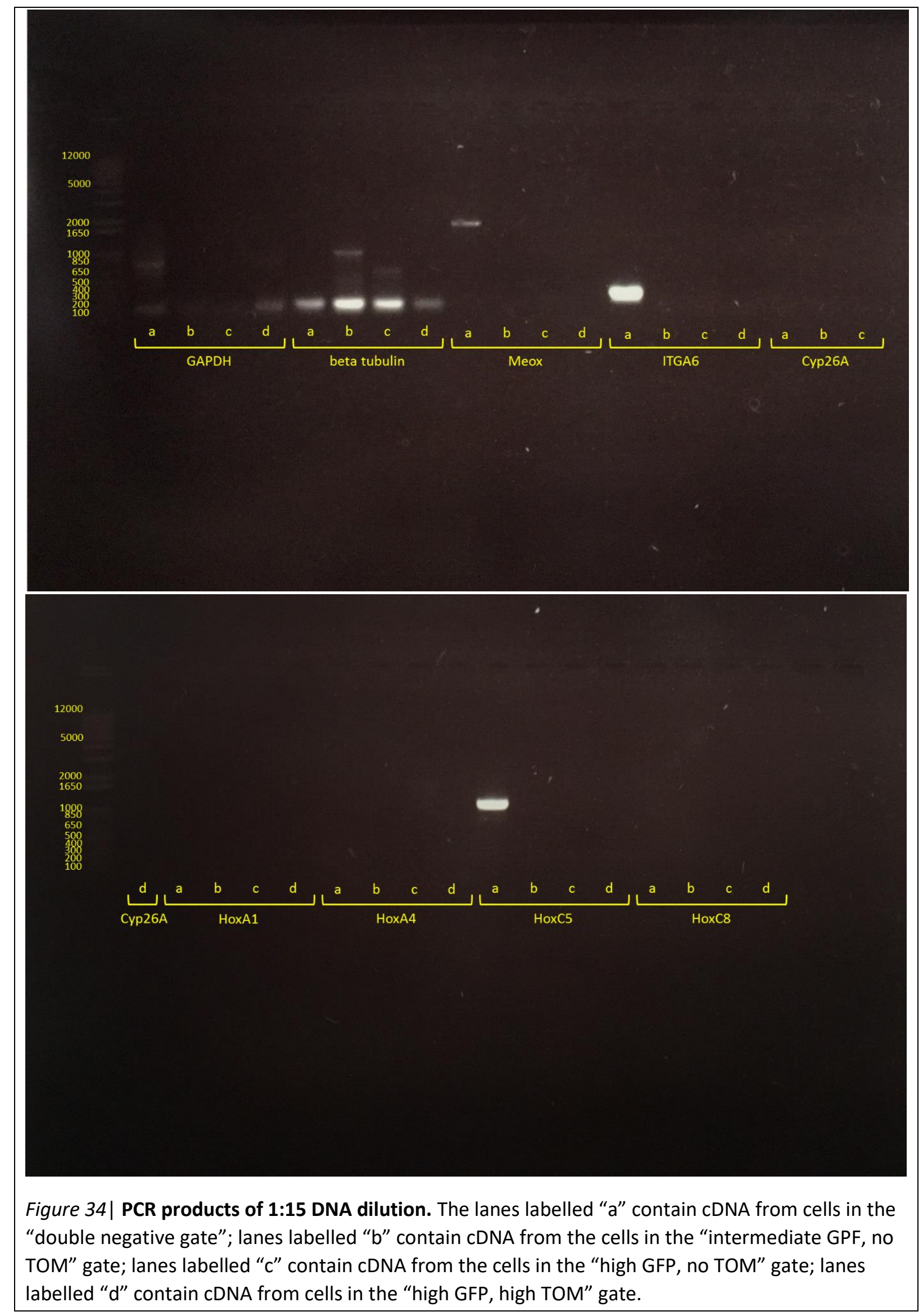




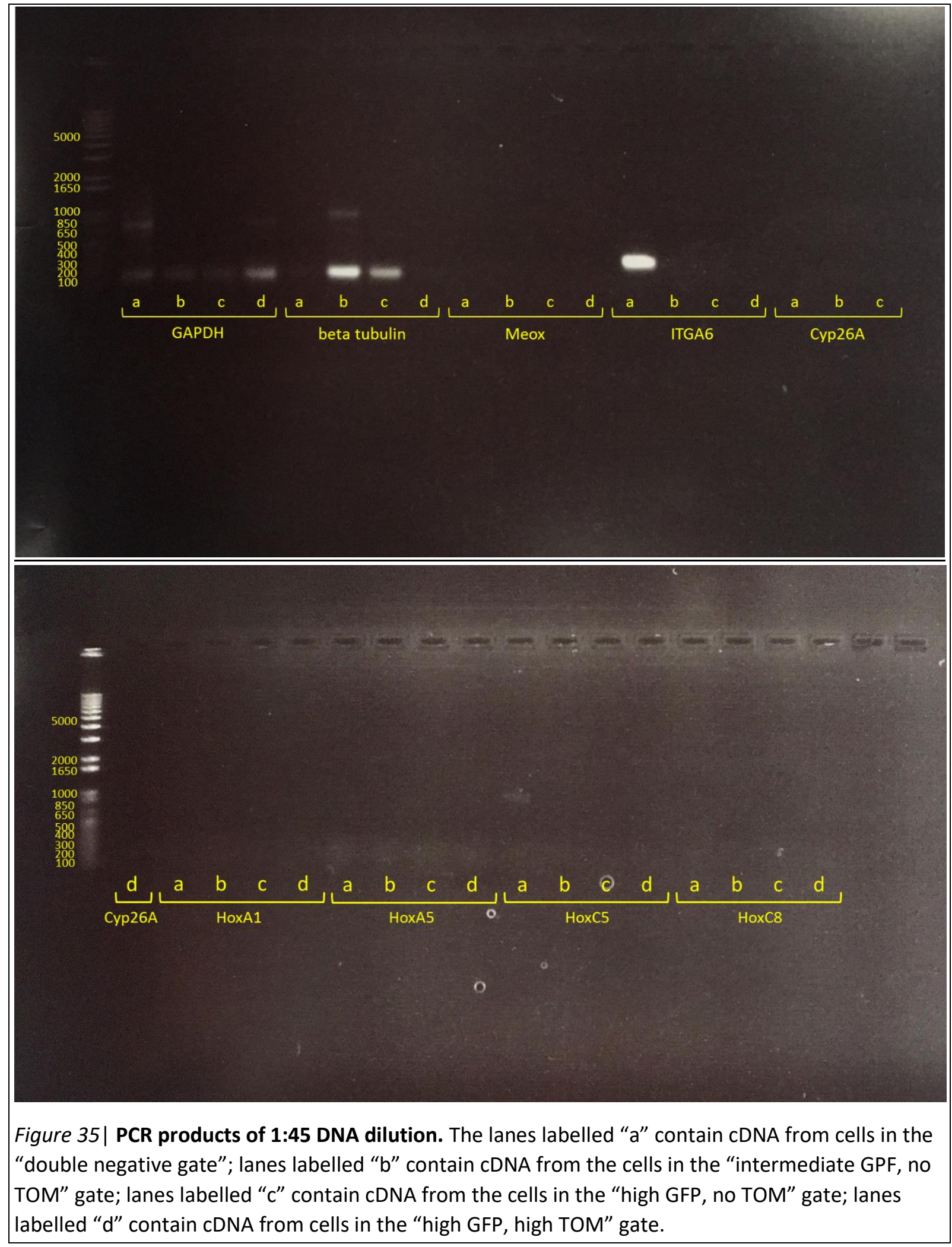


To be sure that the lack of results seen from the PCR of our CDNA was not due to an issue with the primers, we tested the primers on cDNA samples that had been obtained for other work. These samples came from E8.5 embryos and 12-somite embryos. Figure 36 shows that the primers were able to amplify product from these cDNA samples, indicating that the primers were not the cause of the unexpected results seen in Figure 34 and 35.

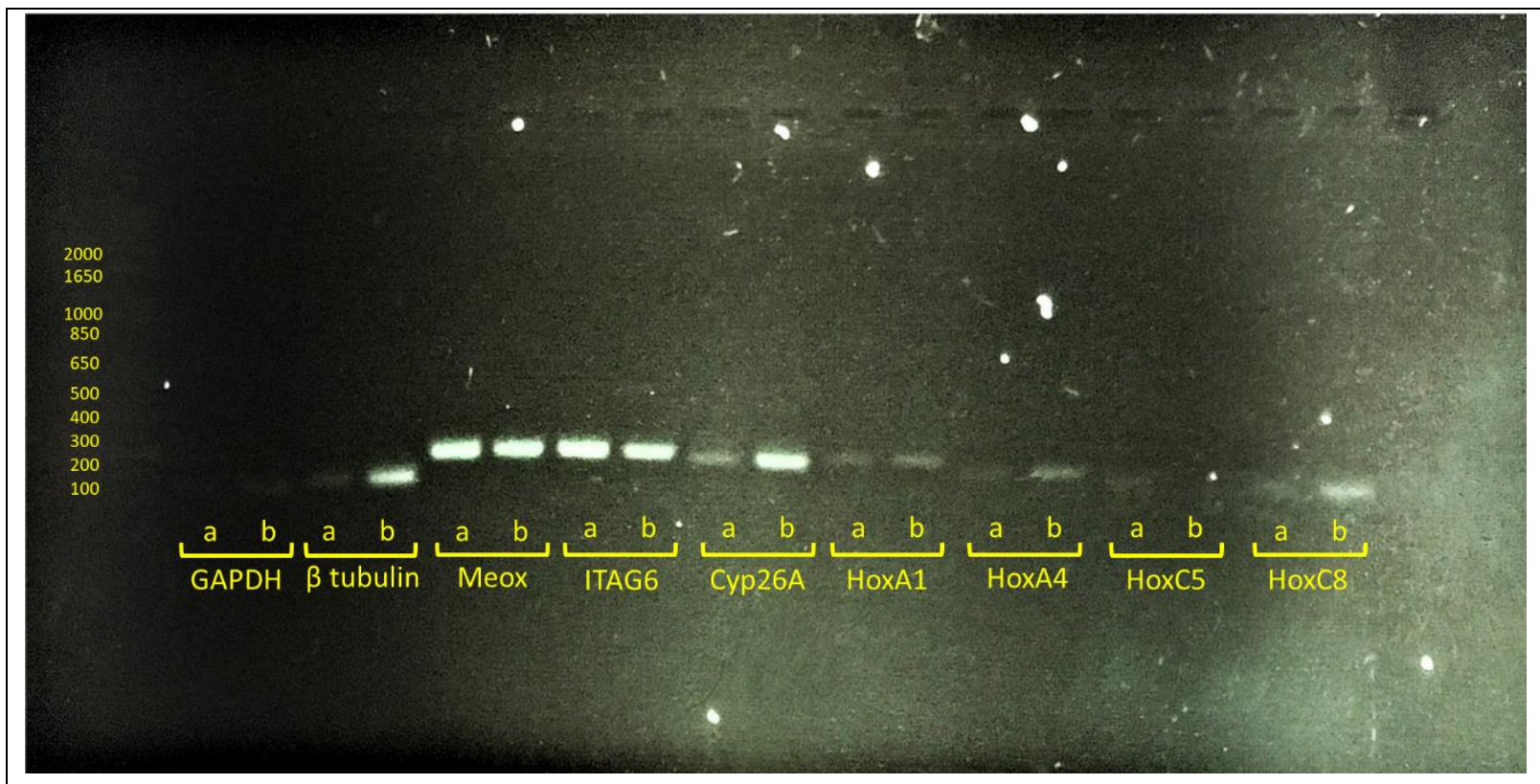

Figure 36| Testing the primers on two types of cDNA. Lanes labelled "a" contain cDNA from an E8.5 embryo, lanes labelled "b" contain cDNA from a 12-somite embryo. 


\section{Discussion}

In this project, I aimed to characterise the activity of the RAstat4xhiHspGFP2xhiHspTOM reporter system and use that reporter to sort the cells of an embryo into separate tissue types and within those, into cells that came from regions expressing different levels of RA. The first experiments done were to characterise the dual activity of the reporter in vitro. Cell transfection experiments and subsequent flow cytometry of these cells showed that the high sensitivity portion of the reporter system was able to respond to different concentrations of RA, with brighter GFP signal generally seen in the cells exposed to higher concentrations of RA than those exposed to lower concentrations. This was true for all three of the different cell types tested - transfected NIH3T3 cells, RAstat4xhiHspGFP2xhiHspTOM primary embryonic cells and RAstat12xhiHspGFP primary embryonic cells. TOMATO signal was expected only in the higher concentration treatments. There was very little TOMATO signal seen in both the transfected NIH3T3 cells and the RAstat4xhiHspGFP2xhiHspTOM primary embryonic cells. This may be due to the limited capacity of the FACS-Cantoll flow cytometer to properly excite and record the emission of TOMATO-fluorescent proteins. On the other hand, it may be the activity of the reporter itself which poses the issue. The lower sensitivity portion of the reporter construct may not respond in the expected way, and therefore may not be able to accurately represent areas of high RA concentration.

To further investigate the functionality of the reporter system, we tested its response to RA concentration in an in vivo setting. A transgenic mouse line containing the RAstat4xhiHspGFP2xhiHspTOM reporter system was used to create transgenic embryos which were recovered at various stages of early embryonic development from E7.5 to E10.5. These stages were chosen due to the fact that this time frame covers the beginning of RA expression and many of the developmental events that require RA presence, e.g. Hox gene expression, axis formation and somite development.

At E7.5, embryos are 600-800 $\mu \mathrm{m}$ long and are cup-shaped. They have a fluid filled amniotic cavity in the middle, and the posterior embryonic tissue is beginning to show all three embryonic cell layers - endoderm, mesoderm and ectoderm (Theiler, 1989). Structures such as the head process and the neural groove are beginning to develop, and the tissues which 
will become the future somites are beginning to take on somatic traits (Jackson Laboratory, 1966). GFP fluorescence in response to RA expression was seen in the posterior tissues of the embryo, along the proximal-distal axis where the somites and neural tissues will be formed (Figure 19). TOMATO-protein fluorescence was not seen at this stage of development, possibly due to the fact that RA has only recently begun to be expressed, and is therefore not yet expressed at levels high enough for the low sensitivity reporter to respond to.

At E8.5, embryos have undergone a marked developmental change from E7.5 embryos. They have grown in length to $800-1000 \mu \mathrm{m}$ and have become flattened and " $\mathrm{S}$ " shaped with the head region facing one way and the tail region pointing in the opposite direction (Jackson Laboratory, 1966). They show bulging head folds, and have developed 7-8 somites on either side of the neural groove (Theiler, 1989). The heart has begun to rapidly grow and is beginning to beat (Jackson Laboratory, 1966). GFP fluorescence in embryos at this stage (Figure 20) was excluded from the head folds and was observed only posterior to the cardiac area. The posterior boundary of fluorescent protein expression was positioned below the newest somite pair, making the tail folds negative for GFP. This was expected based on the literature (Cunningham et al., 2011). Similar to E7.5, TOMATO protein fluorescence above background level was not seen at this stage of development.

Embryonic day 9.5 embryos have grown again in size, they are now around $\sim 4 \mathrm{~mm}$ long and different structures can be identified with the naked eye. The embryos have undergone a process known as embryonic turning, where they change from being " $\mathrm{S}$ " shaped, to being " $\mathrm{C}$ " shaped, with the head and tail both pointing in the same direction (Figure 37). The circulatory system has developed further, with visible blood vessels and although the ventricles and atria are not yet connected, the heart is able to circulate blood through the embryo (Theiler, 1989). The embryos have undergone neural development and all three regions of the embryonic brain can be identified (Figure 21A). The embryo has developed optic vesicles and the future lens, the lens placode, has also begun to develop (Theiler, 1989). Both fore- and hindlimb buds have developed. The forelimb bud is found at the level of the $8^{\text {th }}-12^{\text {th }}$ somite and the hindlimb bud is bulging at the level of the $23^{\text {rd }}-28^{\text {th }}$ somite. GFP fluorescence is present in this stage posterior to the embryonic heart (Figure 22B). The 
brightest GFP signal is seen at the level of the forelimb bud and another area of bright fluorescence is seen just anterior to the newest (i.e. most posterior) somite pairs. A strong GFP signal is also seen in the head regions, specifically in the optic vesicle and developing ear vesicle. E9.5 is the first stage where we were able to see TOMATO protein fluorescence above background levels. It was seen in the anterior region of the RA expression domain where GFP was also brightest (Figure 22C). This indicates that, at E9.5, the concentration of RA in these tissues has reached a level where the low sensitivity portion of the reporter becomes responsive.

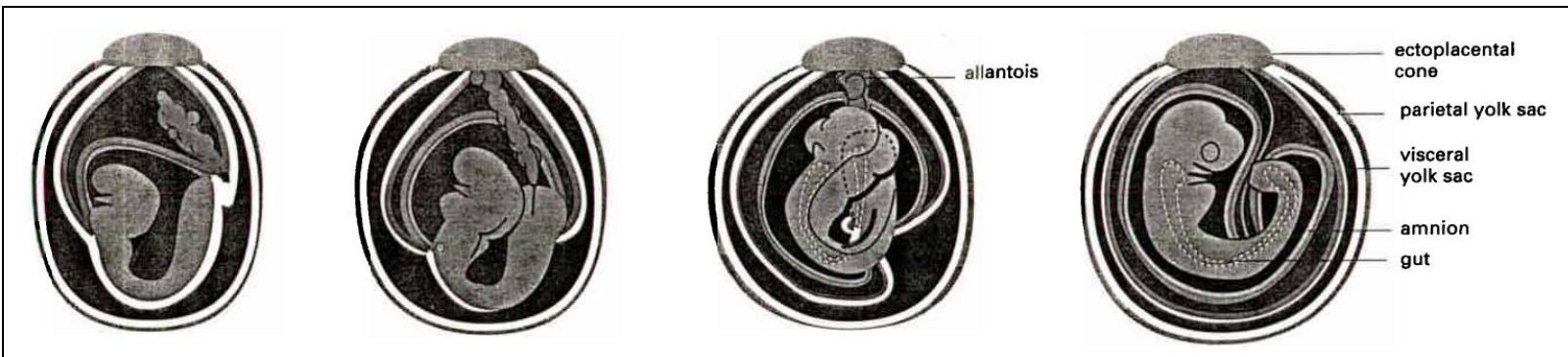

Figure 37| Embryonic turning between E8.5 and E.9.5. Image from Hogan et al., 1994.

By E10.5, embryos have grown to a length of 4.5-5 $\mathrm{mm}$ and they have retained their " $\mathrm{C}$ " shaped conformation. Limb buds and the tail are elongating and the tail bud has now become longer than that of human embryos at a comparable stage (Theiler, 1989). The CNS is rapidly developing, with the first nerves elongating from the cranial regions of the embryo, although they have not yet reached the tail. The intestinal tract has begun to form, with a short oesophagus leading into to primitive stomach, and other gut organs such as the liver and pancreas have also begun to develop (Theiler, 1989). The fluorescent protein distribution in E10.5 embryos was very similar to that of E9.5, possibly owing to the fact that physically, the embryos are very similar in terms of shape structure. GFP expression begins just anterior to the forelimb bud and is seen throughout the length of the embryo until just posterior of the hindlimb bud. As in E9.5, the E10.5 embryo showed strong GFP signal from the developing eyes. The brightest signal, again, comes from the most anterior region of GFP expression as well as the most posterior where the somites are still forming. TOMATO protein fluorescence confirms that this is due to higher RA concentration as these are the only areas of the embryo where it is also seen. 
Although the in vitro work with cell lines gave inconclusive results regarding the dual functionality of the reporter system, the fact that the in vivo work with whole embryos showed expression of both GFP and TOMATO proteins pointed to the fact that the reporter system is able to respond to both low and high concentrations of RA. In light of this, we chose to proceed with sorting the cells based on fluorescent protein expression as we had been able to visualise both.

Although we were able to identify cell populations expressing different levels of fluorescent proteins through flow cytometry, and the subsequent cDNA library construction did give a high DNA yield, PCR analysis was not able to show the presence of anything bar housekeeping genes. As these genes are expressed in all cells, it is possible that the mRNA reverse transcribes and amplified during library construction did not belong to the cells we had wanted to isolate. While the actual sorting experiment itself may have been the issue and we were not, in fact, sorting the cells that we thought, there were other steps after the sort that may have given rise to potential issues.

As we only worked with $300-500$ cells at a time, it was not possible to see a cell pellet after centrifugation. We therefore could not directly ascertain whether we had retained cells. Another point where the cells may have been lost was pelleting the cells to be able to resuspend them in a smaller volume of liquid. As a pellet was not visible, we were essentially required to work blind, assuming that the cells had in fact pelleted and were not still suspended in the supernatant. We attempted to solve this by looking at the aspirated supernatant on a slide under a microscope, however with the relatively large volume required for sorting into $(200 \mu \mathrm{L})$ and only very few cells, it would have been very difficult to find any cells, had they been present.

Further experiments would be required in order to confirm whether or not it is possible to sort cells based on the activity of a dual reporter system responding to RA concentration. An obvious issue here was the number of cells that were available to be sorted. This could be solved by co-ordinating to run the sorting experiment on a day where several female mice were $8.5 \mathrm{dpc}$, giving more embryonic cells to work with. However, as we were reliant on the availability of a highly used piece of equipment at a different research institute, we did not 
have the option to wait until a day where we had several pregnant females at the same stage.

A different method of mRNA identification may also be a way optimising the experiment. Again, we were restricted to methods that were appropriate for a low number of cells but methods for constructing libraries from a larger amount of cells could be tested in tandem with collecting more cells to begin with.

The result of the work in cell lines suggested that the manner in which the RAstat4xhiHspGFP2xhiHspTOM dual reporter system responds to RA concentration is not dose-dependent - where, the more RA is present, the more fluorescent protein is expressed - but rather a threshold response, where fluorescent protein is expressed above a particular RA concentration and any increase in concentration has no effect on protein levels. This would be an important issue to resolve, as our experiment relied on the reporter showing a dose-dependent response in order to isolate cells from a range of RA concentrations based on difference in fluorescence intensity as well as GFP/TOMATO presence. Further experiments would be required to determine whether these are reliable parameters, or whether sorting is only possible based purely upon presence or absence of GFP/TOMATO. A more in depth analysis of the above-mentioned variables would be required to reliably make a conclusion on whether it is possible to use our proposed method to sort embryonic cells into populations of varying RA concentration as well as different tissue types. Although the final result of the PCR was unable to show the effect of RA concentration on gene expression throughout the embryo, we are reluctant to conclude that the cell sorting itself was unsuccessful, as there were a number of other steps afterwards where issues may have arisen.

The advantage of our chosen method for visualisation of RA concentration was that the two systems designed to report on low and high RA concentration were coupled together, making the GFP expression levels comparable with TOMATO-protein expression levels. A main disadvantage of our approach was the possibility of random firing of the reporter system. Being a strong promoter, the HSP may randomly promote the transcription of fluorescent protein genes, even in the absence of RA. Other methods of visualising 
concentration gradients within an organism have been developed by various research groups, each with their merits and drawbacks.

Shimozono et al. (2013) developed genetically encoded probes for RA (GEPRAs) to visualise RA concentrations in zebrafish embryos. This involved engineering the ligand binding domains of RARs with yellow fluorescent protein (YFP) and cyan fluorescent protein (CFP). A conformational change caused by RA binding to the receptor resulted in a change in fluorescence resonance energy transfer from CFP to YFP. They also developed a GEPRA with a lower affinity for RA, by introducing amino acid substitutions. Zebrafish embryos were created that were transgenic for either the high affinity probe or the lower affinity probe and the fluorescent protein profiles of the two embryo groups were compared. The principle behind this approach is similar to the principle of our RAstat4xhiHspGFP2xhiHspTOM reporter system, in that the high affinity/sensitivity system shows the presence of low concentrations of RA, where the low affinity/sensitivity system shows the presence of high RA concentration. With this approach, Shimozono et al. were able to visualise a retinoic acid concentration gradient and characterise RA expression in the developing zebrafish embryo.

Harvey and Smith (2009) visualised the nodal gradient in developing zebrafish embryos through the use of bimolecular fluorescence complementation. In this technique, two halves of a fluorescent protein are coupled to interacting proteins. This interaction brings together the two halves of the fluorescent protein, causing fluorescence which can be visualised with standard microscopy techniques. In their experiment, Harvey and Smith ligated the $\mathrm{N}$ - and C-terminal halves of Venus, a yellow fluorescent protein, to Smad2 and Smad4. Smad2 and Smad4 interact in the presence of Nodal, so yellow fluorescence was seen where Nodal was present. Their approach is able to provide a clear positive signal, as without the protein interaction, no fluorescence is seen. This means that the system is not able to produce random fluorescent events, which is a possibility with the reporter system used in our experiments. However, this approach may not be suitable for RA as, rather than facilitating protein interaction as Nodal does, RA functions as a transcription factor, promoting the expression of its target genes through binding to the promoter region. 
Other approaches, such as those described by Srinivasan et al. (2002), Strigini \& Cohen (2000) and Kurata et al. (2001) use fluorescently tagged antibodies to label their targets for visualisation. Although this method is able to provide accurate information on the amount of target molecule present, this approach was not appropriate for this experiment as RA is an intracellular molecule.

Antibodies were, however, of use to us for labelling different tissue types. The aim was to sort cells into groups based on tissue type as well as RA concentration. After it became clear that a manual separation of different tissues was not possible due to the size of the tissues, we employed fluorescently tagged antibodies to label the tissues of interest. The pool of antibodies available to us for this was extremely limited, due to the fact that the targets had to be expressed at our chosen developmental stage, restricted to a single tissue type and be membrane proteins with the $A b$ target on the outside of the cell. The availability of proteins that fit these parameters led us to choose to work with E8.5 embryos. Using online tools (MGI webpage and QIAGEN Ingenuity pathways analysis tool), we identified the antibodies CD49 as a marker for paraxial mesoderm and CD349 as a marker for neural tissue as fitting into these parameters. Unfortunately, during the sorting experiment, it became clear that CD349 was not bound to cells, resulting in us being able to sort only paraxial mesoderm cells. While antibodies provided a simple solution to separating the different tissue types, in this experiment we were unable to use this method to obtain cells from neural tissues. This was most likely due to our choice in antibody rather than a problem in the method. Other cell sorting methods exist, such as those based on cell density, or their affinity for adhering to a particular surface (Tomlinson et al., 2012), but these are unable to reliably separate cells into homogeneous populations and are mostly used for removing large quantities of unwanted cells from a sample. Antibody staining methods are the current gold standard for labelling and sorting individual cell populations (Tomlinson et al., 2012), so any improvements to the sorting method here would be around the type of antibody, rather than the method of labelling.

While the ultimate aim - to assess the effect that RA has on gene expression throughout early developmental stage mouse embryos - was not able to be fully achieved in this Masters project, many of the methods required for this were developed. Using a range of 
techniques, the efficacy of a fluorescent reporter construct as a means for sorting cells was investigated both in vitro and in vivo, and shown to be successful. This will hopefully inform future studies on the topic and help to advance the methodologies for sorting embryonic cells. 


\section{Future directions}

Further PCR analysis experiments will be needed in order to determine whether the results that showed no DNA bands in the samples that had primers for Hox genes came about because these genes were not present, or if there was a sensitivity issue.

An avenue to explore in future to extend this work is to repeat the experiment with a reporter system that is flipped, i.e. RAstat4xhiHspTOM2xhiHspGFP. This would test whether the actual fluorescent proteins themselves are influencing the results. Differences in emission brightness of the two fluorescent proteins may result in the signals not being directly comparable. By testing a reporter that is a flipped version of the original, and comparing the signals of each of the high and low sensitivity segments with the two different fluorescent proteins, this would act as a control for any difference in emission brightness between GFP and TOMATO-fluorescent-protein.

Proof of principle experiments should also be carried out. This could include creating strains of knock-out mice lacking, for example, Cyp26a, any of the enzymes involved in RA synthesis, or Hox genes. This would provide information on the distribution and effect of RA when the system is not functioning as it should. This approach, of testing what happens when pathways are altered, is often very useful when trying to characterise the normal activity of a pathway. 


\section{References}

Aker, M., Tubb, J., Groth, A., Bukovsky, A., Bell, A., Felsenfeld, G., Kiem, H., Stamatoyannapoulos, G. \& Emery, D. (2007). Extended core sequences from the cHS4 insulator are necessary for protecting retroviral vectors from silencing position effects. Human Gene Therapy, 18, 333-343.

Berenguer, M., Lancman, J., Cunningham, T., Duc Si Dong, P. \& Duester, G. (2018). Mouse but not zebrafish requires retinoic acid for control of neuromesodermal progenitors and body axis extension. Developmental Biology, 441, 127-131.

Burgess, R., Rawls, A., Brown, D., Bradley, A. \& Olson, E. (1996). Requirement of paraxis gene for somite formation and musculoskeletal patterning. Nature, 384, 570-573.

Bryja, V., Bonilla, S. \& Arenas, E. (2006). Derivation of mouse embryonic stem cells. Nature Protocols, 1, 2082-2087

Chambon, P. (1996). A decade of molecular biology of retinoic acid receptors. The FASEB Journal, 10(9), 940-954.

Christ, B. \& Ordahl, C. (1995). Early stages of chick somite development. Anatomy and Embryology, 191(5), 381-396.

Conlon, R. (1995). Retinoic acid and pattern formation in vertebrates. Trends in Genetics, 11(8), 314-319

Costa, R. H., Kalinchenko, V. V. \& Lim, L. (2001). Transcription factors in mouse lung development and function. American Journal of Physiology - Lung cellular and Molecular Physiology, 280(5), 823-838.

Cunningham, T., Zhao, X. \& Duester, G. (2011). Uncoupling of retinoic acid signalling from tailbud development before termination of body axis extension. Genesis, 49(10), 776-783.

del Corral, R., Olivera-Martinez, I., Goriely, A., Gale, E., Maden, M. \& Storey, K. (2003). Opposing FGF and retinoid pathways control ventral neural patterna, neuronal differentiation, and segmentation during body axis extension. Neuron, 40(1), 65-79. Dollé, P. (2009). Developmental expression of retinoic acid receptors (RARs). Nuclear Receptor Signaling, 7, e006

Downs, K. M. (2011). Lineage commitments: emphasis on embryonic-extraembryonic interfaces. EMBO Reports, 12(10), 987-990.

Duester, G. (2008). Retinoic acid synthesis and signaling during early organogenesis. Cell, $134,921-931$

Dupé, V. \& Lumsden, A. (2001). Hindbrain patterning involves graded responses to retinoic acid signalling. Development, 128(12), 2199-2208. 
Durston, A. J., Timmermans, J. P. M., Hage, W. J., Hendriks, H. F. J., de Vries, N. J., Heideveld, M. \& Nieuwkoop, P. D. (1989). Retinoic acid causes an anteroposterior transformation in the developing central nervous system. Nature, 340(6229), 140-144

Favier, B. \& Dollé, P. (1997). Developmental functions of mammalian Hox genes. Molecular Human Reproduction, 3(2), 115-131.

Geada, A., Gaunt, S., Azzawi, M., Shimeld, S., Pearce, J. \& Sharpe, P. (1992). Sequence and expression of the murine Hox-3.5 gene. Development, 116(2), 497-506.

Gibb, S., Maroto, M. \& Dale, J. (2010). The segmentation clock mechanism moves up a notch. Trends in Cell Biology, 20(10-2), 593-600.

Grandel, H., Lun, K., Rauch, G., Rhinn, M., Piotrowski, T., Houart, C., Sordino, P., ... \& Brand, M. (2002). Retinoic acid signalling in the zebrafish embryo is necessary during presegmentation stages to pattern the anterior-posterior axis of the CNS and to induce a pectoral fin bud. Development, 129, 2851-2865.

Harrison, N., del Corral, R. \& Vasiev, B. (2011). Coordination of cell differentiation and migration in mathematical models of caudal embryonic axis extension. PLOS One, 6(7), e22700.

Harvey, S. \& Smith, J. (2009). Visualisation and quantification of morphogen gradient formation in the zebrafish. PLoS Biology, 7(5), e1000101

Hogan, B., Beddington, R., Costantini, F. \& Lacy, E. (1994). Manipulating the mouse embryo: A laboratory manual ( $2^{\text {nd }}$ ed.). Cold Spring Harbor, NY: Cold Spring Harbor Laboratory Press.

Huang, F., Hsuuw, Y., Lan, K., Kang, H., Chang, S., Hsu, Y. \& Huang, K. (2006). Adverse effects of retinoic acid on embryo development and the selective expression of retinoic acid receptors in mouse blastocysts. Human Reproduction, 21(1), 202-209.

Jackson Laboratory (1966). Biology of the laboratory mouse ( $2^{\text {nd }}$ ed.). Mineola, NY: Dover Publications.

Kam, R., Deng, Y., Chen, Y. \& Zhao, H. (2012) Retinoic acid synthesis and functions in early embryonic development. Cell \& Bioscience, 2(11)

Kastner, P., Mark, M., Leid, M., Gansmuller, A., Chin, W., Grondona, J., Décimo, D., ... \& Chambon, P. (1995). Abnormal spermatogenesis in RXRß mutant mice. Genes \& Development, 10, 80-92.

Kastner, P., Messaddeq, N., Mark, M., Wendling, O., Grondona, J., Ward, S., Ghyselinck, N. \& Chambon, P. (1997). Vitamin A deficiency and mutations of RXR $\alpha, R X R \beta$ and RXR $\alpha$ lead to early differentiation of embryonic ventricular cardiomyocytes. Development, 124(23), 47494758.

Kearse, M., Moir, R., Wilson, A., Stones-Havas, S., Cheung, M., Sturrock, S., Buxton, S., ... \& Drummond, A. (2012). Geneious Basic: an integrated and extendable desktop software 
platform for the organization and analysis of sequence data. Bioinformatics, 28(12), 16471649.

Krezel, W., Dupé, V., Mark, M., Dierich, A., Kastner, P. \& Chambon, P. (1996). RXRץ null mice

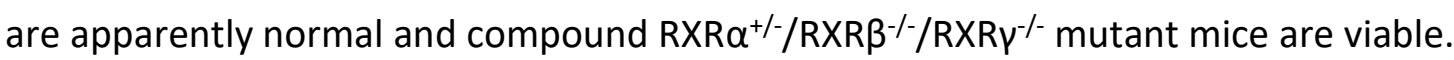

Developmental Biology, 93, 9010-9014.

Krumlauf, R. (1994). Hox genes in vertebrate development. Cell, 78, 191-201.

Kuhn, E. \& Geyer, P. (2003). Genomic insulators: connecting properties to mechanism.

Current Opinion in Cell Biology, 15(3), 259-265.

Kurata, T., Nakabayashi, J., Yamamoto, T., Mochii, M. \& Ueno, N. (2001). Visualization of endogenous BMP signaling during Xenopus development. Differentiation, 67, 33-40.

Mangelsdorf, D., Thummel, C., Beato, M., Herrlich, P., Schütz, G., Umesono, K., Blumberg, B., ... \& Evans, R. (1995). The nuclear receptor superfamily: the second decade. Cell, 83, 835839.

Mark, M., Ghyselinck, N. \& Chambon, P. (2009). Function of retinoic acid receptors during embryonic development. Nuclear Receptor Signalling, 7, e002

Mic, F.A., Molotkov, A., Benbrook, D. \& Duester, G. (2003). Retinoid activation of retinoic acid receptor but not retinoid $X$ receptor is sufficient to rescue lethal defect in retinoic acid synthesis. Proceedings of the National Academy of Sciences of the United States of America, 100(2), 7135-7140

Niederreither, K. \& Dollé, P. (2008). Retinoic acid in development: towards an integrated view. Nature Reviews Genetics, 9, 541-553.

Oosterveen, T., van Vliet, P., Deschamps, J. \& Meijlink, F. (2003). The direct context of a Hox retinoic acid response element is crucial for its activity. The Journal of Biological Chemistry, 278(26), 24103-24107

QIAGEN (2016). QIAseq FX single cell RNA library kit handbook. Retrieved from https://www.qiagen.com/us/resources/resourcedetail?id=d6498389-8b76-437f-a22099998d71c4ac\&lang=en.

Rhinn, M. \& Dollé, P. (2012) Retinoic acid signalling during development. Development, 139, 843-858

Ross, S., McCaffery, P., Drager, U. \& de Luca, L. (2000). Retinoids in embryonal development. Physiological Reviews, 80(3), 1021-1054.

Rossant, J., Zirngibl, R., Cado, D., Shago, M. \& Giguère. (1991). Expression of a retinoic acid response element-hsplacZ transgene defines specific domains of transcriptional activity during mouse embryogenesis. Genes and Development, 5, 1333-1344.

Ruddle, F., Bartels, J., Bentley, K., Kappen, C., Murtha, M. \& Pendleton, J. (1994). Evolution of Hox genes. Annual Review of Genetics, 28, 423-442. 
Shimeld, S. (1996). Retinoic acid, HOX genes and the anterior-posterior axis in chaordates. BioEssays, 18(8), 613-616.

Shimozono, S., limura, T., Kitaguchi, T., Higashijima, S. \& Miyawaki, A. (2013). Visulaisation of an endogenous retinoic acid gradient across embryonic development. Nature, 496, 363366.

Shiotsugu, J., Katsuyama, Y., Arima, K., Baxter, A., Kiode, T., Song, J., Chandraratna, R. \& Blumberg, B. (2004). Multiple points of interaction between retinoic acid and FGF signalling during embryonic axis formation. Development, 131, 2653-2667

Simeone, A., Acampora, D., Arcioni, L., Andrews, PW, Boncinelli, E. \& Mavilio, F. (1990). Sequential activation of HOX2 homeobox genes by retinoic acid in human embryonal carcinoma cells. Nature, 346(6286), 763-766.

Simeone, A., Avantaggiato, V., Moroni, M., Mavilio, F., Arra, C., Cotelli, F., Nigro, V. \& Acampora, D. (1995). Retinoic acid induces stage-specific antero-posterior transformation of rostral central nervous system. Mechanisms of development, 51, 83-98

Srinivasan, S., Rashka, K. \& Bier, E. (2002). Creation of a Sog morphogen gradient in the Drosophila embryo. Developmental Cell, 2, 91-101.

Strigini, M. \& Cohen, S. (2000). Wingless gradient formation in the Drosophila wing. Current Biology, 10(6), 293-300.

Theiler, K. (1989). The house mouse: Atlas of embryonic development ( $2^{\text {nd }}$ ed.). West Hanover, MA: Springer-Verlag.

Thaller, C. \& Eichele, G. (1987). Identification and spatial distribution of retinoids in the developing chick limb bud. Nature, 327(6123), 625-628.

Tomlinson, M., Tomlinson, S., Yang, X. \& Kirkham, J. (2012). Cell separation: Terminology and practical considerations. Journal of Tissue Engineering, 4, 2041731412472690.

Wang, W., Jia, Y., Li, Y., Jing, C., Guo, X., Shang, X., Zhao, C. \& Wang, T. (2017). Impact of different promoters, promoter mutation, and an enhancer on recombinant protein expression in CHO cells. Scientific Reports, 7, article number: 10416.

Wilson, V., Oliver-Martinez, I. \& Storey, K. (2009). Stem cells, signals and vertebrate body extension. Development, 136, 1591-1604.

Zhang, X., Salbert, G., Lee, M. \& Pfahl, M. (1994). Mutations that alter ligand-induced switches and dimerization activities in the retinoid $X$ receptor. Molecular and Cellular biology, 14(6), 4311-4323. 


\section{$\underline{\text { Appendix }}$}

Recipes

TAE buffer 50x

- 242 g Tris-base

- $57.1 \mathrm{~mL}$ glacial acetic acid

- $100 \mathrm{~mL} 500 \mathrm{mM}$ EDTA

Make up to $1 \mathrm{~L}$ with distilled $\mathrm{H}_{2} \mathrm{O}$.

To make a $0.5 x$ working solution, dilute $50 x$ stock 1:100.

LB broth (to make $100 \mathrm{~mL}$ )

- $1 \mathrm{~g} \mathrm{NaCl}$

- $1 \mathrm{~g}$ bactotryptone

- 0.5 g yeast extract

Make up to $100 \mathrm{~mL}$ with distilled $\mathrm{H}_{2} \mathrm{O}$.

LB agar

Per $100 \mathrm{~mL}$ of LB broth, add $1.5 \mathrm{~g}$ of agar and autoclave. Allow to cool enough so that the agar is still liquid but no scalding hot (i.e. $<60^{\circ} \mathrm{C}$ ) and add $100 \mu \mathrm{L}$ ampicillin. Pour into Petri dishes and allow plates to set at room temperature. Store plates at $4^{\circ} \mathrm{C}$ until needed.

\section{Alkaline lysis solutions for miniprep}

- Alkaline lysis solution I
○ 25 mM Tris-Cl (pH 8.0)
○ 10 mM EDTA (pH 8.0)

- Alkaline lysis solution II
○ $\quad 0.2 \mathrm{M} \mathrm{NaOH}$
$\circ 1 \%$ SDS 
- Alkaline lysis solution III
- $60 \mathrm{~mL}$ potassium acetate
○ $11.5 \mathrm{~mL}$ glacial acetic acid
- $28.5 \mathrm{~mL}$ dd $-\mathrm{H}_{2} \mathrm{O}$

Proteinase $\mathrm{K}$ buffer solution

- $100 \mathrm{mM}$ Tris (pH 8.0)

- 5 mM EDTA

- $0.1 \%$ SDS

- $200 \mathrm{mM} \mathrm{NaCl}$

\section{Glycerol stock}

- $15 \%$ glycerol

- $85 \%$ cell suspention

\section{Tris-EDTA 1x}

- 10 mM Tris-Cl

- 1 mM EDTA (pH 8.0) 


\section{Simplified Protocols for Experienced Users}

\subsection{Purifying DNA from Solutions}

1. Measure DNA volume.

2. Add 3 volumes Nal solution to DNA.

3. Calculate amount of EZ-GLASSMILK needed.

4. Resuspend EZ-GLASSMILK $K^{\circledast}$ by vortexing for 1 minute.

5. Add EZ-GLASSMILK ${ }^{\oplus}$ to the DNANNal solution and mix.

6. Incubate at room temperature for 5 minutes and mix.

7. Pellet the EZ-GLASSMILK ${ }^{\circ}$ with the bound DNA and discard supematant.

8. Add $500 \mu$ l prepared NEW Wash and resuspend.

9. Centrifuge for 5 seconds and discard supernatant.

10. Repeat wash (Steps 8-9).

11. Dry pellet to remove residual ethanol.

12. Add a volume of TE or water equal to the amount of EZ-GLASSMIL $K$ added in Step 5. Resuspend pellet to mix and elute DNA.

13. Centrifuge for 30 seconds and remove supernatant containing DNA. 


\section{GENECLEAN ${ }^{\circledR}$ III Kit}

\subsection{Purifying DNA from TAE or TBE Agarose Gels}

1. Excise DNA band from agarose gel.

2. Determine the weight of the gel stice in micrograms.

3. Determine approximate volume of gel slice $(100 \mathrm{mg}=100 \mu l)$.

4. Transfer gel silce to microcentrifuge tube

5. For TAE gels, add 3 volumes Nal solution. For TBE gels, add 0.5 volume TBE Modifier and 4.5 volumes Nal solution per 1 volume of agarose.

6. Incubate gel slice and $\mathrm{Nal}$ solution at $55^{\circ} \mathrm{C}$ to melt gel.

7. Mix contents of tube.

8. Continue incubation until agarose is dissolved ( 5 minutes).

9. Calculate amount of EZ-GLASSMILK needed.

10. Resuspend EZ-GLASSMILK ${ }^{5}$ by vortexing for 1 minute.

11. Add EZ-GLASSMILK $K^{\oplus}$ to Nal/DNA solution as calculated in Step 9 and mix.

12. Incubate at room temperature for 5 minutes and mix.

13. Pellet the EZ-GLASSMILK with the bound DNA and discard supernatant.

14. Add 500 ul prepared NEW Wash and resuspend.

15. Centrifuge for 5 seconds and discard supernatant.

16. Repeat wash (Steps 14-15).

17. Dry pellet to remove residual ethanol.

18. Add a volume of TE or water equal to the amount of EZ-GLASSMILK ${ }^{\mathbb{E}}$ added in Step 11.

Resuspend pellet to mix and elute DNA.

19. Centrifuge for 30 seconds and remove supernatant containing DNA. 


\section{QIAGEN ${ }^{\circledR}$ Plasmid Mini, Midi and Maxi Kits}

The QIAGEN Plasmid Mini Kit (cat. nos. 12123 and 12125), the QIAGEN Plasmid Midi Kit (cat. nos. 12143 and 12145), the QIAGEN Plasmid Maxi Kit (cat. nos. 12162, 12163 and 12165) and the Plasmid Buffer Set (cat. no. 19046) can be stored at room temperature $\left(15-25^{\circ} \mathrm{C}\right)$ for up to 2 years if not otherwise stated on label.

Further information

- QIAGEN Plasmid Purification Handbook: www.qiagen.com/HB-1193

- Safety Data Sheets: www.qiagen.com/safety

- Technical assistance: support.qiagen.com

Notes before starting

- Add RNase A solution to Buffer PI, mix and store at $2-8^{\circ} \mathrm{C}$.

- Optional: Add LyseBlue ${ }^{\circledR}$ reagent to Buffer P1 at a ratio of 1:1000.

- Prechill Buffer P3 at $4^{\circ} \mathrm{C}$. Check Buffer P2 for SDS precipitation.

- Isopropanol and 70\% ethanol are required.

- Symbols: - QIAGEN Plasmid Mini Kit; $\triangle$ QIAGEN Plasmid Midi Kit; and QIAGEN Plasmid Maxi Kit.

Table 1. Recommended LB culture volumes

\begin{tabular}{|lcc|}
\hline Kit & High-copy plasmid & Low-copy plasmid \\
\hline QIAGEN Plasmid Mini & $3 \mathrm{ml}$ & Not recommended \\
QIAGEN Plasmid Midi & $25 \mathrm{ml}$ & $100 \mathrm{ml}$ \\
QIAGEN Plasmid Maxi & $100 \mathrm{ml}$ & $500 \mathrm{ml}$ \\
\hline
\end{tabular}

1. Harvest overnight bacterial culture by centrifuging at $6000 \times \mathrm{g}$ for $15 \mathrm{~min}$ at $4^{\circ} \mathrm{C}$.

2. Resuspend the bacterial pellet in $0.3 \mathrm{ml}, \boldsymbol{\Delta} 4 \mathrm{ml}$ or $10 \mathrm{ml}$ Buffer $\mathrm{Pl}$. 
3. Add $0.3 \mathrm{ml}, \boldsymbol{\Delta} 4 \mathrm{ml}$ or $10 \mathrm{ml} \mathrm{Buffer} \mathrm{P} 2$, mix thoroughly by vigorously inverting 4-6 times and incubate at room temperature $\left(15-25^{\circ} \mathrm{C}\right)$ for $5 \mathrm{~min}$. If using LyseBlue reagent, the solution will turn blue.

4. Add $0.3 \mathrm{ml}, \boldsymbol{\Delta} 4 \mathrm{ml}$ or $10 \mathrm{ml}$ prechilled Buffer P3, mix thoroughly by vigorously inverting 4-6 times. Incubate on ice for $5 \mathrm{~min}, \boldsymbol{\Delta} 15 \mathrm{~min}$ or $20 \mathrm{~min}$. If using LyseBlue reagent, mix the solution until it is colorless.

5. -: Centrifuge at $14,000-18,000 \times g$ for $10 \mathrm{~min}$ at $4^{\circ} \mathrm{C}$. Re-centrifuge if the supernatant is not clear. $\boldsymbol{\Delta}$ and $\mathbf{m}$ : Centrifuge at $\geq 20,000 \times \mathrm{g}$ for $30 \mathrm{~min}$ at $4^{\circ} \mathrm{C}$. Re-centrifuge the supernatant at $\geq 20,000 \times \mathrm{g}$ for $15 \mathrm{~min}$ at $4^{\circ} \mathrm{C}$.

6. Equilibrate a QIAGEN-tip $\bullet 20, \Delta 100$ or 500 by applying $\bullet 1 \mathrm{ml}, \boldsymbol{\Delta} 4 \mathrm{ml}$ or - $10 \mathrm{ml}$ Buffer QBT, and allow column to empty by gravity flow.

7. Apply the supernatant from step 5 to the QIAGEN-tip and allow it to enter the resin by gravity flow.

8. Wash the QIAGEN-tip with $2 \times 2 \mathrm{ml}, \boldsymbol{\Delta} 2 \times 10 \mathrm{ml}$ or $2 \times 30 \mathrm{ml}$ Buffer QC. Allow Buffer $Q C$ to move through the QIAGEN-tip by gravity flow.

9. Elute DNA with $0.8 \mathrm{ml}, \Delta 5 \mathrm{ml}$ or $15 \mathrm{ml}$ Buffer QF into a clean $\bullet 2 \mathrm{ml}, \boldsymbol{\Delta} 15 \mathrm{ml}$ or $50 \mathrm{ml}$ vessel. For constructs larger than $45 \mathrm{~kb}$, prewarming the elution buffer to $65^{\circ} \mathrm{C}$ may help to increase the yield.

10.Precipitate DNA by adding $0.56 \mathrm{ml}, \boldsymbol{\Delta} 3.5 \mathrm{ml}$ or $10.5 \mathrm{ml}$ (0.7 volumes) roomtemperature isopropanol to the eluted DNA and mix. Centrifuge at $\geq 15,000 \times \mathrm{g}$ for $30 \mathrm{~min}$ at $4^{\circ} \mathrm{C}$. Carefully decant the supernatant.

11. Wash the DNA pellet with $\bullet 1 \mathrm{ml}, \boldsymbol{\Delta} 2 \mathrm{ml}$ or $5 \mathrm{ml}$ room-temperature $70 \%$ ethanol and centrifuge at $\geq 15,000 \times \mathrm{g}$ for $10 \mathrm{~min}$. Carefully decant supernatant.

12. Air-dry pellet for 5-10 $\mathrm{min}$ and redissolve DNA in a suitable volume of appropriate buffer (e.g., TE buffer, pH 8.0, or $10 \mathrm{mM}$ Tris. $\mathrm{Cl}$, pH 8.5).

\section{茴得. Scan QR code for handbook.}

For up-to-date licensing information and product-specific disclaimers, see the respective QIAGEN kit handbook or user manual. Trademarks: QIAGEN, Sample to Insight", LyseBlue (QIAGEN Group). 1101291 03/2016 HB-0586-002 @ 2016 QIAGEN, all rights reserved.

Ordering www.qiagen.com/contact | Technical Support support.qiagen.com | Website www.qiagen.com 

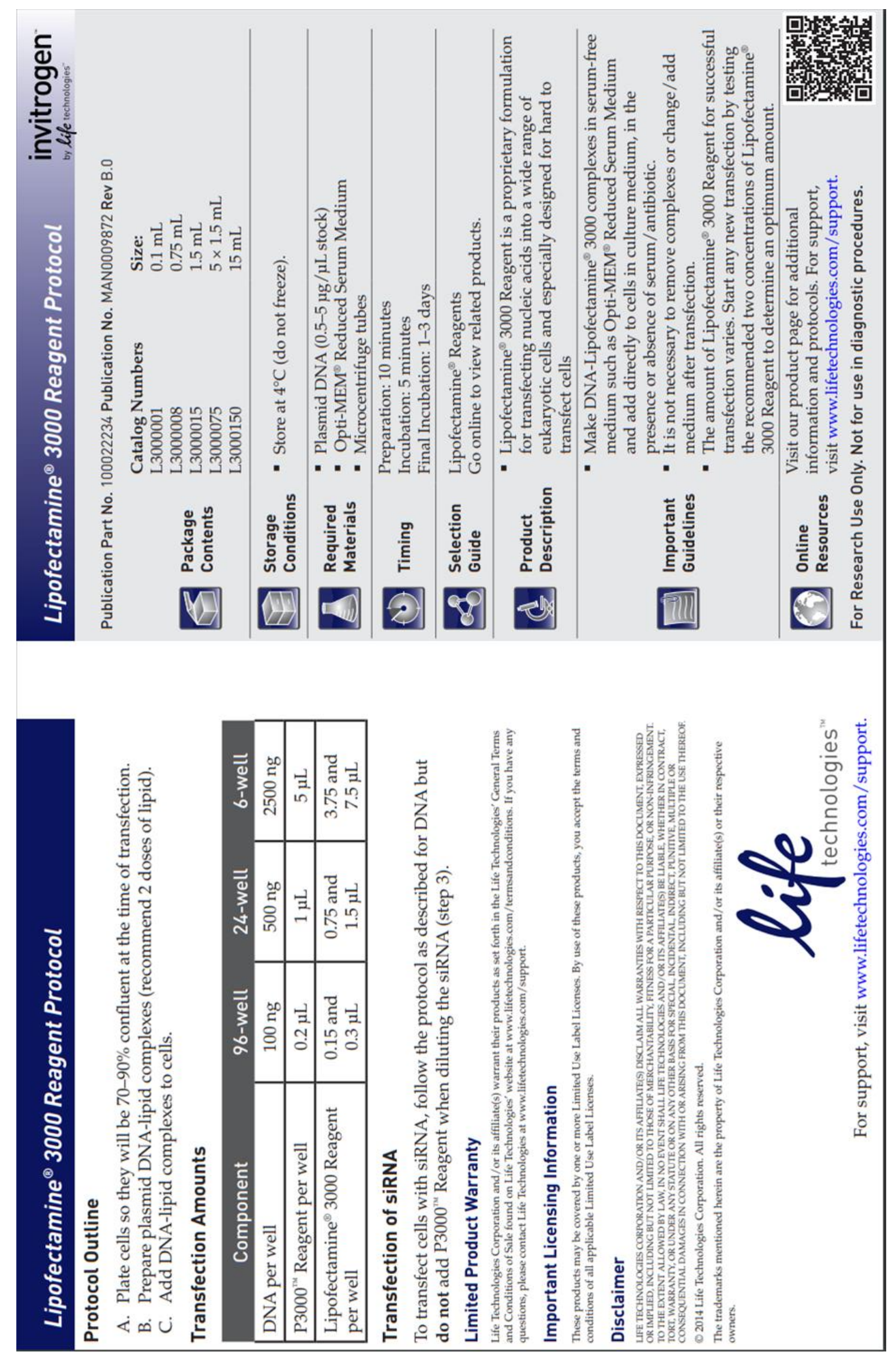


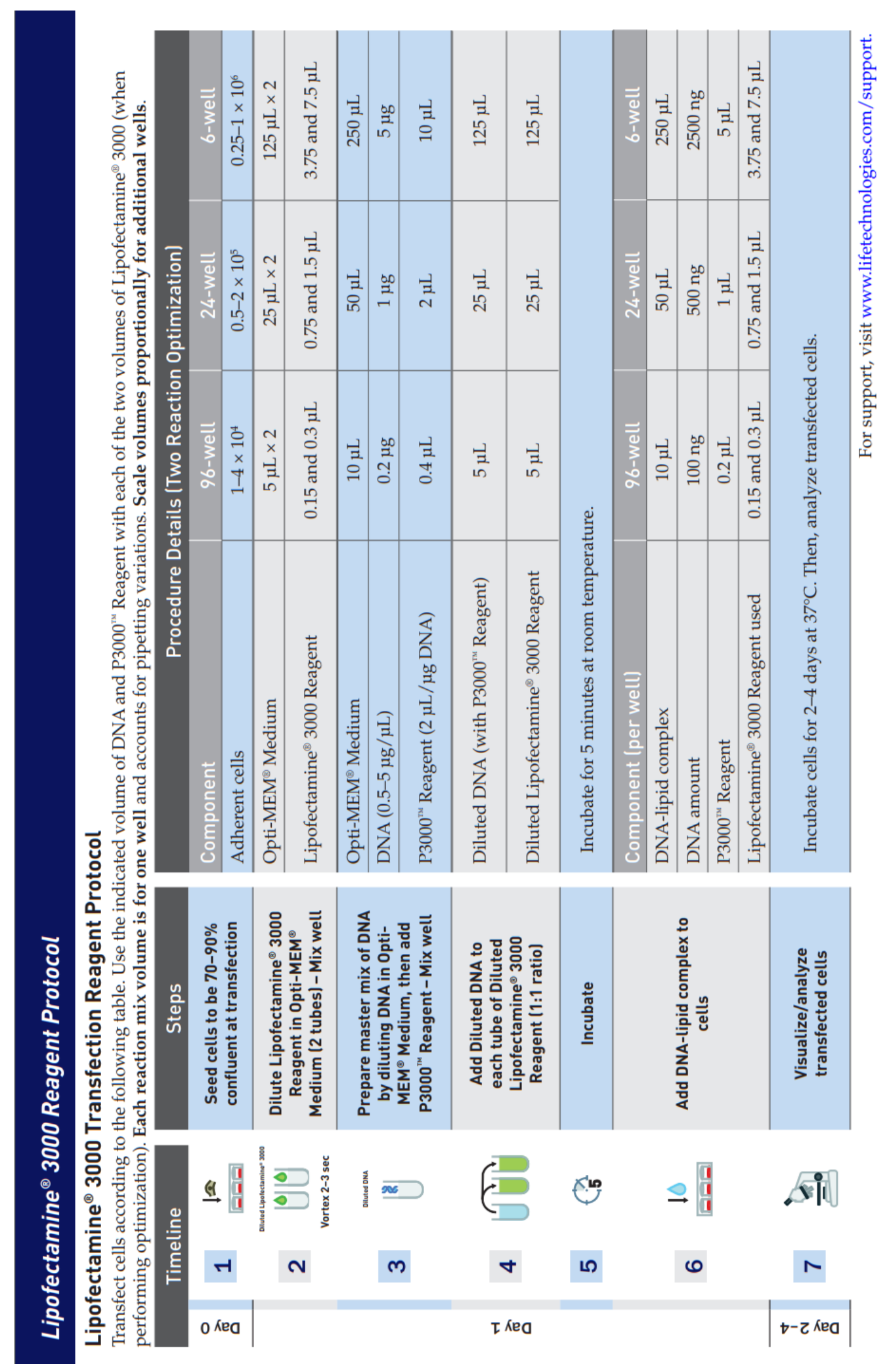




\section{QIAseq FX Single Cell RNA Library Kit}

The REPLl-g Single Cell RNA Library Kit (cat. no. 180733, 180735) should be stored immediately upon receipt at $-15^{\circ} \mathrm{C}$ to $-30^{\circ} \mathrm{C}$. If stored under these conditions, kits are stable up to the date indicated on the QC label inside the kit lid.

Further information:

- QIAseq FX Single Cell RNA Library Handbook: www.qiagen.com/HB-2139

- Safety Data Sheets: www.qiagen.com/safety

- Technical assistance: www.qiagen.com/support

Notes before starting:

- This protocol is for the generation of cDNA from single cells and production of NGS libraries for RNA-Seq experiments. Refer to the kit handbook for additional information.

- Maintain RNAse-free environment, and thaw all enzyme mixes and gDNA Wipeout Buffer on ice. All other components can be thawed at room temperature $\left(15-25^{\circ} \mathrm{C}\right)$.

- This protocol is optimized for eukaryotic single cells from species that lack a cell wall and for microdissected cells from frozen sections. It cannot be used for cells that are treated with formalin or other cross-linking agents.

- Library amplification is not required; this entire process is PCR-free.

- This kit is for use with Illumina $\circledast$ instruments.

Procedure: Amplification of 3 '-enriched mRNA from Single Cells

1. Place $7 \mu$ of cell material (1-1000 cells suspended in PBS) into a microcentrifuge tube.

2. Add $4 \mu$ l Lysis Buffer. Mix carefully by flicking the tube and centrifuge briefly. Avoid getting cell material stuck to the wall of the tube.

3. Incubate at $24^{\circ} \mathrm{C}$ for $5 \mathrm{~min}$, followed by $95^{\circ} \mathrm{C}$ for $3 \mathrm{~min}$. Cool to $4^{\circ} \mathrm{C}$. 
4. Add $2 \mu \mathrm{gDNA}$ Wipeout Buffer, mix, centrifuge and incubate at $42^{\circ} \mathrm{C}$ for $10 \mathrm{~min}$.

5. Prepare Quantiscript RT mix according to Table 1 and mix well.

Table 1. Preparing Quantiscript RT mix*

\begin{tabular}{|ll|}
\hline Component & Volume/reaction \\
\hline RT/Polymerase Buffer & $4 \mu l$ \\
Oligo dT Primer & $1 \mu l$ \\
Quantiscript RT Enzyme Mix & $1 \mu l$ \\
\hline Total volume & $6 \mu l$ \\
\hline
\end{tabular}

* Scale up accordingly if performing several reactions simultaneously.

6. Add $6 \mu$ l of freshly prepared Quantiscript RT to the lysed cell sample. Mix, centrifuge and incubate at $42^{\circ} \mathrm{C}$ for $60 \mathrm{~min}$.

7. Stop the reaction by incubating at $95^{\circ} \mathrm{C}$ for $3 \mathrm{~min}$, then cool on ice.

8. Prepare the ligation mix by adding the components as shown in Table 2.

Table 2. Preparing ligation mix $^{*}$

\begin{tabular}{|ll|}
\hline Component & Volume/reaction* \\
\hline Ligase Buffer & $8 \mu \mathrm{l}$ \\
Ligase Mix & $2 \mu \mathrm{l}$ \\
\hline Total volume & $10 \mu \mathrm{l}$ \\
\hline * Scale up accordingly if performing several reactions simultaneously.
\end{tabular}

9. Add $10 \mu \mathrm{l}$ of freshly prepared ligation mix to the Quantiscript RT reaction from step 7. Mix, centrifuge briefly and incubate at $24^{\circ} \mathrm{C}$ for $30 \mathrm{~min}$.

10. Stop the reaction by incubating at $95^{\circ} \mathrm{C}$ for $5 \mathrm{~min}$.

11. Prepare the REPLl-g SensiPhi amplification mix (Table 3).

Table 3. Preparing REPL-g SensiPhi amplification mix*

\begin{tabular}{|ll|}
\hline Component & Volume/reaction* \\
\hline REPLI-g sc Reaction Buffer & $29 \mu \mathrm{l}$ \\
REPLI-g SensiPhi DNA Polymerase & $1 \mu \mathrm{l}$ \\
\hline Total volume & $30 \mu \mathrm{l}$ \\
\hline
\end{tabular}

* Scale up accordingly if performing several reactions simultaneously.

12. Add $30 \mu$ l of freshly prepared REPLI-g SensiPhi amplification mix to the ligation reaction from step 10. Mix, centrifuge briefly and incubate at $30^{\circ} \mathrm{C}$ for $2 \mathrm{~h}$.

13. Stop the reaction by incubating at $65^{\circ} \mathrm{C}$ for $5 \mathrm{~min}$. 
14. Amplified cDNA behaves like purified genomic DNA and has an approximate length of up to $70,000 \mathrm{bp}$. See the kit handbook for QC of the WTA reaction and storage.

Procedure: PCR-Free Library Construction from Amplified cDNA

FX Single-Tube Fragmentation, End Repair and A-addition

1. Thaw all kit components on ice, program a thermocycler according to Table 4 and start the program. When the thermocycler block reaches $4^{\circ} \mathrm{C}$, pause the program.

Table 4. Reaction mix for end-repair FX reaction cycling conditions

\begin{tabular}{|lll|}
\hline Step & Temperature & Incubation time \\
\hline 1 & $4^{\circ} \mathrm{C}$ & $1 \mathrm{~min}$ \\
2 & $32^{\circ} \mathrm{C}$ & $15 \mathrm{~min}{ }^{*}$ \\
3 & $65^{\circ} \mathrm{C}$ & $30 \mathrm{~min}$ \\
4 & $4^{\circ} \mathrm{C}$ & Hold \\
\hline
\end{tabular}

* The insert size of the completed libraries is determined by the duration of step 2. Using 200-1000 ng input amplified cDNA, 15 min fragmentation time produces a fragment distribution of around $350 \mathrm{bp}$. For detailed recommendations, please refer to the QIAseq FX Single Cell RNA Library Handbook. Use a thermocycler with heated lid.

2. Prepare a WTA DNA dilution 200-1000 ng in $10 \mu \mathrm{l} \mathrm{H}_{2} \mathrm{O}$ sc.

3. Prepare the FX Reaction Mix on ice according to Table 5 and mix by pipetting.

Table 5. FX Reaction Setup for $>200 \mathrm{ng}$ input WTA-DNA

\begin{tabular}{|ll|}
\hline Component & Volume/reaction* \\
\hline FX Buffer, 10x & $5 \mu l$ \\
H2O sc & $20 \mu l$ \\
FX Enhancer & $5 \mu l$ \\
FX Enzyme Mix & $10 \mu l$ \\
\hline Total reaction volume & $\mathbf{4 0} \boldsymbol{\mu l}$ \\
\hline
\end{tabular}

Note: Mix by pipetting and keep on ice.

4. Add $40 \mu$ FX Reaction Mix to each WTA cDNA sample on ice and gently mix.

5. Briefly spin down the PCR plate/tubes and immediately transfer to the pre-chilled thermocycler $\left(4^{\circ} \mathrm{C}\right)$ and resume the program. Once the fragmentation program is complete, transfer samples to ice. Proceed with the next step. 


\section{Adapter Ligation}

6. Mix and spin down the adapter plate. Remove the protective adapter plate lid, pierce the foil seal and transfer $5 \mu$ from one DNA adapter well to each sample. Track the barcodes used. Freeze unused adapters.

7. Prepare the Ligation master mix on ice according to Table 6. Mix by gently mixing.

Table 6. Ligation master mix (per sample)

\begin{tabular}{lc|}
\hline Component & Volume/reaction* \\
\hline DNA Ligase Buffer, 5x & $20 \mu \mathrm{l}$ \\
$\mathrm{H}_{2} \mathrm{O}$ sc & $15 \mu \mathrm{l}$ \\
DNA Ligase & $10 \mu \mathrm{l}$ \\
\hline Total reaction volume & $\mathbf{4 5} \mu \mathrm{l}$ \\
\hline
\end{tabular}

8. Add $45 \mu \mathrm{l}$ master mix to each sample. Mix well and incubate at $20^{\circ} \mathrm{C}$ for $15 \mathrm{~min}$.

9. Proceed immediately to adapter ligation cleanup (steps 10-18).

10. Add $80 \mu$ resuspended Agencourt AMPure XP beads to each sample and mix.

11. Incubate for $5 \mathrm{~min}$ at room temperature.

12. Pellet the beads on a magnetic stand and carefully discard the supernatant.

13. Add $200 \mu$ fresh $80 \%$ ethanol to each pellet on the magnetic stand and carefully discard the supernatant. Repeat this step once for a total of 2 ethanol washes.

14. Incubate on the magnetic stand for 5-10 min or until the beads are dry. Avoid overdrying since this may result in lower DNA recovery. Remove from the magnetic stand.

15. Elute by resuspending in $52.5 \mu$ Buffer EB. Pellet beads on the magnetic stand. Carefully transfer $50 \mu$ supernatant to a new PCR plate.

16. Add $50 \mu$ l of resuspended Agencourt AMPure XP beads to each sample and mix.

17. Follow steps 11-14 and continue to step 18.

18. Elute by resuspending in $26 \mu$ Buffer EB. Pellet the beads on the magnetic stand. Carefully transfer $23.5 \mathrm{\mu l}$ of supernatant into a new PCR plate. Store purified libraries at $-20^{\circ} \mathrm{C}$ until ready for sequencing.

Tư Scan QR code for handbook

For up-to-date licensing information and productspecific disclaimers, see the respective QIAGEN kit handbook or user manual. Trademarks: QIAGEN GeneReadTM, REPLl-g\% (QIAGEN Group); Illumina (lllumina Inc.). 1102470 06/2016 HB-2139-001 @ 2016 QlAGEN, all rights reserved. 